\title{
Aspirin Inhibits TGF $\beta 2$-Induced Epithelial to Mesenchymal Transition of Lens Epithelial Cells: Selective acetylation of K56 and K122 in histone H3
}

Mi-Hyun Nam ${ }^{1}$, Andrew J.O. Smith², Mina B. Pantcheva ${ }^{1}$, Ko Uoon Park ${ }^{1}$, Joseph A. Brzezinski IV $^{1}$, James J. Galligan ${ }^{4,5}$, Kristofer Fritz ${ }^{3}$, I. Michael Wormstone ${ }^{2}$ and Ram H. Nagaraj ${ }^{1,3, *}$

${ }^{1}$ Sue Anschutz-Rodgers Eye Center and Department of Ophthalmology, School of Medicine, University of Colorado, Anschutz Medical Campus, Aurora, CO 80045, ${ }^{2}$ Department of Ophthalmology, University of East Anglia, Norwich, United Kingdom, ${ }^{3}$ Department of Pharmaceutical Sciences, Skaggs School of Pharmacy and Pharmaceutical Sciences, University of Colorado, Anschutz Medical Campus, Aurora, CO 80045 and ${ }^{4}$ Vanderbilt Institute of Chemical Biology, Vanderbilt University Medical Center, Nashville, TN 37232smad ${ }^{5}$ Current address: Department of Pharmacology and Toxicology, College of Pharmacy, University of Arizona, Tucson, Arizona 85721

${ }^{*}$ Correspondence should be addressed to: Ram H. Nagaraj, Ph.D., Sue Anschutz-Rodgers Eye Center and Department of Ophthalmology, University of Colorado School of Medicine, 12800 East 19th Avenue, RC-1 North, 5102, Aurora, CO 80045. Phone: 303-724-5922. Fax: 303-7245270. E-mail: ram.nagaraj@ucdenver.edu 


\section{Abstract}

Posterior capsule opacification (PCO) is a complication after cataract surgery that can disrupt vision. The epithelial to mesenchymal transition (EMT) of lens epithelial cells (LECs) in response to transforming growth factor $\beta 2$ (TGF $\beta 2$ ) has been considered an obligatory mechanism for PCO. In this study, we tested the efficacy of aspirin in inhibiting the TGF $\beta 2$ mediated EMT of human LECs, LECs in human lens capsular bags, and lensectomized mice. In human LECs, the levels of the EMT markers $\alpha$-smooth muscle actin ( $\alpha$-SMA) and fibronectin were drastically reduced by treatment with $2 \mathrm{mM}$ aspirin. Aspirin also halted the EMT response of TGF 32 when introduced after EMT initiation. In human capsular bags, treatment with $2 \mathrm{mM}$ aspirin significantly suppressed posterior capsule wrinkling and the expression $\alpha-S M A$ in capsule-adherent LECs. The inhibition of TGF $\beta 2$-mediated EMT in human LECs was not dependent on Smad phosphorylation or MAPK and AKT-mediated signaling. We found that aspirin significantly increased the acetylation of K56 and K122 in histone H3 of human LECs. Chromatin immunoprecipitation assays using acetyl-H3K56 or acetyl-H3K122 antibody revealed that aspirin blocked the TGF 32 -induced acetylation of $\mathrm{H} 3 \mathrm{~K} 56$ and $\mathrm{H} 3 \mathrm{~K} 122$ at the promoter regions of ACTA2 and COL1A. After lensectomy in mice, we observed an increase in the proliferation and $\alpha$-SMA expression of the capsule-adherent LECs, which was ameliorated by aspirin administration through drinking water. Taken together, our results showed that aspirin inhibits TGF 32 -mediated EMT of LECs, possibly from epigenetic downregulation of EMT-related genes.

Keywords: aspirin, epithelial-mesenchymal transition, posterior capsule opacification, lens epithelial cells, histone acetylation 
Abbreviations: LECs, lens epithelial cells; EMT, epithelial to mesenchymal transition; PCO, posterior capsule opacification; TGF $\beta$, transforming growth factor-beta; $\alpha$-SMA, $\alpha$-smooth muscle actin; FN, fibronectin; HDAC, histone deacetylase; ChIP, chromatin immunoprecipitation 


\section{INTRODUCTION}

During cataract surgery, a small portion of the anterior lens capsule is excised, and the cloudy lens is removed and replaced with an artificial intraocular lens (IOL). During this procedure, efforts are made to remove epithelial cells adhering to the anterior capsule, but some cells still remain. These remaining lens epithelial cells (LECs) can proliferate, migrate and undergo EMT and cause wrinkling of the posterior capsule, ultimately resulting in posterior capsule opacification (PCO) [1]. PCO is one of the most common post cataract surgery complications that can impede vision. It is reported to occur in $20 \%$ to $40 \%$ of patients 2 to 5 years after surgery [2]. PCO is even more prevalent in children younger than 4 years old who undergo cataract surgery; the rate can reach $100 \%$ within 2 years after surgery, probably due to the high proliferative and migratory abilities of LECs in this population [3]. Neodymium doped: yttriumaluminum-garnet (Nd:YAG) laser capsulotomy is the treatment of choice for PCO [4]. However, Nd:YAG laser treatment can lead to macular edema, retinal tear, endophthalmitis, anterior uveitis and myopia [5-7]; therefore more effective methods to prevent PCO are needed.

The TGF $\beta$ signaling pathway is a common driver of EMT, which is characterized by the loss of epithelial cell properties and the acquisition of mesenchymal cell properties [8]. TGF $\beta$-induced activation of the TGF $\beta$ receptor leads to the phosphorylation of the transcription factors Smad2 and Smad3. Phosphorylated Smad2 and Smad3 form a triad with Smad4 and translocate to the nucleus, where they associate and cooperate with DNA binding transcription factors to activate or repress target genes [9]. TGF $\beta 2$ is the predominant cytokine in the aqueous humor of the eye. Numerous studies support that TGF $\beta 2$ signaling plays a central role in the pathogenesis of PCO (reviewed in [10]).

Aspirin (acetylsalicylic acid) is one of the most widely used drugs to treat pain, fever, and inflammation [11]. Low doses of aspirin are widely used for the treatment of acute coronary 
diseases such as heart attacks, strokes, and thrombosis [12]. The antithrombotic effect of aspirin is due to inhibition of cyclooxygenases 1 and 2 (COX-1 and COX-2) via acetylation of serine residues 530 and 516 at the active site of the enzyme [13]. Aspirin also acetylates lysine residues in cellular and extracellular proteins [14-17]. A recent comprehensive proteomic study identified more than 12,000 lysine acetylation sites in HeLa cells that were treated with $5 \mathrm{mM}$ aspirin for $6 \mathrm{~h}$ [18]. In addition, aspirin has been shown to acetylate and modify histones. For example, Guo et al. [19] suggested that aspirin protects against experimentally induced colon cancer via acetylation of histone $\mathrm{H} 3$ at lysine $(\mathrm{K})$ residue 27 . In another study, aspirin was found to cooperate with p300 to promote histone $\mathrm{H} 3 \mathrm{~K} 9$ acetylation [20], and this property was implicated in the induction of apoptosis in cultured colorectal stem cells. Histone deacetylases (HDACs) reverse the aspirin-mediated lysine acetylation [14], and HDAC inhibitors cause cytotoxic effects from aspirin-mediated hyperacetylation of proteins [21, 22]. Whether the beneficial effects of aspirin intake are due to its acetylation of proteins is an active topic of investigation. With regard to its effect in the eye, regular intake of aspirin was found to be associated with an increased risk of incident neovascular AMD [23], but an earlier Physicians' Health Study-I showed a slightly better outcome for AMD [24]. Aspirin intake did not alter the progression of retinopathy [25] or open-angle glaucoma [26]. Aspirin has been shown to inhibit experimental cataracts through acetylation of lens proteins [27, 28]. In human trials, some studies have shown protective effects against cataracts [29, 30], while others did not [31]. Whether aspirin has any effect on PCO has not been investigated. It is known that histone acetylation at arginine or lysine residues is associated with the repression of EMT [32, 33]. Studies have shown that inhibitors of HDACs suppress EMT in epithelial cells, including LECs, by increasing the acetylation of histones and $\alpha$-tubulin [34-36]. It has also been shown that acetylated $\alpha$-tubulin plays an important role in microtubule stabilization and cell morphology, and it is profoundly decreased during TGF $\beta$-induced EMT [37].This suggests that deacetylation of $\alpha$-tubulin is not just a marker for EMT but also plays a direct role in controlling EMT. However, 
the precise role of histone acetylation in the EMT of LECs, especially in the regulation of transcriptional factors, remains unclear. In this study we tested the hypothesis that the acetylation of proteins by aspirin is inhibitory against the TGF 32 -mediated EMT in LECs.

\section{EXPERIMENTAL}

\section{Treatment of human LECs with TGF $\beta 2$}

The fetal human lens epithelial cell line (FHL124) was kindly provided by Prof. Michael Wormstone (School of Biological Sciences, University of East Anglia, UK, originally from Prof. John Reddan, Oakland University, MI). FHL124 cells were cultured as previously described [38] and treated with aspirin (Sigma-Aldrich, St. Louis, MO, Cat\# A5376) at $2 \mathrm{mM}$ for $24 \mathrm{~h}$ and then cotreated with 10 ng/ml TGFß2 (Peprotech, Inc., Rocky Hill, NJ, Cat\# 100-35B,10 ng/ml) for the additional indicated times. The MTT assay was used to determine the cytotoxicity of aspirin or cell proliferation.

\section{Measurement of aspirin in the culture medium}

To determine the effective concentration of aspirin in the cell culture medium, $2 \mathrm{mM}$ aspirin was incubated in MEM with or without 5\% FBS. After $48 \mathrm{~h}$, serum albumin-bound aspirin was removed using Amicon Ultra-0.5 ml centrifugal filters (10,000 NMWL, UFC501024, Millipore). The filtrate was incubated with $1 \mathrm{~N} \mathrm{NaOH}$ at $50^{\circ} \mathrm{C}$ for $10 \mathrm{~min}$, and the volume was made up to $200 \mu \mathrm{L}$ with $0.02 \mathrm{M}$ iron(III) chloride solution. The reaction product was measured spectrophotometrically at $530 \mathrm{~nm}$ using aspirin as the standard.

\section{Western blotting}

Total cell lysates were prepared using RIPA buffer (Thermo Fisher Scientific, Cat\# 89900) containing a protease inhibitor (Sigma-Aldrich, Cat\# P8465, 1:100 dilution) and/or phosphatase 
inhibitor cocktail (Sigma-Aldrich, Cat\# P8340, 1:100 dilution). The cells were separated into cytoplasmic and nuclear fractions using a NucBusterTM protein extraction kit (Novagen, San Diego, CA, Cat\# 711833) according to the manufacturer's protocol. Total histones were extracted using a standard extraction kit (Abcam, Cambridge, MA, Cat\# ab113476). Western blotting was carried out as previously described [39]. The primary antibodies (applied overnight at $\left.4^{\circ} \mathrm{C}\right)$ for western blotting were as follows: $\alpha$-SMA (1:5,000 dilution, Sigma-Aldrich, Cat\# A5228), aB-crystallin (1:10,000 dilution, Developmental Studies Hybridoma Bank, University of lowa, IA), fibronectin (FN, 1:200 dilution, Santa Cruz Biotechnology, Cat\# sc-9068), acetyl histone H3K115 (1:500 dilution, Abcam , Cat\# ab240888), acetyl histone H3K122 (1:1,000 dilution, Abcam, Cat\# ab33309), histone H3 (1:1,000 dilution, Cat\# 9715), acetyl-histone H3K9, K14, K18, K56 (acetyl-histone H3 antibody sampler kit, 1:1,000 dilution, Cat\# 9927), Smad2 (1:1,000 dilution, Cat\# 9339), p-Smad2 (1:1,000 dilution, Cat\# 3101), Smad3 (1:1,000 dilution, Cat\# 9523), p-Smad3 (1:1,000 dilution, Cat\# 9520), Smad4 (1:500 dilution, Cat\# 9515), ERK (1:2,000 dilution, Cat\# 4695), p-ERK (1:1,000 dilution, Cat\# 4370), P38 (1:2,000 dilution, Cat\# 9212), p-P38 (1:1,000 dilution, Cat\# 4511), AKT (1:2,000 dilution, Cat\# 9272), p-AKT (1:1,000 dilution, Cat\# 9271), acetyllysine (1:2,000 dilution, Cat\# 9681), acetyl-a-tubulin (1:1,000 dilution, Cat\# 5335), and $\beta$-actin (1:5,000 dilution, Cat\# 4970). HRP-conjugated anti-rabbit IgG (1:5,000 dilution, Cat\# 7074) or anti-mouse IgG (1:5,000 dilution, Cat\# 7076) (Cell Signaling Technology, Inc., Beverly, MA) secondary antibodies were incubated at room temperature (RT) for $1 \mathrm{~h}$ and detected with the SuperSignal West Pico or Femto Kit (Pierce Chemicals, Rockford, IL). Band intensities were normalized to housekeeping genes using ImageJ software and presented as the fold change over controls.

\section{Quantitative real-time PCR}

Quantitative real-time PCR was performed as previously described [39]. RNA was isolated using the RNeasy Plus Micro Kit (Qiagen, Valencia, CA). Two micrograms of RNA was reverse- 
transcribed to synthesize cDNA using the QuantiTect Reverse Transcription Kit (Qiagen). Quantitative real-time PCR was performed with SsoAdvanced ${ }^{\mathrm{TM}}$ Universal SYBR® Green Supermix (Bio-Rad, Richmond, CA, USA) using an iCycler iQ5 Real-Time PCR Detection System (Bio-Rad). The primers used are listed in Table 1. The mRNA levels were normalized to GAPDH.

\section{F-actin staining}

FHL124 cells were stained with Texas Red-X phalloidin (1:40 dilution, Life Technologies) for 45 $\min$ at $37^{\circ} \mathrm{C}$ for visualization of the $\mathrm{F}$-actin cytoskeleton. The preparations were washed three times with 5\% normal goat serum in PBS and mounted with Vectashield mounting medium with DAPI (H-1200, Vector Laboratories Inc., Burlingame, CA). Images were viewed using a confocal microscope (Zeiss confocal laser scanning microscope LSM 510).

\section{Cell migration}

FHL124 cells were scraped in a straight line with a $200 \mu$ l pipet tip, debris was washed out twice with PBS, and cells were photographed for the initial time point under a phase-contrast microscope (Day 0). After images were acquired, cells were treated with either serum-free medium or serum-free medium containing 2 mM aspirin for 24 h. On Day 1, TGF $\beta 2$ was added for an additional $24 \mathrm{~h}$. After the incubation, cells were imaged in the same region (Day 2), and the rate of cell migration was analyzed by quantifying the total distance the cells moved from the edge of the scratch toward the center.

\section{Human capsular bag model to study the effect of aspirin on the EMT of LECs}

Simulated cataract operations were performed to create capsular bags from human donor lenses [40] that were obtained with informed consent and used in accordance with the tenets of 
the Declaration of Helsinki. Approval for the study and experimental protocols (04/Q0102/57) was granted by a National Research Ethics Committee (UK). A small capsulorhexis, approximately $5 \mathrm{~mm}$ in diameter, was created in the anterior lens capsule, thus allowing access to the lens fiber mass, which was removed by hydroexpression. Residual lens fibers were removed by joint irrigation and aspiration. The product of this procedure was termed a capsular bag, which was then removed from the eye by dissecting it from the zonular fibers. The capsular bag was then secured onto a sterile $35-\mathrm{mm}$ polymethylmethacrylate petri dish using eight entomological pins (Anglian Lepidopterist Supplies, Norfolk, UK) inserted at the edge of the capsule to ensure that the capsular bag maintained its shape. The capsular bags were maintained in either serum-free or 5\% FCS-supplemented Eagle's minimum essential medium (EMEM) (Sigma-Aldrich, Dorset, UK) as standard control medium. Match-paired experiments were performed using capsular bags prepared from the same donor. The four match-paired combinations tested were: SF EMEM $\pm 2 \mathrm{mM}$ aspirin; SF EMEM supplemented with $10 \mathrm{ng} / \mathrm{ml}$ TGF $\beta \pm 2 \mathrm{mM}$ aspirin; 5\% FCS EMEM $\pm 2 \mathrm{mM}$ aspirin; 5\% FCS EMEM supplemented with 10 $\mathrm{ng} / \mathrm{ml} \mathrm{TGF} \beta \pm 2 \mathrm{mM}$ aspirin. In all cases, $50 \mu \mathrm{g} / \mathrm{ml}$ gentamicin (Sigma-Aldrich) was present, and preparations were incubated at $35^{\circ} \mathrm{C}$ in a $5 \% \mathrm{CO} 2$ atmosphere. The medium was replaced every 2-4 days, and ongoing observations of cell growth were performed using a Nikon phasecontrast microscope (Nikon, Tokyo, Japan) and a digital camera (Nikon) to capture images. At the experimental end point, the culture medium was removed from the petri dishes, and the capsular bags were fixed in $4 \%$ formaldehyde (Sigma-Aldrich) for $30 \mathrm{~min}$. Quantification of cell growth across the posterior lens capsule was performed using image analysis software (ImageJ, 1.48v). Capsular wrinkling/matrix contraction was assessed at the experimental endpoint by analyzing modified dark-field images of the central posterior capsule. Images were subjected to the find edges function on ImageJ. Edges associated with wrinkles appear bright against a dark background. The image is then subjected to thresholding, which allows quantification. 


\section{Immunofluorescence}

Fixed capsular bags were rinsed three times with PBS, followed by three washes in a solution containing $0.02 \% \mathrm{w} / \mathrm{v}$ BSA and $0.05 \% \mathrm{v} / \mathrm{v}$ IGEPAL (Sigma-Aldrich) in PBS. The preparations were permeabilized with PBS containing $0.5 \%$ v/v Triton X-100 (Sigma-Aldrich) for 30 min. Three additional washes with $0.02 \% \mathrm{w} / \mathrm{v}$ BSA and $0.05 \% \mathrm{v} / \mathrm{v}$ IGEPAL in PBS were performed before nonspecific binding sites were blocked for $1 \mathrm{~h}$ with normal goat serum (Sigma-Aldrich) diluted $1: 50$ in 1\% w/v BSA in PBS. Primary anti- $\alpha$-SMA mouse monoclonal antibody (SigmaAldrich, Cat\# A2547) was diluted 1:100 with 1\% w/v BSA in PBS and applied for $1 \mathrm{~h}$ at $37^{\circ} \mathrm{C}$. Three washes with $0.02 \% \mathrm{w} / \mathrm{v}$ BSA and $0.05 \% \mathrm{v} / \mathrm{v}$ IGEPAL in PBS were subsequently performed, and a-SMA was visualized using an Alexa Fluor 488-conjugated goat anti-mouse secondary antibody (Invitrogen, Paisley, UK, Cat\# 10256302) diluted 1:100 with 1\% w/v BSA in PBS for $1 \mathrm{~h}$ at $37^{\circ} \mathrm{C}$. Samples were then counterstained with 4',6-diamidino-2-phenylindole (DAPI; Sigma-Aldrich) to visualize the nuclei. The preparations were washed a final three times with $0.02 \% \mathrm{w} / \mathrm{v}$ BSA and $0.05 \% \mathrm{v} / \mathrm{v}$ IGEPAL solution, floated onto glass microscope slides and placed in Hydromount mounting medium (National Diagnostics, Hull, UK). Images were viewed using a Zeiss epifluorescence microscope and Zeiss software (Axiovision). To quantify transdifferentiation through $\alpha$-SMA expression, captured fluorescence micrographs were analyzed following transformation into binary images by defined thresholding techniques using Adobe Photoshop to identify fluorescence. These images were then transferred to ImageJ, and the black area within the image was calculated.

\section{Effect of aspirin on HDAC activity}

HDAC activity was measured using a colorimetric assay kit (Biovision, Cat\# K331). Briefly, the HDAC colorimetric substrate Ac-Lys(Ac)-pNA was incubated with either nuclear or cytoplasmic 
extracts of cells for $1 \mathrm{~h}$. Treatment with the lysine developer produces a chromophore, which was measured by reading the absorbance in a microplate reader at $405 \mathrm{~nm}$.

\section{Proteomic characterization of histone adducts in aspirin-treated cells}

Chromatin $(5 \mu \mathrm{g})$ was separated on a 15\% SDS-PAGE gel and stained with SimplyBlue SafeStain (Invitrogen, Carlsbad, CA). Histone H3 was excised corresponding to the molecular weight of the protein and digested as previously described [41]. Histone $\mathrm{H} 3$ was digested with trypsin, and peptides were extracted as previously described [41]. The peptide mixtures were loaded onto a capillary reverse-phase analytical column (360 $\mu$ m o.d. x $100 \mu \mathrm{m}$ i.d.) using an Eksigent NanoLC Ultra HPLC and auto sampler. The analytical column was packed with $20 \mathrm{~cm}$ of C18 reverse-phase material (Jupiter, $3 \mu \mathrm{m}$ beads, $300 \AA$ or Aqua C18, $3 \mu \mathrm{m}$ beads, Phenomenex) directly into a laser-pulled emitter tip. Peptides were gradient eluted at a flow rate of $500 \mathrm{nl} / \mathrm{min}$, and the mobile phases consisted of water containing $0.1 \%$ formic acid (solvent $\mathrm{A}$ ) and acetonitrile containing $0.1 \%$ formic acid (solvent B). A 90 -min gradient was performed, consisting of the following: $0-15 \mathrm{~min}, 2 \% \mathrm{~B}$ (during sample loading); $15-60 \mathrm{~min}, 2-40 \% \mathrm{~B}$; 60-70 min, 40-90\% B; 70-73 min, 90\% B; 73-76 min, 90-2\% B; and 76-90 min, 2\% B (column re-equilibration). For select LC-MS/MS analyses, LC conditions were modified such that peptides were loaded at $0 \% \mathrm{~B}$, and after sample loading, the peptide elution portion of the gradient consisted of 0-40\% B from 15-60 min. Upon gradient elution, the peptides were mass analyzed on an LTQ Orbitrap Velos mass spectrometer (Thermo Scientific) equipped with a nanoelectrospray ionization source. The instrument was operated using a data-dependent method with dynamic exclusion enabled. Full-scan (m/z 300-2000) spectra were acquired with the Orbitrap (resolution 60,000), and the top 16 most abundant ions in each MS scan were selected for fragmentation in the LTQ. An isolation width of $2 \mathrm{~m} / \mathrm{z}$, activation time of $10 \mathrm{~ms}$, and $35 \%$ normalized collision energy were used to generate the MS2 spectra. Dynamic exclusion settings allowed for a repeat count of 2 within a repeat duration of $10 \mathrm{~s}$, and the exclusion 
duration time was set to $15 \mathrm{~s}$. For identification of $\mathrm{H} 3$ peptides, tandem mass spectra were searched with Sequest (Thermo Fisher Scientific) against a human subset database created from the UniProtKB protein database (www.UniProt.org). Database searches were performed using the following variable modifications: +57.0214 (carbamidomethylation) on Cys; +15.9949 (oxidation) on Met; and +14.0157 (methylation), +28.0313 (dimethylation), and +42.0106 (acetylation) on Lys. The search results were assembled using Scaffold 3.0 (Proteome Software), and spectra of interest were inspected using Xcalibur 2.1 Qual Browser software (Thermo Scientific).

\section{Chromatin immunoprecipitation (ChIP) assay}

ChIP was carried out according to the manufacturer's (Invitrogen) instructions. Briefly, $5 \times 10^{6}$ cells were crosslinked with $0.75 \%$ formaldehyde for $7 \mathrm{~min}$ and quenched with $1.25 \mathrm{M}$ glycine for 5 min. Cells were washed and suspended in NP40 lysis buffer containing protease inhibitors and the HDAC inhibitor sodium butyrate and then subjected to sonication (Diagenode Bioruptor, Diagenode Inc., Denville, NJ) for 30 min to shear chromatin to between 150-500 bp. Chromatin was immunoprecipitated with $2 \mu \mathrm{g}$ of antibody (against acetylated H3K56, acetylated H3K122, or rabbit lgG) bound to magnetic beads (Dynabeads ${ }^{\mathrm{TM}}$ Protein A, Cat\# 10001D, Invitrogen/Dynal, Oslo, Norway) at $4^{\circ} \mathrm{C}$. The antibody and histone complex along with the magnetic beads were washed with RIPA buffer, the crosslinking was reversed by protease treatment, and the DNA was purified. Quantitative PCR was carried out for the promoter regions of $\alpha$-SMA (ACTA2) and collagen type I (COL1A1). The primer pairs are listed in Table 1. The relative levels of DNA amplification were normalized to an input sample. To verify whether the Smad2/3/4 complex is associated with acetyl-H3K56 or H3K122, cell lysates were treated with a microbead-conjugated antibody to acetyl-H3K56 or H3K122 overnight at $4^{0} \mathrm{C}$. The bound proteins were rinsed with RIPA buffer 3 times, mixed with $1 \mathrm{X}$ loading dye, boiled for 5 min and then subjected to western blotting for Smad4. 


\section{Effect of aspirin on the EMT of LECs in lensectomized mice}

All animal experiments were performed in accordance with the ARVO statement for the Use of Animals in Ophthalmic and Vision Research and the University of Colorado IACUC guidelines. Lensectomy in mice was performed as previously described [42]. In the case of mice (strain $129 / \mathrm{Sv}, 12$-week-old males) receiving aspirin, the animals were orally administered $1 \mathrm{mg} / \mathrm{ml}$ aspirin or $0.89 \mathrm{mg} / \mathrm{ml}$ sodium salicylic acid (SA, molar equivalent to aspirin) in $25 \mathrm{mM}$ sodium phosphate-buffered (SPB, $\mathrm{pH}$ 7.4) drinking water for 5 days prior to the lensectomy and for 5 days after the procedure. The control group received $25 \mathrm{mM}$ SPB alone. Mice consumed 3.5 to $4 \mathrm{ml}$ of drinking water per day. To test whether aspirin reached the lens, one lens was homogenized, and the homogenate was subjected to western blotting and another lens was fixed, sectioned and immunostained for acetyllysine. Mice were anaesthetized with ketamine/xylazine solution and the eyes were prepped with betadine and $1 \%$ proparacaine hydrochloride. The pupils were dilated using $1 \%$ tropicamide and $1 \%$ ophthalmic phenylephrine eye drops (1:4 ratio). A horizontal incision was made in the cornea and the anterior capsule with an ophthalmic knife. The lens fiber mass was gently hydrodissected with Hank's balanced salt solution (BSS) and squeezed out of the eye through the corneal opening, leaving behind the lens capsule. The lens capsule was flushed with BSS, which was followed by injection of sodium hyaluronate viscoelastic material (Alcon Labs; $0.1 \mathrm{ml}$ ) into the empty capsular bag to prevent collapse of the bag. The corneal incision was sutured using 10-0 nylon suture. Antibiotic ointment was applied immediately after surgery and once daily until visible wound healing occurred. Lensectomy was carried out on day 5 , and the animals were sacrificed on day 10. The animals received aspirin or SA at the same concentration for 5 days after lensectomy. The eyes were fixed for $2 \mathrm{~h}$ in Davidson's fixative solution and then changed to $4 \%$ paraformaldehyde overnight. The eyes were then paraffin embedded, sectioned and subjected 
to immunofluorescence detection of $\alpha$-SMA (1:100 dilution) and collagen type IV (1:100 dilution, Sigma, Cat\# 9272), as previously described [43].

\section{Statistical analysis}

GraphPad Prism software version 7 (GraphPad Prism Software, Inc., San Diego, CA) was used for all statistical analyses. The data are expressed as the mean \pm standard deviation (SD) of at least three independent experiments. We used Tukey's multiple comparison test for significant differences among treatment groups. A p value of $<0.05$ was considered to be statistically significant.

\section{RESULTS}

\section{Effect of aspirin on the cell viability, proliferation, and acetylation of cellular proteins}

We first determined the highest aspirin concentration that could be used with minimal toxicity to lens epithelial cells. FHL124 cells were treated with increasing concentrations of aspirin (0-5 $\mathrm{mM}$ ) for $48 \mathrm{~h}$. The results showed that aspirin up to $2.5 \mathrm{mM}$ for $48 \mathrm{~h}$ did not affect cell viability (Fig. 1A). We then determined whether aspirin inhibits cell proliferation. Cells were treated with aspirin $(0-5 \mathrm{mM})$ for $24 \mathrm{~h}$ in the presence of $5 \%$ serum, followed by $10 \mathrm{ng} / \mathrm{ml}$ TGF 2 treatment along with 0-5 mM aspirin for an additional $24 \mathrm{~h}$. The results showed that aspirin up to $2.5 \mathrm{mM}$ did not alter cell proliferation, even in the presence of TGF $\beta 2$ (Fig. 1B). We measured the concentration of aspirin in the cell culture medium (MEM) after $48 \mathrm{~h}$ of incubation to determine whether aspirin binds to serum albumin in the medium and reduces its effective concentration. Our results showed that after $48 \mathrm{~h}$ of incubation, there was no change in the aspirin concentration (Supplementary Fig. 1). Based on these results, $2 \mathrm{mM}$ aspirin was used for all subsequent experiments. When tested at a $2 \mathrm{mM}$ concentration, aspirin did not affect BrdU- 
incorporation into cells (Supplementary Fig. 2). We tested the reversibility of protein acetylation in cells treated with $2 \mathrm{mM}$ aspirin alone for $24 \mathrm{~h}$. Cells were treated with aspirin for $24 \mathrm{~h}$, and the medium was then changed to remove the aspirin, after which the cells were incubated for an additional $24 \mathrm{~h}$. The cells exposed to aspirin continuously for $48 \mathrm{~h}$ showed higher levels of acetylated proteins than that of the cells exposed to aspirin for $24 \mathrm{~h}$ (Fig. 1C). The removal of aspirin after $24 \mathrm{~h}$ led to a substantial reversal of protein acetylation. We treated cells with $2 \mathrm{mM}$ aspirin for $24 \mathrm{~h}$ and then changed the medium and added TGF $32(10 \mathrm{ng} / \mathrm{ml}$, with or without aspirin) and incubated for an additional $24 \mathrm{~h}$. As shown in Fig. 1D, during the 24-h post incubation without aspirin, overall protein acetylation levels decreased, which were unaffected by the TGF $\beta 2$ treatment.

\section{Effect of aspirin on TGFß2-induced EMT}

To determine the effect of aspirin on the TGF $\beta 2$-induced EMT of FHL124 cells, the cells were treated with $2 \mathrm{mM}$ aspirin for $24 \mathrm{~h}$, followed by $10 \mathrm{ng} / \mathrm{ml}$ TGF $\beta 2$ treatment along with $2 \mathrm{mM}$ aspirin for an additional $24 \mathrm{~h}$. The treatment of TGF 32 for $24 \mathrm{~h}$ increased the expression of $\alpha$ SMA and FN (EMT makers in LECs) and aB-crystallin protein levels by 1.3-, 2.1- and 2.8-fold, respectively, compared to the control (no TGF 32 ) (Fig. 2A). Treatment with aspirin significantly inhibited the TGF $\beta 2$-induced increases in $\alpha$-SMA, FN and $\alpha B$-crystallin. In cells that were treated with $2 \mathrm{mM}$ aspirin for $24 \mathrm{~h}$, followed by $10 \mathrm{ng} / \mathrm{ml}$ TGFß2 treatment along with aspirin $(2 \mathrm{mM})$ for another $6 \mathrm{~h}$, aspirin reduced the mRNA levels for $\alpha-S M A, F N$ and $\alpha B$ crystallin that were induced by TGF 32 (Fig. 2B), suggesting that the inhibition of EMT occurred at the transcriptional level. Immunofluorescence for a-SMA showed that aspirin suppressed TGF $\beta 2$-induced $\alpha$-SMA expression (Fig. 2C).

We tested whether the inhibition of EMT was due to the acetyl group or salicylic acid in aspirin. Aspirin significantly reduced the TGF $\beta 2$-induced expression of $\alpha$-SMA $(p<0.05)$, but at 
equimolar concentrations, sodium salicylate (SA) failed to produce a similar response (Supplementary Fig. 3). These data indicated that the acetyl moiety is likely responsible for the inhibitory effect of aspirin.

To determine whether aspirin inhibits stress fiber formation (through filamentous cytoskeletal actin assembly) during EMT, cells were stained with Texas Red-X phalloidin (Fig. 2D).

Treatment with TGF $\beta 2$ strongly promoted stress fiber formation ( $\mathrm{F}$-actin staining) within $24 \mathrm{~h}$, but aspirin robustly inhibited stress fiber formation. Since the filamentous cytoskeleton network regulates cell migration, we tested the effect of aspirin on cell migration. Forty-eight hours after a scratch was created, cells in the serum-free medium alone migrated to close the scratch by $15.7 \%$. However, cells treated with TGF $\beta 2$ migrated by $60.9 \%$ within $24 \mathrm{~h}(p<0.05)$. Aspirin significantly inhibited TGF $\beta 2$-mediated cell migration $(p<0.05$, compared to TGF $\beta 2$, Fig. $2 E$ and $F$ ).

To further test whether aspirin blocks the EMT effect already initiated by TGF $\beta 2$, FHL124 cells were first treated with $10 \mathrm{ng} / \mathrm{ml}$ TGF $\beta 2$ for $24 \mathrm{~h}$. Aspirin was then added along with TGF $\beta 2$, and the cells were incubated for an additional $24 \mathrm{~h}$. TGF 32 increased the expression of $\alpha-S M A, F N$ aB-crystallin and by 1.8-, 2.4- and 2.9-fold, respectively (Fig. 3). The addition of aspirin at $24 \mathrm{~h}$ significantly inhibited the increase in $\alpha$-SMA (by 1.2-fold, p<0.01) and aB-crystallin (by 2.2-fold, $\mathrm{p}<0.05)$. The increase in FN was inhibited (1.8-fold) but not significantly.

\section{Effect of aspirin in human capsular bag cultures}

The addition of TGF $\beta 2$ induces profound changes within human lens capsular bags, which include increased levels of transdifferentiation and matrix contraction [44]. We first assessed the effects of $2 \mathrm{mM}$ aspirin on basal cell behavior following simulated cataract surgery. In the control preparations maintained in serum-free Eagle's minimum essential medium (EMEM), cells 
recolonized the anterior capsule and steadily covered the previously cell-free posterior capsule that lies within the visual axis (Fig. 4A). Treatment with aspirin did not have a profound effect on the anterior lens epithelium, but it significantly reduced the coverage of the central posterior capsule. Treatment with $10 \mathrm{ng} / \mathrm{ml}$ TGF $\beta 2$ promoted contraction of the posterior capsule, and coverage was possibly impaired; these findings are in agreement with previous reports $[40,45]$. Cotreatment with TGF $\beta 2$ and aspirin resulted in significantly less cell coverage of the posterior lens capsule and matrix contraction. End-point evaluation of transdifferentiation using a-SMA immunocytochemistry demonstrated expression in cells growing on the central posterior capsule maintained in serum-free conditions. Treatment with $2 \mathrm{mM}$ aspirin significantly suppressed this signal either alone or in combination with TGFß2 (Fig. 4B).

While these data strongly point to an ability of aspirin to counter events in PCO, we accept that changes to the ocular environment following surgery will occur, such that blood proteins will be present along with increased growth factors produced or activated within the eye. We therefore elected to undertake further tests to evaluate the effects of aspirin in medium supplemented with $5 \%$ FCS (with or without TGF $\beta 2$ ). Supplementing the medium with $5 \%$ serum (5\% FCS EMEM) accelerated the changes in the capsular bag, such that in 5\% FCS EMEM alone, cell coverage of the posterior capsule was complete within 7 days. Treatment with aspirin significantly impaired the rate of coverage. However, aspirin failed to prevent the cell coverage of PC when cells were treated with TGF $\beta 2$ in serum-containing media. The addition of $10 \mathrm{ng} / \mathrm{ml}$ TGF $\beta 2$ to 5\% FCS EMEM-cultured capsular bags resulted in marked matrix contraction and reduced $\alpha-$ SMA expression (Fig. 4C and D). Treatment with $2 \mathrm{mM}$ aspirin did not halt matrix contraction, but the degree was significantly inhibited (Fig. 4C). A significant reduction in a-SMA was also observed both in the presence or absence of TGF $\beta 2$. These data suggest that aspirin inhibits 
not only TGFß2-dependent but also basal formation of myofibroblasts (Fig. 4D). Together, these data further support the observations that aspirin inhibits the TGFß2-mediated EMT of LECs.

\section{Effect of aspirin on TGF $\beta 2$-mediated signaling pathways}

To determine whether aspirin blocks TGF 32 -mediated signaling in cells, we evaluated the canonical and noncanonical signaling pathways. Cells were treated with $2 \mathrm{mM}$ aspirin for $24 \mathrm{~h}$ prior to treatment with TGF $\beta 2$ + aspirin for 0.5 or $2 \mathrm{~h}$. While both Smad2 and Smad3 were phosphorylated by TGF $\beta 2$, aspirin did not change the phosphorylation levels upon TGF $\beta 2$ treatment for $0.5 \mathrm{~h}$ (Fig. 5A). Cells were fractionated into cytoplasmic and nuclear fractions and phosphorylated (p) Smad levels were measured. We found that the $p$-Smad2 levels were significantly increased in both in the nuclear $(p<0.001)$ and cytoplasmic $(p<0.05)$ fractions upon TGF 32 treatment for $2 \mathrm{~h}$, and these increases were unaffected by aspirin (Fig. 5B).

During EMT, activation of noncanonical TGF $\beta$ signaling through MAP kinases and PI3K/AKT can also regulate gene expression [46-48]. Several previous studies have shown that the inhibition of the noncanonical TGF $\beta$ pathway prevents the EMT response in LECs [39, 49]. Treatment with TGF 2 for $0.5 \mathrm{~h}$ increased $\mathrm{p}$-p38 MAPK or $\mathrm{p}-\mathrm{AKT}$ (but not $\mathrm{p}$-ERK) but aspirin had no effect on such phosphorylation (Fig. 5C). Together, these data suggest that aspirin does not block the canonical or noncanonical TGF 32 signaling pathways during EMT in FHL124 cells. This led to the determination of whether the inhibition of EMT by aspirin occurred through the acetylation of histones.

\section{Effect of aspirin on HDAC activity and acetylation of $\alpha$-tubulin}

Previous studies have shown that HDAC inhibitors block EMT [35, 50, 51]. To explore whether aspirin inhibits the enzyme activities of HDACs, we performed an assay that measured the 
activities of HDACs (class I and II) in the cytoplasmic and nuclear fractions. FHL124 cells were first treated with $2 \mathrm{mM}$ aspirin for $24 \mathrm{~h}$ and then with $10 \mathrm{ng} / \mathrm{ml}$ TGF $\beta 2$ for $24 \mathrm{~h}$ along with aspirin. The HDAC activity was reduced by $56 \%$ upon treatment with $20 \mu \mathrm{M}$ trichostatin A (TSA, positive control). However, HDAC activity was not affected by aspirin in either the nuclear or cytoplasmic fractions (Fig. 6A).

HDAC6 regulates the acetylation of $\alpha$-tubulin (Ac- $\alpha$-tubulin). Its inhibition promotes the acetylation of $\alpha$-tubulin and inhibits TGF $\beta$-induced EMT [37]. To explore whether aspirin increases the acetylation of $\alpha$-tubulin, FHL124 cells were treated with aspirin for $24 \mathrm{~h}$ and then treated with TGFß2 $(10 \mathrm{ng} / \mathrm{ml})$ along with aspirin for an additional $24 \mathrm{~h}$. We found that aspirin did not induce the acetylation of $\alpha$-tubulin (Fig. 6B), thus precluding $\alpha$-tubulin's acetylation as a possible cause for the inhibition of EMT.

\section{Effect of aspirin and TGF $\beta 2$ on the acetylation of proteins}

Based on the above results, we postulated that aspirin's EMT inhibitory property could be due to the acetylation of cellular proteins. Cells treated with TGF $\beta 2(10 \mathrm{ng} / \mathrm{ml}$ for $24 \mathrm{~h})$ in the presence or absence of aspirin were subjected to western blotting for acetyllysine-bearing proteins. Supplementary Fig. 4A demonstrates that treatment with aspirin resulted in the acetylation of lysine residues in a concentration-dependent manner. However, cotreatment with TGF $\beta 2$ did not further alter these levels. We treated cells with $2 \mathrm{mM}$ aspirin in the presence or absence of TGF $\beta 2(10 \mathrm{ng} / \mathrm{ml})$ for $24 \mathrm{~h}$ and fractionated the cells into nuclear and cytoplasmic fractions, followed by western blotting for acetyllysine-bearing proteins. Aspirin acetylated both cytoplasmic and nuclear proteins (Supplementary Fig. 4B), but TGF $\beta 2$ had no effect on acetylation. 


\section{Effect of aspirin on histone acetylation}

Posttranslational modification of histones regulates gene expression by altering the chromatin structure [52, 53]. Histone acetylation regulates many cellular processes, including chromatin dynamics and transcription, gene silencing, cell cycle progression, apoptosis, differentiation, DNA replication, DNA repair, nuclear import, and neuronal repression [54]. We observed that aspirin did not affect either TGF 32 signaling or HDAC activity. This led us to hypothesize that aspirin acetylates histones, leading to alterations in EMT-related genes. To test this hypothesis, we analyzed histones from cells treated with aspirin via LC-MS/MS. The data shown in Table 2 reveal acetylation of $\mathrm{K} 9, \mathrm{~K} 14, \mathrm{~K} 27, \mathrm{~K} 79$, and $\mathrm{K} 115$ of histone $\mathrm{H} 3$ in control cells. In TGF $\beta 2$ treated cells, we observed acetylation in all of the above lysine residues except for $\mathrm{K} 115$. Aspirin treatment (in the presence or absence of TGF $\beta 2$ ) showed acetylation of all the above lysine residues in addition to $\mathrm{K} 56$ and $\mathrm{K} 122$.

To further confirm the mass spectrometric results, we performed western blotting. Cells were treated with aspirin $(2 \mathrm{mM})$ for $24 \mathrm{~h}$ and then with aspirin $(2 \mathrm{mM})$ with or without TGF 32 (10 $\mathrm{ng} / \mathrm{ml}$ ) for an additional $6 \mathrm{~h}$, and histones were extracted. While the levels of histones were unaltered by either aspirin or aspirin + TGFß2 treatment (Fig. 7A, left panel), the western blotting results showed that histones $\mathrm{H} 3 / \mathrm{H} 2 \mathrm{~A}$ were predominantly acetylated by aspirin, but TGF 32 did not have an effect on its acetylation (Fig. 7A, right panel). We next sought to evaluate the site-specific acetylation marks on histone H3. The western blotting results showed that treatment with TGF $\beta 2$ alone does not affect the acetylation levels of any of the lysine residues tested. However, treatment with aspirin strongly increased the acetylation of K56 and K122 (in the presence or absence of TGF 32 ), but not other lysine residues (Fig. 7B). These 
data suggest that aspirin acetylates discrete lysine residues on histone $\mathrm{H} 3$, which may play an underlying role in the inhibition of EMT in FHL124 cells.

\section{Aspirin-mediated acetylation of $\mathrm{H} 3 \mathrm{~K} 56$ and $\mathrm{H} 3 \mathrm{~K} 122$ at the promoter region of EMT- associated genes}

To determine whether aspirin-mediated acetylation of K56 and K122 is associated with EMT gene regulation, we performed ChIP assays. The ChIP assay results showed that there were significantly elevated levels of acetylation of $\mathrm{H} 3 \mathrm{~K} 56$ and $\mathrm{H} 3 \mathrm{~K} 122$ at the promoter regions of ACTA2 and COL1A in TGF $\beta 2$-treated cells compared to controls (Fig. 8A and B). Interestingly, even though aspirin globally enhanced acetylation at H3K56 and H3K122, it significantly $(p<0.001)$ reduced the TGF $\beta 2$-mediated enhancement of acetylation at the promoter regions of ACTA2 and COL1A1. This decreased acetylation is consistent with the decreased EMT gene expression we observed in aspirin-treated cells (Fig. 2B). In control experiments in which naive rabbit IgG was used, there was very low amplification for ACTA2 and no amplification for COL1A1. These results led us to hypothesize that aspirin reduces the binding of transcription factors such as Smads to the promoter region of EMT-related genes and consequently inhibits EMT of LECs.

Coimmunoprecipitations were performed to confirm that the Smad2/3/4 complex is associated with acetylated H3K56 and H3K122. Co-IPs indicated that the Smad complex could be pulled down by antibodies against either acH3K56 or acH3K122 (Fig. 8C). In both acH3K56 and acH3K122 immunoprecipitated samples, Smad4 levels were significantly $(p<0.01)$ higher in the TGF $\beta 2$-treated cells compared to those in untreated or aspirin-treated control cells. The Smad4 levels were significantly $(\mathrm{p}<0.01)$ reduced in samples immunoprecipitated with anti-acH3K122 antibody in TGF $\beta 2$ + aspirin-treated cells. Such an inhibition was not observed in samples immunoprecipitated with anti-acH3K56 antibody, although the trend was similar to that of 
acH3K122 (Fig. 8D). These results suggested that aspirin inhibits TGF $\beta 2$-mediated EMT of LECs by blocking Smad4 binding to the promoter region of EMT genes.

\section{Effect of aspirin on the EMT of LECs in lensectomized mice}

We evaluated the effect of aspirin on the EMT of capsule-adherent LECs in lensectomized mice. Oral administration of aspirin to mice increased the acetylation of proteins of the lens and LECs (Fig. 9A and B). Mice were pretreated with aspirin for 5 days, followed by lensectomy. After 5 days, mice were sacrificed, and the eyes were fixed and immunostained for $\alpha$-SMA and collagen IV (a marker of the lens capsule). The immunohistochemical images indicated that LECs in lensectomized mice proliferated and expressed $\alpha$-SMA, whereas aspirin treatment prevented both $\alpha$-SMA expression and cell proliferation (Fig. 9C). We next determined whether the observed effects were due to salicylate, a product of aspirin. Both buffer (control) and SAtreated mouse LECs had higher $\alpha$-SMA levels and LEC proliferation compared to aspirin-treated controls. These data indicated that aspirin treatment strongly inhibits the EMT response in LECs after lensectomy through the acetylation of proteins

\section{DISCUSSION}

In this study, we evaluated whether aspirin can block the TGF $\beta 2$-mediated EMT response in LECs. This was based on the ability of HDAC inhibitors to prevent histone deacetylation and blockade of TGF 32 -mediated EMT of LECs $[35,51]$. The major finding of our study is that aspirin inhibits TGFß2-mediated EMT of LECs in vitro, ex vivo, and in lensectomized mice, possibly through acetylation of histone H3 K56 and K122. 
We found that treatment with aspirin resulted in the acetylation of a number of cellular proteins in LECs. Interestingly, as we increased the aspirin concentration from 0 to $2 \mathrm{mM}$ for cell treatment, the extent of acetylation increased in the same proteins but not in new proteins. This suggests that aspirin targets specific proteins in cells that are incrementally acetylated with increasing concentrations of aspirin. Similar observations have been made in other cells $[55,56]$. Why aspirin-mediated acetylation is specific to some proteins requires further investigation.

A previous study reported that the aberrant induction of cyclooxygenase-2 (COX-2) plays a role in TGF $\beta /$ Smad3-mediated EMT in human breast cancer cells [57]. It has also been reported that the upregulation of COX-2 and PI3K/AKT phosphorylation promotes EMT in hepatocellular carcinoma cells [58]. Based on these reports, we considered the possibility that aspirin inactivated COX-2 in LECs, resulting in the inhibition of TGF 32 -mediated EMT. A previous study has shown that COX-2 is present in canine lens epithelial cells and that treatment with COX-2 inhibitors can block LEC proliferation [59], and another study showed decreased PCO in dogs upon treatment with COX-2 inhibitors, which was ascribed to induction of apoptosis in LECs [60]. Thus, it was possible that aspirin inhibited EMT in LECs through inhibition of cell migration and blockade of COX-2. However, it is unlikely under these conditions because aspirin at $2 \mathrm{mM}$ (used in most experiments) did not inhibit proliferation or reduce the viability of LECs.

Nonetheless, we cannot rule out COX-2-mediated effects of aspirin on the observed inhibition of lens epithelial cell proliferation in lensectomized mice. Whether aspirin affects other signaling mechanisms related to cell proliferation and fiber cell differentiation needs to be investigated in future studies.

The fact that SA was unable to exhibit similar effects as aspirin clearly implicates acetylation by aspirin as the cause for EMT inhibition. The aspirin concentration we used to obtain the 
inhibitory effect was $2 \mathrm{mM}$. At concentrations below $2 \mathrm{mM}$, aspirin failed to show inhibitory effects. The fact that aspirin acetylates the same proteins but to a higher extent when used in increasing concentrations suggests that there could be an acetylation threshold for the inhibition of EMT. What is striking is that aspirin's uninterrupted presence is required for protein acetylation. When removed for $24 \mathrm{~h}$, the majority of acetylated proteins lost their acetylation, suggesting the presence of robust deacetylation mechanisms in FHL124 cells. In fact, we have previously observed that FHL124 cells contain SIRT3 and SIRT5, which could deacetylate proteins [61]. Surprisingly, when aspirin was removed from cells during TGF $\beta 2$ treatment, there was no further increase in a-SMA expression, suggesting that the EMT inhibitory response persisted after the removal of aspirin for at least $24 \mathrm{~h}$.

One possibility for the inhibition of TGF $\beta 2$-mediated EMT by aspirin could be that aspirin reacted directly with TGF $\beta 2$ and inactivated it. Aspirin spontaneously acetylates proteins upon incubation with proteins [55]. Therefore, it was reasonable to assume that TGF $\beta 2$ was acetylated by aspirin in the culture medium. However, we found that at the concentration of aspirin $(2 \mathrm{mM})$ and TGFß2 $(10 \mathrm{ng} / \mathrm{ml})$ used, the TGF $\beta 2$-mediated signal transduction was similar in the presence or absence of aspirin. Thus, the observed inhibitory effects of aspirin were not due to a direct reaction of aspirin with TGF $\beta 2$. We also considered the possibility that inhibition of EMT by aspirin could be due to acetylation of Smads. However, several previous studies have shown that acetylation of Smads promotes their nuclear translocation and transcriptional activity [62-64]. These observations suggest that the acetylation of Smads may not have contributed to the inhibition of TGF $\beta 2$-mediated EMT by aspirin. The downregulation of aB-crystallin by aspirin could have also contributed to the inhibition of EMT, as we have previously shown that $\mathrm{aB}$-crystallin binds to Smads and Snail and translocates to the nucleus during the TGF $\beta 2$-mediated EMT of LECs [42]. Such binding could have stabilized the transcription factors and allowed them to bind to DNA and promote EMT. 
Several studies have shown that HDAC-mediated epigenetic mechanisms are involved in the EMT response in renal epithelial cells [50] and hepatocytes [65]. In particular, trichostatin A (TSA), a class I and II HDAC inhibitor, inhibited the TGFß2-induced EMT of LECs [34, 35, 51]. However, the epigenetic mechanism by which HDAC inhibitors block the TGF $\beta 2$-mediated EMT of LECs is unclear. We reasoned that aspirin could inactivate HDACs and thereby inhibit TGFß2-mediated EMT of LECs, similar to HDAC inhibitors. However, we found that aspirin did not inactivate HDACs in LECs. Further, previous studies have shown that TGF 1 -induced EMT is regulated by HDAC6-dependent deacetylation of a-tubulin in immortalized mammary epithelial cells [37] and human lung adenocarcinoma cells [36]. However, TGFß2 did not deacetylate $\alpha$-tubulin, and aspirin did not increase the acetylation of tubulin in LECs. Together, these observations ruled out a role for HDACs in aspirin's inhibition of EMT of LECs.

One major finding in our study is that aspirin increased the acetylation of K56 and K122 on histone $\mathrm{H} 3$ in the presence or absence of TGF 32 . Past studies on histone modification have focused mainly on the acetylation of histone tails. However, we found aspirin-mediated acetylation at $\mathrm{K} 56$ and $\mathrm{K} 122$, which are in the globular domain of $\mathrm{H} 3$. The modification of histones can affect two of their properties: the DNA binding affinity and the recruitment of nonhistone proteins $[66,67]$. The lateral side of histones regulates transcriptional activity [68]. Interestingly, aspirin-mediated acetylated K56 and K122 are on the lateral surface of histone H3. This modification of histones is important for RNA transcription, but the exact mechanisms are unclear. A study showed that acetylation of the lateral surface of histone $\mathrm{H} 3$ reduces the free energy of histone octamer binding and directly influences the positioning of nucleosomes, which increases DNA unwrapping from the octamer [69]. Further, acetylation of K56 on histone H3 has been found to play important roles in transcriptional activation; deacetylation of K56 drives chromatin toward the assembled state and represses transcription [70]. In addition, acetylation 
of K122 activates transcription, and the lack of it significantly impairs gene induction [71]. These observations point to the possibility that aspirin promotes acetylation at K56 and K122 globally, but at the EMT loci, it inhibits acetylation of the two lysine residues, thereby inhibiting the binding of transcription factors and repressing EMT genes. The reduced mRNA levels for $\alpha-$ SMA, $\alpha B$-crystallin and FN in TGF $\beta 2$ - and aspirin-treated cells when compared to levels with treatment with TGF $\beta 2$ alone support this view. A previous study showed that TSA suppresses the TGF 1 1-mediated EMT of human kidney tubular epithelial cells by acetylation of histone H3 and $\mathrm{H} 4$ without exerting effects on the phosphorylation of Smad2 and Smad3 [50]. This is somewhat similar to our finding in this study that aspirin did not alter the TGF $\beta 2$-mediated phosphorylation of Smad2 and Smad3 but decreased acetylated histone H3 levels during inhibition of EMT of LECs. Further, aspirin could modulate the levels/activities of Smad transcriptional corepressors, such as TG-interacting factor (TGIF), Sloan-Kettering Institute (Ski), Ski-related novel gene (SnoN), or antagonists of TGF $\beta$ signaling, such as bone morphologic protein (BMP)-7, Smad6 or Smad7, during the inhibition of EMT, which needs to be investigated.

Further evidence for the ability of aspirin to inhibit TGF 32 -mediated EMT came from our work on human lens capsular bags. Treatment with aspirin at a $2 \mathrm{mM}$ concentration inhibited capsule wrinkling and $\alpha$-SMA expression during the 28-day period of incubation, suggesting that chronic exposure to aspirin can block changes in the capsule that are integral to PCO. Our mouse experiments further validated the human capsule results. Initially, we administered $1 \mathrm{mg}$ (10 $\mathrm{mg} / \mathrm{ml}, 100 \mu \mathrm{l}$ ) of aspirin through oral gavage once a day for 5 days and found that it had no effect on the acetylation of lens proteins (Supplementary Fig. 5). We then administered aspirin through drinking water and found that acetylation was occurring on lens proteins both in LECs and lens fiber cells. These results further reiterated the notion that chronic exposure to aspirin is required to acetylate lens proteins and inhibit EMT of LECs. 
Lensectomy in mice has been used as a model for human PCO [72]. Epithelial cells on the capsule synthesize $\alpha$-SMA in response to the wound created during lensectomy [42]. Although an IOL cannot be implanted in the mouse lens capsule bag, the capsular bag was filled with a viscoelastic material that prevented, to some extent, the collapse of the anterior and posterior capsules. Aspirin administration for 5 days prior to lensectomy and for 5 days post lensectomy inhibited a-SMA production in the LECs, a clear indication that aspirin can block EMT in lensectomized mice.

Taken together, these results suggest that aspirin may block the EMT of LECs during PCO in humans. However, the concentration needed to realize the effect, at least in cell culture and mouse experiments, was $2 \mathrm{mM}$ and $1 \mathrm{mg} / \mathrm{ml}$ in drinking water daily, respectively. Whether one can achieve such concentrations in the lens after cataract surgery remains to be determined. Many patients with cardiovascular complications or individuals intending to prophylactically prevent cardiovascular diseases take aspirin at 75 to $100 \mathrm{mg} /$ day quantities [73]. It has been shown that $40 \mathrm{~min}$ after ingesting $100 \mathrm{mg}$ of aspirin, the plasma concentration was $2.2 \pm 1.6$ $\mu \mathrm{g} / \mathrm{ml}$, and with $1500 \mathrm{mg}$, it was $21.1 \pm 8.9 \mu \mathrm{g} / \mathrm{ml}$ [74]. What portion of the ingested aspirin makes its way to the lens in humans is unclear. If sufficient aspirin reaches the LECs after cataract surgery, it could inhibit PCO development. It will be interesting to determine in a retrospective study whether the incidence of PCO or the need for YAG laser treatment is lower in chronic users of aspirin compared to those of nonusers and whether the effects, if any, correlate with the dosage of aspirin.

\section{Acknowledgments}

We thank Drs. Johanna Rankenberg, Rooban Nahomi, Sandip Nandi and Niklaus Mueller for critical reading of the manuscript. 


\section{Declarations of interest}

The authors declare no conflict of interest.

\section{Funding information}

This work was supported by the National Institutes of Health Grants EY022061 and EY028836 and a challenge grant by Research to Prevent Blindness, NY to the Department of Ophthalmology, University of Colorado School of Medicine, and The University of Colorado School of Medicine Translational Award: Consortium for Fibrosis Research and Translation (CFReT) postdoctoral fellowship award.

\section{Author contribution statement}

RHN and MHN conceived, designed and analyzed all the cell and mouse experiments. MHN performed all cell experiments. MW and AJOS designed, performed and analyzed human capsular bag culture experiments, KF and JJG performed LC-MS/MS analysis of histone H3 for acetyllysine residues. MP and MHN performed lensectomy. JAB, KUP, and MHN designed and performed the ChIP assays. All authors reviewed the results and approved the final version of the manuscript. 


\section{References}

1 Wormstone, I. M., Wang, L. and Liu, C. S. (2009) Posterior capsule opacification. Exp Eye Res. 88, 257-269

2 Awasthi, N., Guo, S. and Wagner, B. J. (2009) Posterior capsular opacification: a problem reduced but not yet eradicated. Arch Ophthalmol. 127, 555-562

3 Spierer, A., Desatnik, H. and Blumenthal, M. (1999) Refractive status in children after long-term follow up of cataract surgery with intraocular lens implantation. J Pediatr Ophthalmol Strabismus. 36, 25-29

4 Karahan, E., Er, D. and Kaynak, S. (2014) An Overview of Nd:YAG Laser Capsulotomy. Med Hypothesis Discov Innov Ophthalmol. 3, 45-50

5 Burq, M. A. and Taqui, A. M. (2008) Frequency of retinal detachment and other complications after neodymium:Yag laser capsulotomy. J Pak Med Assoc. 58, 550-552

$6 \quad$ Koch, D. D., Liu, J. F., Gill, E. P. and Parke, D. W. (1989) Axial Myopia Increases the Risk of Retinal Complications after Neodymium-Yag Laser Posterior Capsulotomy. Arch Ophthalmol-Chic. 107, 986-990

7 Dardenne, M. U., Gerten, G. J., Kokkas, K. and Kermani, O. (1989) Retrospective Study of Retinal-Detachment Following Neodymium - Yag Laser Posterior Capsulotomy. J Cataract Refr Surg. 15, 676-680

8 Lamouille, S., Xu, J. and Derynck, R. (2014) Molecular mechanisms of epithelialmesenchymal transition. Nat Rev Mol Cell Biol. 15, 178-196

9 Gonzalez, D. M. and Medici, D. (2014) Signaling mechanisms of the epithelialmesenchymal transition. Sci Signal. 7, re8

10 Eldred, J. A., Dawes, L. J. and Wormstone, I. M. (2011) The lens as a model for fibrotic disease. Philos Trans R Soc Lond B Biol Sci. 366, 1301-1319

11 Vane, J. R. and Botting, R. M. (2003) The mechanism of action of aspirin. Thromb Res. $110,255-258$ 
12 Mekaj, Y. H., Daci, F. T. and Mekaj, A. Y. (2015) New insights into the mechanisms of action of aspirin and its use in the prevention and treatment of arterial and venous thromboembolism. Ther Clin Risk Manag. 11, 1449-1456

13 Roth, G. J. and Majerus, P. W. (1975) The mechanism of the effect of aspirin on human platelets. I. Acetylation of a particulate fraction protein. J Clin Invest. 56, 624-632

14 Jung, S. B., Kim, C. S., Naqvi, A., Yamamori, T., Mattagajasingh, I., Hoffman, T. A., Cole, M. P., Kumar, A., Dericco, J. S., Jeon, B. H. and Irani, K. (2010) Histone deacetylase 3 antagonizes aspirin-stimulated endothelial nitric oxide production by reversing aspirin-induced lysine acetylation of endothelial nitric oxide synthase. Circ Res. 107, 877-887

15 Macdonald, J. M., Haas, A. L. and London, R. E. (2000) Novel mechanism of surface catalysis of protein adduct formation. NMR studies of the acetylation of ubiquitin. J Biol Chem. 275, 31908-31913

16 Liyasova, M. S., Schopfer, L. M. and Lockridge, O. (2010) Reaction of human albumin with aspirin in vitro: mass spectrometric identification of acetylated lysines 199, 402, 519, and 545. Biochem Pharmacol. 79, 784-791

17 Alfonso, L. F., Srivenugopal, K. S. and Bhat, G. J. (2009) Does aspirin acetylate multiple cellular proteins? (Review). Mol Med Rep. 2, 533-537

18 Tatham, M. H., Cole, C., Scullion, P., Wilkie, R., Westwood, N. J., Stark, L. A. and Hay, R. T. (2017) A Proteomic Approach to Analyze the Aspirin-mediated Lysine Acetylome. Mol Cell Proteomics. 16, 310-326

19 Guo, Y., Liu, Y., Zhang, C., Su, Z. Y., Li, W., Huang, M. T. and Kong, A. N. (2016) The epigenetic effects of aspirin: the modification of histone $\mathrm{H} 3$ lysine 27 acetylation in the prevention of colon carcinogenesis in azoxymethane- and dextran sulfate sodiumtreated CF-1 mice. Carcinogenesis. 37, 616-624 
20 Chen, Z., Li, W., Qiu, F., Huang, Q., Jiang, Z., Ye, J., Cheng, P., Low, C., Guo, Y., Yi, X., Chen, W., Yu, Y., Han, Y., Wu, J., Jin, S., Kong, D. and Huang, J. (2018) Aspirin cooperates with $\mathrm{p} 300$ to activate the acetylation of $\mathrm{H} 3 \mathrm{~K} 9$ and promote FasL-mediated apoptosis of cancer stem-like cells in colorectal cancer. Theranostics. 8, 4447-4461

21 Sonnemann, J., Huls, I., Sigler, M., Palani, C. D., Hong le, T. T., Volker, U., Kroemer, H. K. and Beck, J. F. (2008) Histone deacetylase inhibitors and aspirin interact synergistically to induce cell death in ovarian cancer cells. Oncol Rep. 20, 219-224

22 Son, D. S., Wilson, A. J., Parl, A. K. and Khabele, D. (2010) The effects of the histone deacetylase inhibitor romidepsin (FK228) are enhanced by aspirin (ASA) in COX-1 positive ovarian cancer cells through augmentation of p21. Cancer Biol Ther. 9, 928-935

23 Liew, G., Mitchell, P., Wong, T. Y., Rochtchina, E. and Wang, J. J. (2013) The association of aspirin use with age-related macular degeneration. JAMA Intern Med. $173,258-264$

24 Christen, W. G., Glynn, R. J., Ajani, U. A., Schaumberg, D. A., Chew, E. Y., Buring, J. E., Manson, J. E. and Hennekens, C. H. (2001) Age-related maculopathy in a randomized trial of low-dose aspirin among US physicians. Arch Ophthalmol. 119, 11431149

25 (1991) Effects of aspirin treatment on diabetic retinopathy. ETDRS report number 8. Early Treatment Diabetic Retinopathy Study Research Group. Ophthalmology. 98, 757765

26 De Castro, D. K., Punjabi, O. S., Bostrom, A. G., Stamper, R. L., Lietman, T. M., Ray, K. and Lin, S. C. (2007) Effect of statin drugs and aspirin on progression in open-angle glaucoma suspects using confocal scanning laser ophthalmoscopy. Clin Exp Ophthalmol. 35, 506-513 
27 Shastri, G. V., Thomas, M., Victoria, A. J., Selvakumar, R., Kanagasabapathy, A. S., Thomas, K. and Lakshmi. (1998) Effect of aspirin and sodium salicylate on cataract development in diabetic rats. Indian J Exp Biol. 36, 651-657

28 Shi, Q., Yan, H., Li, M. Y. and Harding, J. J. (2009) Effect of a combination of carnosine and aspirin eye drops on streptozotocin -- induced diabetic cataract in rats. Mol Vis. 15, $2129-2138$

29 Seddon, J. M., Christen, W. G., Manson, J. E., Buring, J. E., Sperduto, R. D. and Hennekens, C. H. (1991) Low-dose aspirin and risks of cataract in a randomized trial of US physicians. Arch Ophthalmol. 109, 252-255

30 Harding, J. J., Egerton, M. and Harding, R. S. (1989) Protection against cataract by aspirin, paracetamol and ibuprofen. Acta Ophthalmol (Copenh). 67, 518-524

31 Christen, W. G., Ajani, U. A., Schaumberg, D. A., Glynn, R. J., Manson, J. E. and Hennekens, C. H. (2001) Aspirin use and risk of cataract in posttrial follow-up of Physicians' Health Study I. Arch Ophthalmol. 119, 405-412

32 Bernstein, B. E., Meissner, A. and Lander, E. S. (2007) The mammalian epigenome. Cell. 128, 669-681

33 Ganatra, D. A., Rajkumar, S., Patel, A. R., Gajjar, D. U., Johar, K., Arora, A. I., Kayastha, F. B. and Vasavada, A. R. (2015) Association of histone acetylation at the ACTA2 promoter region with epithelial mesenchymal transition of lens epithelial cells. Eye (Lond). 29, 828-838

34 Chen, X., Xiao, W., Chen, W., Luo, L., Ye, S. and Liu, Y. (2013) The epigenetic modifier trichostatin A, a histone deacetylase inhibitor, suppresses proliferation and epithelialmesenchymal transition of lens epithelial cells. Cell Death Dis. 4, e884

35 Xie, L., Santhoshkumar, P., Reneker, L. W. and Sharma, K. K. (2014) Histone deacetylase inhibitors trichostatin A and vorinostat inhibit TGFbeta2-induced lens epithelial-to-mesenchymal cell transition. Invest Ophthalmol Vis Sci. 55, 4731-4740 
36 Shan, B., Yao, T. P., Nguyen, H. T., Zhuo, Y., Levy, D. R., Klingsberg, R. C., Tao, H., Palmer, M. L., Holder, K. N. and Lasky, J. A. (2008) Requirement of HDAC6 for transforming growth factor-beta1-induced epithelial-mesenchymal transition. J Biol Chem. 283, 21065-21073

37 Gu, S., Liu, Y., Zhu, B., Ding, K., Yao, T. P., Chen, F., Zhan, L., Xu, P., Ehrlich, M., Liang, T., Lin, X. and Feng, X. H. (2016) Loss of alpha-Tubulin Acetylation Is Associated with TGF-beta-induced Epithelial-Mesenchymal Transition. J Biol Chem. 291, 5396-5405

38 Raghavan, C. T. and Nagaraj, R. H. (2016) AGE-RAGE interaction in the TGFbeta2mediated epithelial to mesenchymal transition of human lens epithelial cells. Glycoconj J. 33, 631-643

39 Nam, M. H. and Nagaraj, R. H. (2018) Matrix-bound AGEs enhance TGFbeta2-mediated mesenchymal transition of lens epithelial cells via the noncanonical pathway: implications for secondary cataract formation. Biochem J. 475, 1427-1440

40 Liu, C. S., Wormstone, I. M., Duncan, G., Marcantonio, J. M., Webb, S. F. and Davies, P. D. (1996) A study of human lens cell growth in vitro. A model for posterior capsule opacification. Invest Ophthalmol Vis Sci. 37, 906-914

41 Galligan, J. J., Rose, K. L., Beavers, W. N., Hill, S., Tallman, K. A., Tansey, W. P. and Marnett, L. J. (2014) Stable Histone Adduction by 4-Oxo-2-nonenal: A Potential Link between Oxidative Stress and Epigenetics. J Am Chem Soc

42 Nahomi, R. B., Pantcheva, M. B. and Nagaraj, R. H. (2016) alphaB-crystallin is essential for the TGF-beta2-mediated epithelial to mesenchymal transition of lens epithelial cells. Biochem J. 473, 1455-1469

43 Zukin, L. M., Pedler, M. G., Groman-Lupa, S., Pantcheva, M., Ammar, D. A. and Petrash, J. M. (2018) Aldose Reductase Inhibition Prevents Development of Posterior Capsular Opacification in an In Vivo Model of Cataract Surgery. Invest Ophthalmol Vis Sci. 59, 3591-3598 
44 Wormstone, I. M., Tamiya, S., Anderson, I. and Duncan, G. (2002) TGF-beta2-induced matrix modification and cell transdifferentiation in the human lens capsular bag. Invest Ophthalmol Vis Sci. 43, 2301-2308

45 Cleary, G., Spalton, D. J., Zhang, J. J. and Marshall, J. (2010) In vitro lens capsule model for investigation of posterior capsule opacification. J Cataract Refract Surg. 36, $1249-1252$

46 Bakin, A. V., Rinehart, C., Tomlinson, A. K. and Arteaga, C. L. (2002) p38 mitogenactivated protein kinase is required for TGF beta-mediated fibroblastic transdifferentiation and cell migration. Journal of Cell Science. 115, 3193-3206

47 Bakin, A. V., Tomlinson, A. K., Bhowmick, N. A., Moses, H. L. and Arteaga, C. L. (2000) Phosphatidylinositol 3-kinase function is required for transforming growth factor betamediated epithelial to mesenchymal transition and cell migration. J Biol Chem. 275, $36803-36810$

48 Wendt, M. K., Allington, T. M. and Schiemann, W. P. (2009) Mechanisms of the epithelial-mesenchymal transition by TGF-beta. Future Oncol. 5, 1145-1168

49 Chen, X., Ye, S., Xiao, W., Wang, W., Luo, L. and Liu, Y. (2014) ERK1/2 pathway mediates epithelial-mesenchymal transition by cross-interacting with TGFbeta/Smad and Jagged/Notch signaling pathways in lens epithelial cells. Int J Mol Med. 33, 1664-1670

50 Yoshikawa, M., Hishikawa, K., Marumo, T. and Fujita, T. (2007) Inhibition of histone deacetylase activity suppresses epithelial-to-mesenchymal transition induced by TGFbeta1 in human renal epithelial cells. J Am Soc Nephrol. 18, 58-65

51 Ganatra, D. A., Vasavada, A. R., Vidya, N. G., Gajjar, D. U. and Rajkumar, S. (2018) Trichostatin A Restores Expression of Adherens and Tight Junction Proteins during Transforming Growth Factor beta-Mediated Epithelial-to-Mesenchymal Transition. J Ophthalmic Vis Res. 13, 274-283 
52 Cosgrove, M. S. (2007) Histone proteomics and the epigenetic regulation of nucleosome mobility. Expert Rev Proteomics. 4, 465-478

53 Li, W., Nagaraja, S., Delcuve, G. P., Hendzel, M. J. and Davie, J. R. (1993) Effects of histone acetylation, ubiquitination and variants on nucleosome stability. Biochem J. 296 ( Pt 3), 737-744

54 Zeng, X. Q., Wang, J. and Chen, S. Y. (2017) Methylation modification in gastric cancer and approaches to targeted epigenetic therapy (Review). Int J Oncol. 50, 1921-1933

55 Alfonso, L. F., Srivenugopal, K. S. and Bhat, G. J. (2009) Does aspirin acetylate multiple cellular proteins? (Review). Molecular Medicine Reports. 2, 533-537

56 Marimuthu, S., Chivukula, R. S., Alfonso, L. F., Moridani, M., Hagen, F. K. and Bhat, G. J. (2011) Aspirin acetylates multiple cellular proteins in HCT-116 colon cancer cells: Identification of novel targets. Int J Oncol. 39, 1273-1283

57 Tian, J., Hachim, M. Y., Hachim, I. Y., Dai, M., Lo, C., Raffa, F. A., Ali, S. and Lebrun, J. J. (2017) Cyclooxygenase-2 regulates TGFbeta-induced cancer stemness in triplenegative breast cancer. Sci Rep. 7, 40258

58 Ogunwobi, O. O. and Liu, C. (2011) Hepatocyte growth factor upregulation promotes carcinogenesis and epithelial-mesenchymal transition in hepatocellular carcinoma via Akt and COX-2 pathways. Clin Exp Metastasis. 28, 721-731

59 Chandler, H. L., Barden, C. A., Lu, P., Kusewitt, D. F. and Colitz, C. M. (2007) Prevention of posterior capsular opacification through cyclooxygenase-2 inhibition. Mol Vis. 13, 677-691

60 Brookshire, H. L., English, R. V., Nadelstein, B., Weigt, A. K., Gift, B. W. and Gilger, B. C. (2015) Efficacy of COX-2 inhibitors in controlling inflammation and capsular opacification after phacoemulsification cataract removal. Vet Ophthalmol. 18, 175-185

61 Nandi, S. K., Nahomi, R. B., Harris, P. S., Michel, C. R., Fritz, K. S. and Nagaraj, R. H. (2019) The absence of SIRT3 and SIRT5 promotes the acetylation of lens proteins and 
improves the chaperone activity of alpha-crystallin in mouse lenses. Exp Eye Res. 182, $1-9$

62 Inoue, Y., Itoh, Y., Abe, K., Okamoto, T., Daitoku, H., Fukamizu, A., Onozaki, K. and Hayashi, H. (2007) Smad3 is acetylated by p300/CBP to regulate its transactivation activity. Oncogene. 26, 500-508

63 Tu, A. W. and Luo, K. (2007) Acetylation of Smad2 by the co-activator p300 regulates activin and transforming growth factor beta response. J Biol Chem. 282, 21187-21196

64 Simonsson, M., Kanduri, M., Gronroos, E., Heldin, C. H. and Ericsson, J. (2006) The DNA binding activities of Smad2 and Smad3 are regulated by coactivator-mediated acetylation. J Biol Chem. 281, 39870-39880

65 Lei, W. W., Zhang, K. H., Pan, X. C., Hu, Y., Wang, D. M., Yuan, X. W., Shu, G. W. and Song, J. G. (2010) Histone deacetylase 1 is required for transforming growth factor-beta 1-induced epithelial-mesenchymal transition. Int J Biochem Cell B. 42, 1489-1497

66 Rajagopalan, M., Balasubramanian, S., loshikhes, I. and Ramaswamy, A. (2017) Structural dynamics of nucleosome mediated by acetylations at H3K56 and H3K115,122. Eur Biophys J. 46, 471-484

67 Yun, M. Y., Wu, J., Workman, J. L. and Li, B. (2011) Readers of histone modifications. Cell Research. 21, 564-578

68 North, J. A., Shimko, J. C., Javaid, S., Mooney, A. M., Shoffner, M. A., Rose, S. D., Bundschuh, R., Fishel, R., Ottesen, J. J. and Poirier, M. G. (2012) Regulation of the nucleosome unwrapping rate controls DNA accessibility. Nucleic Acids Res. 40, 1021510227

69 Manohar, M., Mooney, A. M., North, J. A., Nakkula, R. J., Picking, J. W., Edon, A., Fishel, R., Poirier, M. G. and Ottesen, J. J. (2009) Acetylation of Histone H3 at the Nucleosome Dyad Alters DNA-Histone Binding. Journal of Biological Chemistry. 284, 23312-23321 
70 Williams, S. K., Truong, D. and Tyler, J. K. (2008) Acetylation in the globular core of histone $\mathrm{H} 3$ on lysine-56 promotes chromatin disassembly during transcriptional activation. Proc Natl Acad Sci U S A. 105, 9000-9005

71 Tropberger, P., Pott, S., Keller, C., Kamieniarz-Gdula, K., Caron, M., Richter, F., Li, G., Mittler, G., Liu, E. T., Buhler, M., Margueron, R. and Schneider, R. (2013) Regulation of transcription through acetylation of H3K122 on the lateral surface of the histone octamer. Cell. 152, 859-872

72 Lois, N., Taylor, J., McKinnon, A. D. and Forrester, J. V. (2005) Posterior capsule opacification in mice. Arch Ophthalmol. 123, 71-77

73 Ittaman, S. V., VanWormer, J. J. and Rezkalla, S. H. (2014) The role of aspirin in the prevention of cardiovascular disease. Clin Med Res. 12, 147-154

74 Rosenkranz, B. and Frolich, J. C. (1985) Plasma concentrations and anti-platelet effects after low dose acetylsalicylic acid. Prostaglandins Leukot Med. 19, 289-300 


\section{Figure legends}

Figure 1. Effect of aspirin on the cell viability, proliferation, and acetylation of cellular proteins. Cell viability and proliferation were measured by the MTT assay. (A) FHL124 cells were treated with varying concentrations of aspirin for $48 \mathrm{~h}$ in serum-free media and then incubated with MTT reagent for $4 \mathrm{~h}$. (B) Cells were treated with varying concentrations of aspirin for $24 \mathrm{~h}$ in 5\% FBS-containing media, followed by TGF 32 treatment at $10 \mathrm{ng} / \mathrm{ml}$ for an additional $24 \mathrm{~h}$. The reversibility of acetylation was assessed by western blotting using acetyllysine antibody. (C) FHL124 cells were treated with $2 \mathrm{mM}$ aspirin for $24 \mathrm{~h}$ or $48 \mathrm{~h}$ or treated with aspirin for $24 \mathrm{~h}$ and then incubated in serum-free medium for an additional $24 \mathrm{~h}$. Lane 1, control; lane 2, aspirin-24 h; lane 3, aspirin-48 h; and lane 4, aspirin-24 h + serum-free medium for $24 \mathrm{~h}$. (D) FHL124 cells were treated with $2 \mathrm{mM}$ aspirin for $24 \mathrm{~h}$ and then incubated in $10 \mathrm{ng} / \mathrm{ml}$ TGF 2 for an additional $24 \mathrm{~h}$ in the presence or absence of aspirin. Lane 1, control; lane 2, TGF $32-24 \mathrm{~h}$; lane 3, aspirin-48 h; and lane 4, aspirin-24 h + TGF $32-24 \mathrm{~h}$. The data represent the mean \pm SD of three independent experiments. ${ }^{* *} p<0.01,{ }^{* * *} p<0.001,{ }^{* * * *} p<0.0001$ compared to control cells (without any treatment). $M=$ molecular weight markers $(\mathrm{kDa})$.

Figure 2. Effect of aspirin on TGF $\beta 2$-induced EMT, stress fiber formation and cell migration in FHL124 cells. (A) Cells were treated with $2 \mathrm{mM}$ aspirin for $24 \mathrm{~h}$, followed by TGF $\beta 2$ treatment at $10 \mathrm{ng} / \mathrm{ml}$ for an additional $24 \mathrm{~h}$. Total cell lysates were probed for $\alpha-S M A$, fibronectin ( $F N$ ) and $\alpha B$-crystallin by western blotting to measure protein levels. (B) Cells were treated with $2 \mathrm{mM}$ aspirin for $24 \mathrm{~h}$, followed by $10 \mathrm{ng} / \mathrm{ml}$ TGFß2 treatment along with aspirin (2 $\mathrm{mM}$ ) for another $6 \mathrm{~h}$. qRT-PCR was performed to determine the mRNA levels of $\alpha$-SMA, FN and aB-crystallin. (C) Cells were fixed and immunostained for a-SMA (counterstained with DAPI). (D) F-actin was visualized using Texas Red-conjugated phalloidin. (E) Scratch assay images were captured at $4 \mathrm{X}$ magnification after a 24-h incubation with TGF 32 with or without aspirin. (F) The migrated area was quantified as the total distance that the cells moved from the edge of the 
scratch toward the center of the scratch. The values are normalized to control cells. The bars represent the mean $\pm S D$ of three independent experiments. ns $=$ not significant, ${ }^{*} p<0.05$, ${ }^{* *} p<0.01$. Scale bar, $50 \mu \mathrm{m}$.

Figure 3. Halting effect of aspirin on TGF $\beta 2$-induced EMT. FHL124 cells were treated with $10 \mathrm{ng} / \mathrm{ml}$ TGF $\beta 2$ for $24 \mathrm{~h}$, and then $2 \mathrm{mM}$ aspirin was added in the presence of TGF $\beta 2$ for an additional $24 \mathrm{~h}$. Total cell lysates were subjected to western blotting to analyze the expression of $\alpha$-SMA, FN and $\alpha B$-crystallin. The values are normalized to control cells. The bars represent the mean $\pm \mathrm{SD}$ of three independent experiments. $\mathrm{ns}=$ not significant, ${ }^{\star} p<0.05,{ }^{\star \star} p<0.01$.

Figure 4. Effect of aspirin in the human capsular bag. Four series of match-paired experiments were performed. The first two series employed serum-free (SF) EMEM as the standard medium ( $\mathrm{A}$ and $\mathrm{B}$ ) while the final pair of match-paired comparisons utilized $5 \%$ FCS supplemented EMEM as the standard medium ( $C$ and D). Match-paired experiments compared capsular bags maintained in standard medium (SF EMEM or $5 \%$ FCS EMEM) $\pm 2 \mathrm{mM}$ aspirin or involved the addition of $10 \mathrm{ng} / \mathrm{ml}$ TGF $\beta 2$ to each culture maintained in standard medium (SF EMEM or $5 \%$ FCS EMEM) $\pm 2 \mathrm{mM}$ aspirin. (A) Low power modified dark field micrographs showing the coverage of the central posterior capsule $(P C)$ i.e. within the rhexis margin, observed at the end-point (day 19). Preparations were maintained in serum-free EMEM as the standard culture medium. Higher magnification images show cells on the central PC.

Quantitative data showing the percent coverage of the central PC under different culture treatments are also provided along with the quantitative assessment of matrix contraction in TGF $\beta 2$-treated preparations. (B) Representative fluorescence images captured at the end-point (day 19) showing the expression and distribution patterns of the EMT marker, $\alpha$-SMA in cells growing on the central PC with serum-free EMEM as the standard medium. Nuclei were visualized using DAPI as a counterstain. Quantitative data showing the relative levels of $\alpha$-SMA 
under different culture treatments are also provided. (C) Low power modified dark field micrographs showing coverage of the central PC, i.e., within the rhexis margin, observed at the end-point (day 19). Preparations were maintained in 5\% FCS EMEM as the standard culture medium. Higher magnification images show cells on the central posterior capsule. Quantitative data showing the percent coverage of the central PC under different culture treatments are also provided along with the quantitative assessment of matrix contraction in TGF $\beta 2$-treated preparations. (D) Representative fluorescence images captured at the end-point (day 19) showing the expression and distribution patterns of the EMT marker $\alpha$-SMA in cells growing on the central PC with 5\% FCS EMEM as the standard medium. Nuclei were visualized using DAPI as a counterstain. Quantitative data showing the relative levels of $\alpha$-SMA under different culture treatments are also provided. The bars represent the mean \pm SD of three independent experiments. ns $=$ not significant, ${ }^{*} p<0.05,{ }^{* *} p<0.01,{ }^{* *} p<0.001,{ }^{* * *} p<0.0001$.

Figure 5. Effect of aspirin on the TGF $\beta 2$ signaling pathway. Western blot images show the effect of aspirin on canonical (A and B) and noncanonical (C) TGF 2 signaling in FHL124 cells. FHL124 cells were incubated with $2 \mathrm{mM}$ aspirin for $24 \mathrm{~h}$, followed by $10 \mathrm{ng} / \mathrm{ml}$ TGF 32 treatment for an additional 0.5 ( $\mathrm{A}$ and $\mathrm{C}$ ) or $2 \mathrm{~h}(\mathrm{~B})$. Total cell lysates were subjected to western blotting to analyze the phosphorylation levels of each signaling pathway. The bars represent the mean \pm SD of three independent experiments. ns= not significant, ${ }^{*} p<0.05,{ }^{* * *} p<0.001$.

Figure 6. Effect of aspirin on HDAC activity (A) and the acetylation of $\alpha$-tubulin (B).

FHL124 cells were incubated with $2 \mathrm{mM}$ aspirin for $24 \mathrm{~h}$, followed by $10 \mathrm{ng} / \mathrm{ml}$ TGF $\beta 2$ treatment for an additional $24 \mathrm{~h}$. HDAC activity levels were determined in the nuclear and cytoplasmic fractions using a colorimetric assay kit. Protein levels of Ac- $\alpha$-tubulin and $\beta$-actin were quantified by western blot analysis. The bars represent the mean \pm SD of three independent experiments. ns $=$ not significant, ${ }^{* * *} p<0.001$. 
Figure 7. Effect of aspirin on histone acetylation. Cells were treated with aspirin (2 mM) for $24 \mathrm{~h}$ and then with aspirin $(2 \mathrm{mM})$ with or without TGF $32(10 \mathrm{ng} / \mathrm{ml})$ for an additional $6 \mathrm{~h}$, and histones were extracted. (A) Total histones were fractionated by gel electrophoresis and stained with Coomassie blue (left), and the level of acetylation was determined by western blot analysis with anti-acetyllysine (right). (B) Acetylated histone H3 lysine residues were determined by western blot analysis. Bars represent the mean \pm SD of three independent experiments. ns $=$ not significant, ${ }^{*} p<0.05,{ }^{* *} p<0.01 . M=$ molecular weight markers $(k D a)$.

\section{Figure 8. Aspirin-induced histone acetylation regulates EMT-related gene transcription.} FHL124 cells were incubated with $2 \mathrm{mM}$ aspirin for $24 \mathrm{~h}$, followed by $10 \mathrm{ng} / \mathrm{ml}$ TGF 32 treatment for an additional $2 \mathrm{~h}$ in the presence of aspirin. ChIP assays were performed using specific antibodies against acH3K56 and acH3K122 or with normal rabbit lgG. Quantitative PCR was performed using specific primers for the promoter regions of $A C T A 2(\mathrm{~A})$ and $C O L 1 A 1(\mathrm{~B})$. In control experiments in which naive rabbit lgG was used, there was very low amplification for ACTA2 and no amplification for COL1A1 (right panels in A and B). The relative DNA levels were normalized to the input chromatin. (C-D) After immunoprecipitation, total cell lysates were subjected to western blotting for Smad4. The bars represent the mean \pm SD of three independent experiments. ns $=$ not significant, ${ }^{*} p<0.05,{ }^{* *} p<0.01$.

Figure 9. Effect of aspirin on EMT in lensectomized mice. Mice were administered either 0.5 $\mathrm{mg} / \mathrm{ml}(\mathrm{n}=3)$ or $1 \mathrm{mg} / \mathrm{ml}(\mathrm{n}=4)$ of aspirin in drinking water for 5 days. Control mice were treated with $25 \mathrm{mM}$ sodium phosphate buffer in drinking water. $(n=3)$. (A) The level of acetylation in lens proteins was determined by western blot analysis with acetyllysine antibody. (B) Control and 1 $\mathrm{mg} / \mathrm{ml}$ aspirin-treated mouse lenses were immunostained with acetyllysine antibody. The insert was enlarged and is shown in the right panel. The arrowhead denotes the mouse LECs. (C) The 
expression of $\alpha$-SMA (red) on postoperative day 5. Mice were treated with aspirin or sodium salicylic acid (SA) for 5 days prior to the lensectomy and for 5 days thereafter. Collagen type IV (green) was used for the lens capsule marker. Nuclei were stained with DAPI (blue). The dashed line traces the lens capsule. The arrowhead denotes the anterior capsule, and the arrows denote the posterior capsule. $\mathrm{N}=3$. Scale bar $=50 \mu \mathrm{m}$. 
Fig. 1.

A

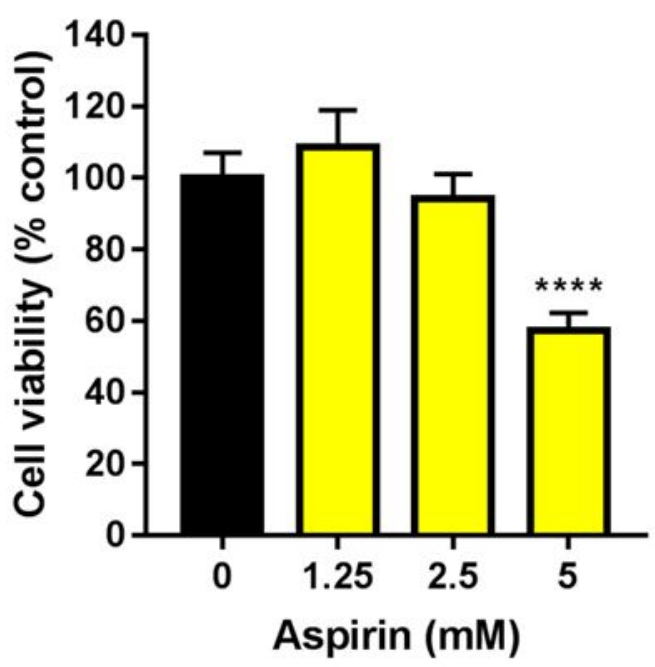

C

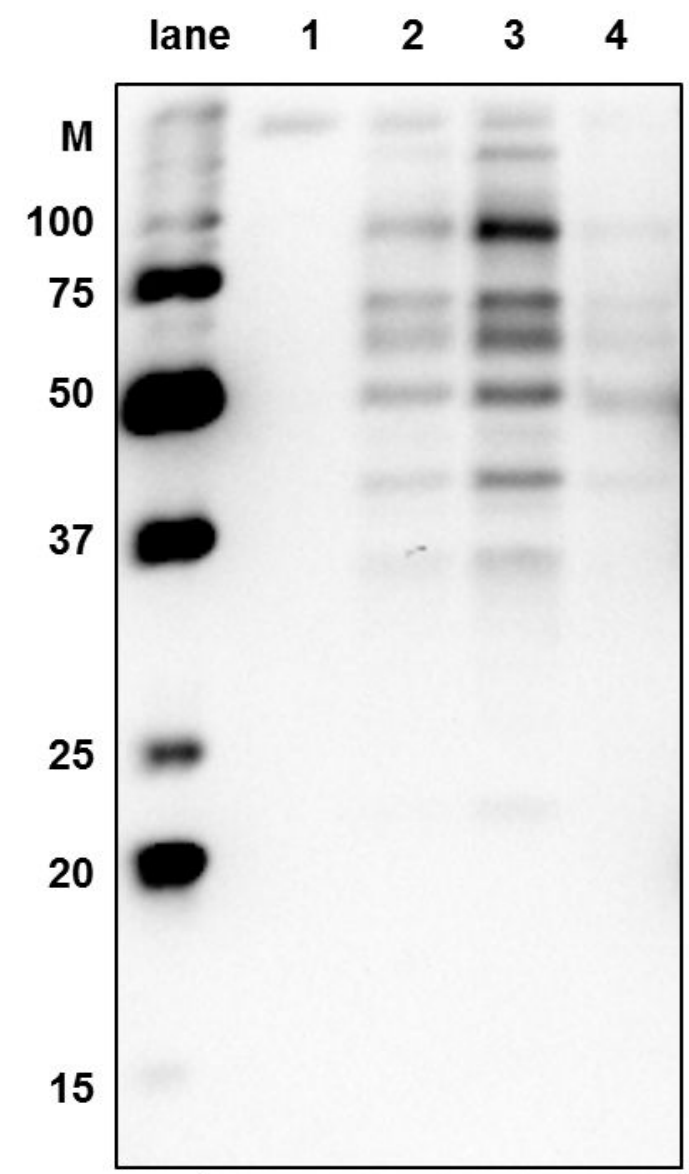

B

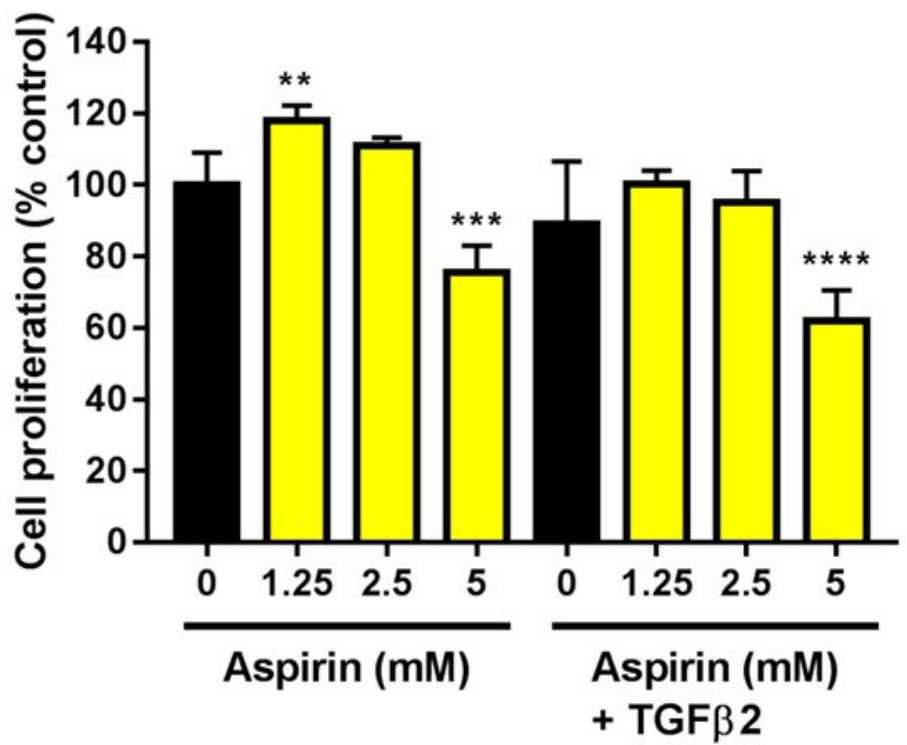

D

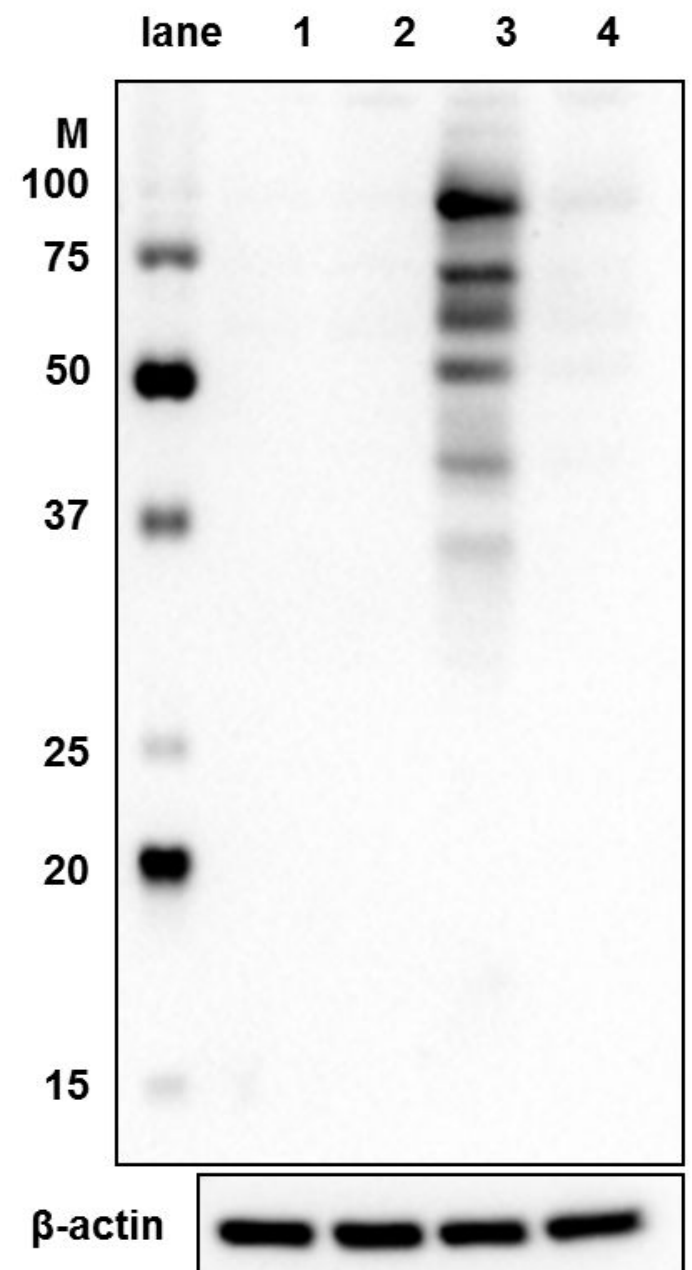


Fig. 2.

A
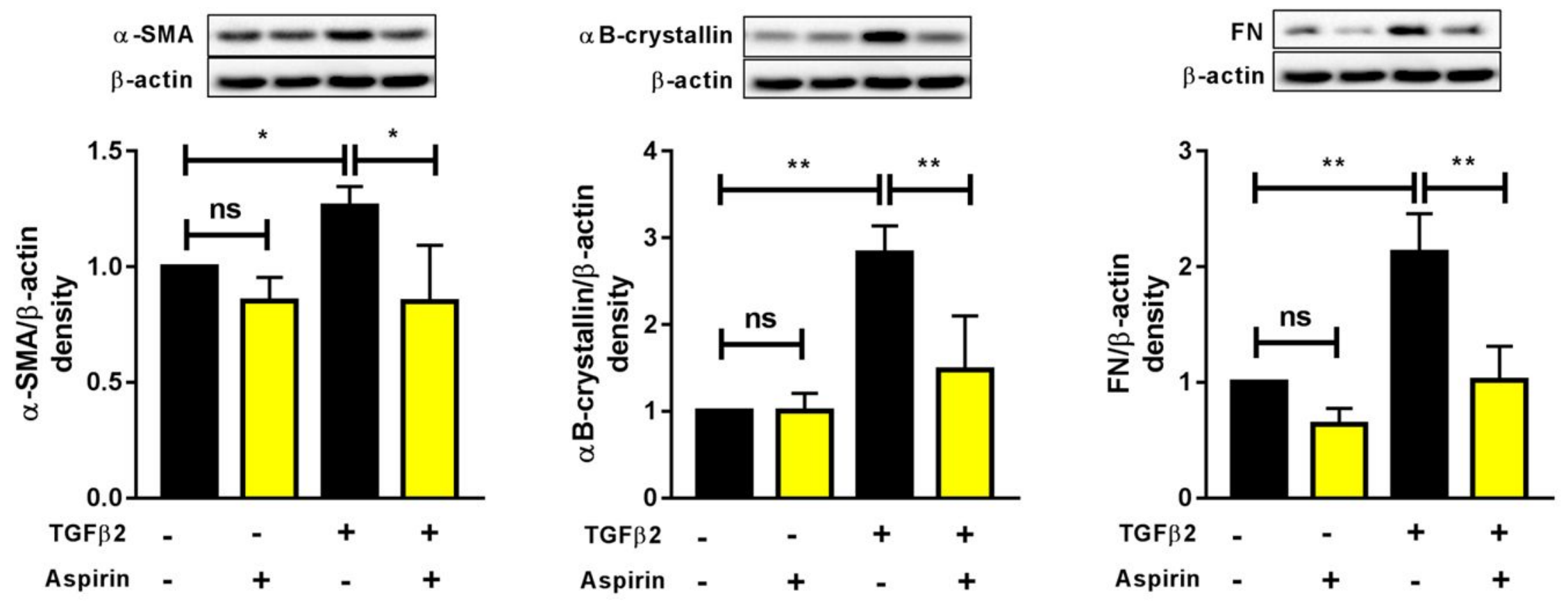

B
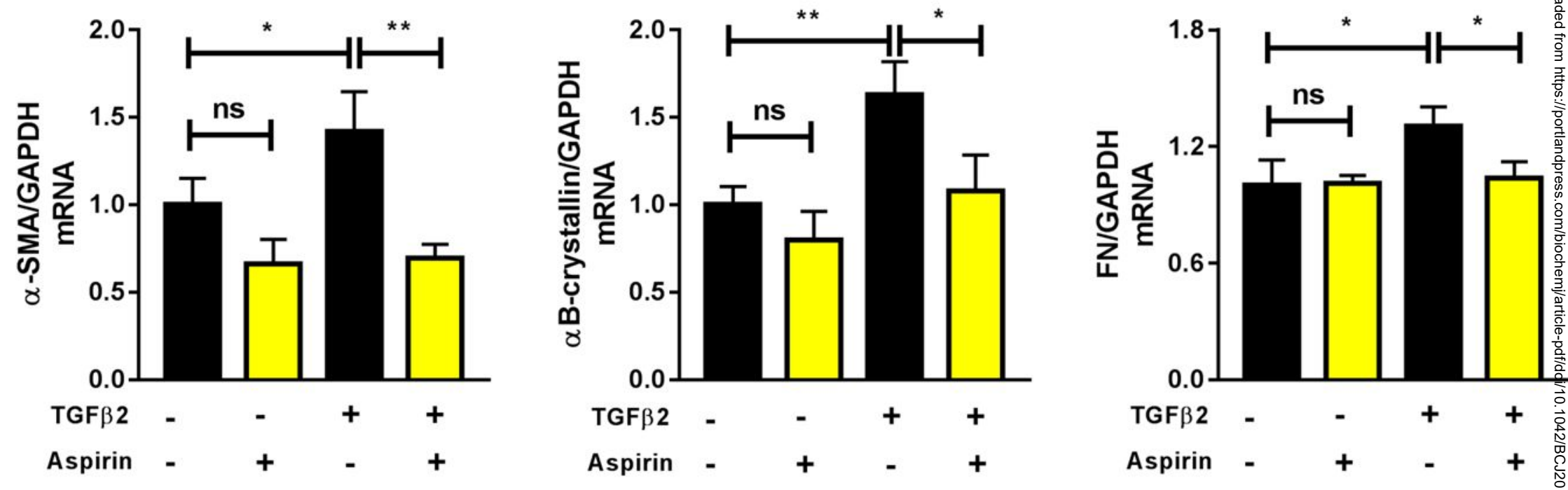

C

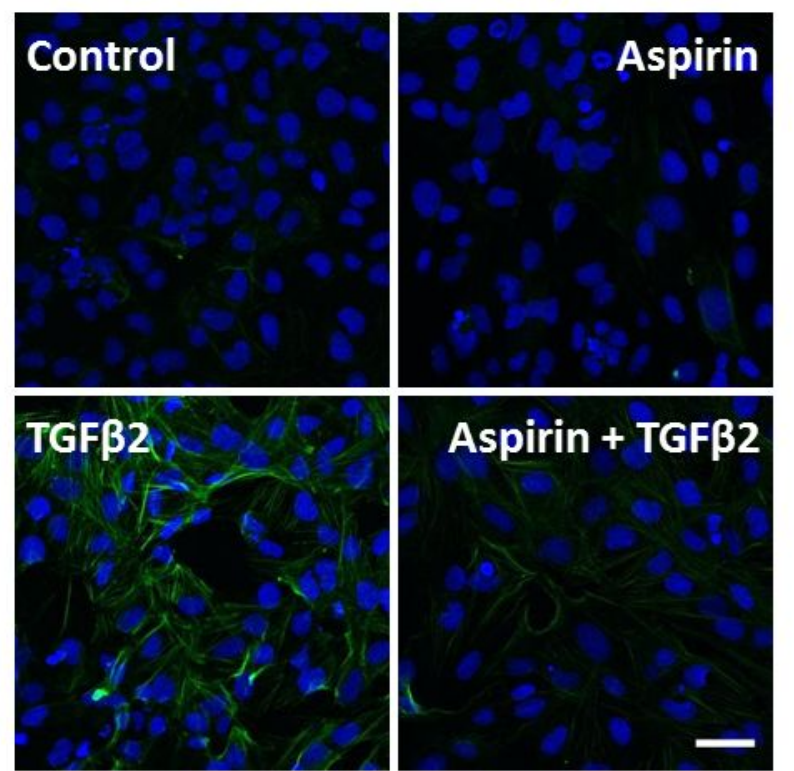

$\alpha$-SMA/DAPI

E

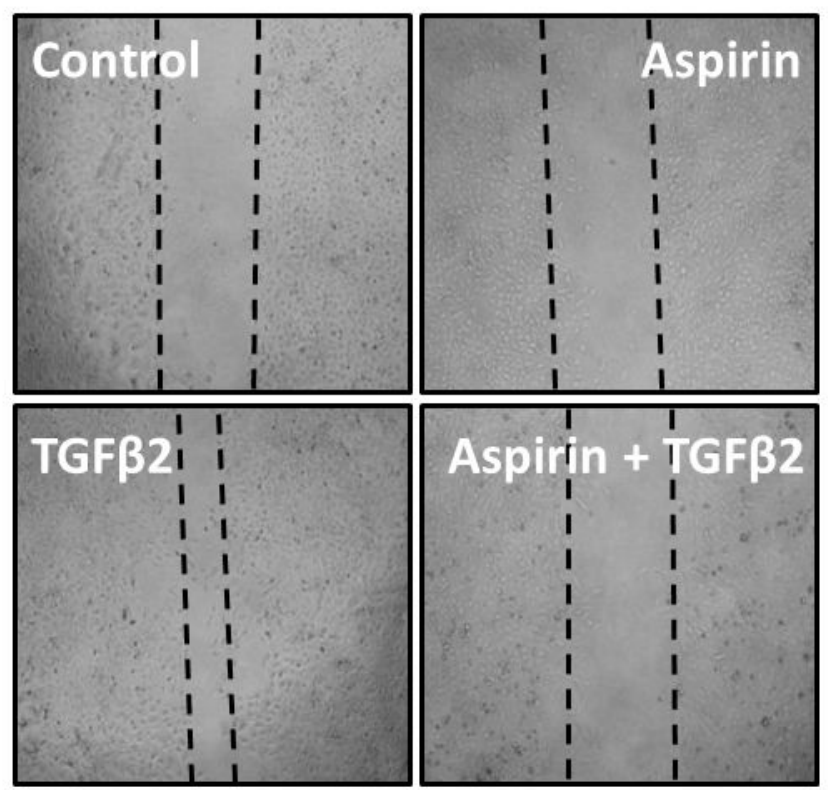

D
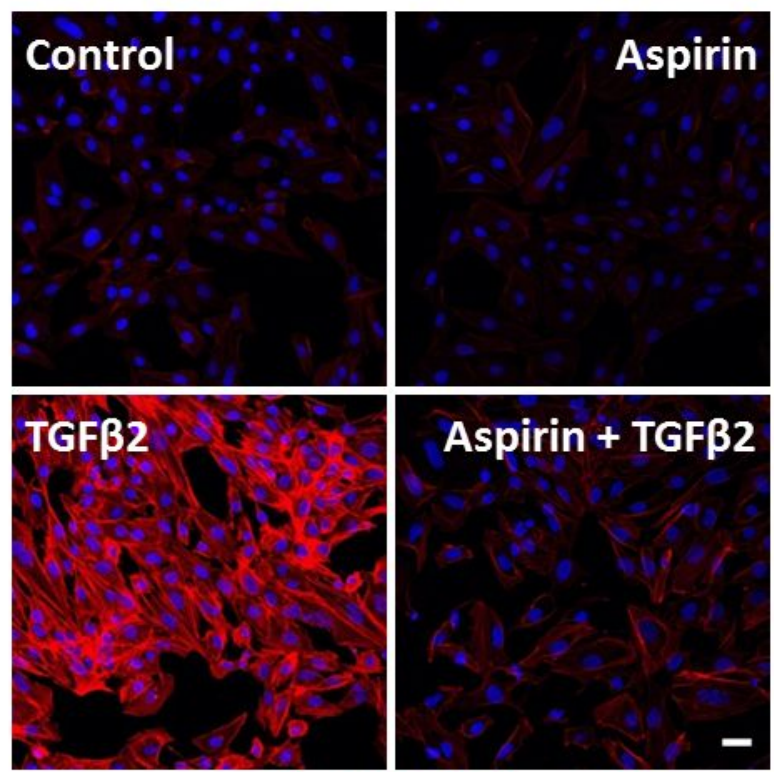

Phalloidin (F-actin)/DAPI

$\mathbf{F}$

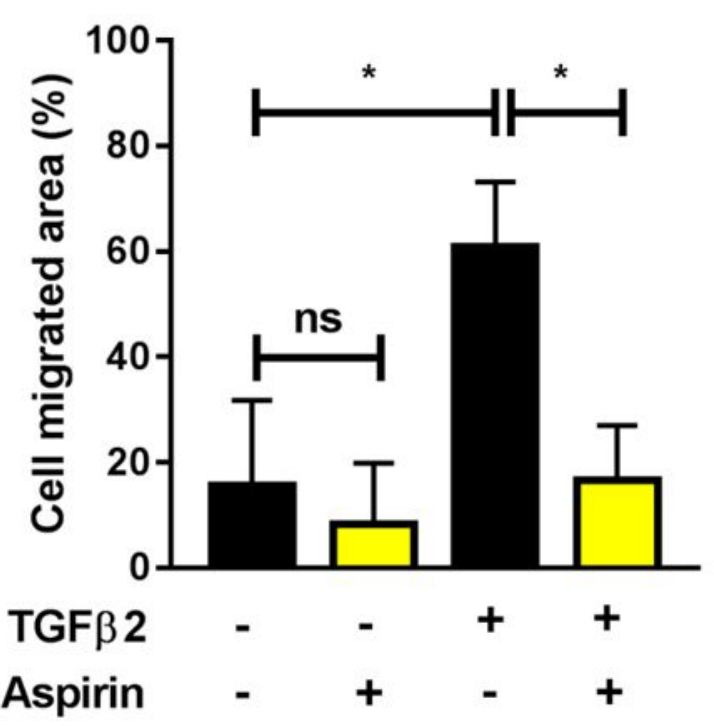


Fig. 3.
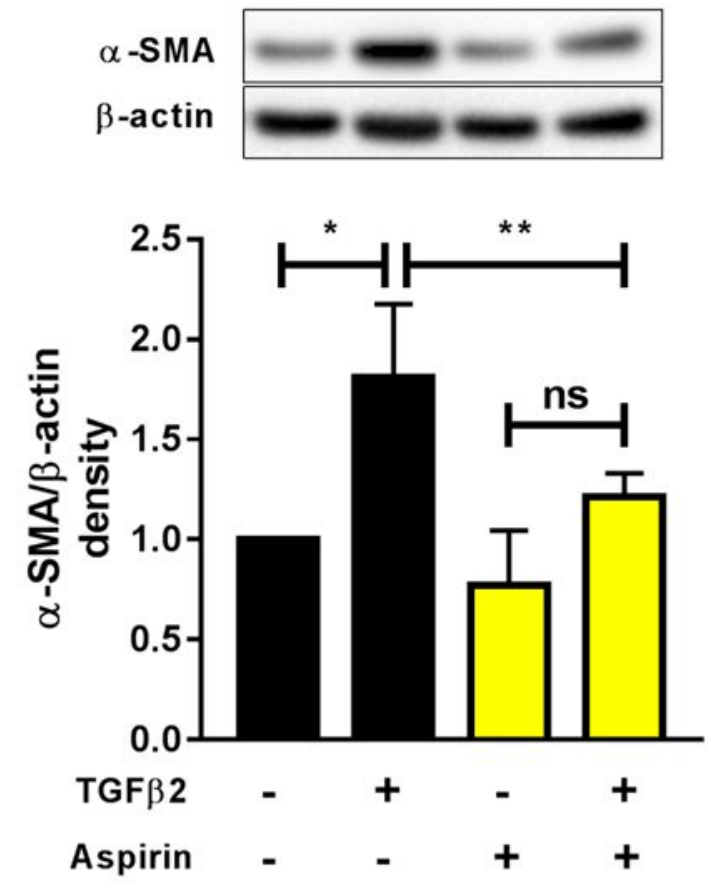
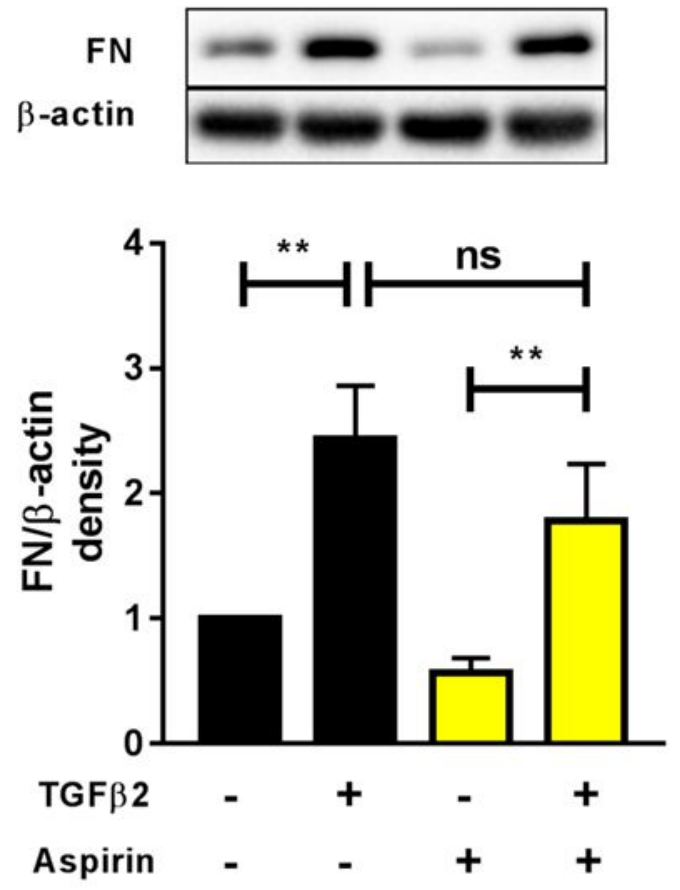

$\alpha$ B-crystallin $\beta$-actin
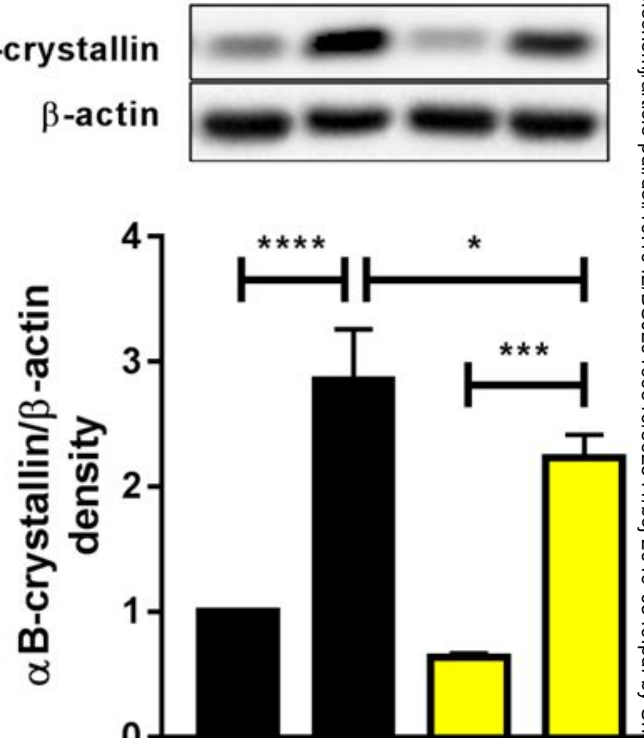

TGF $\beta 2$

Aspirin
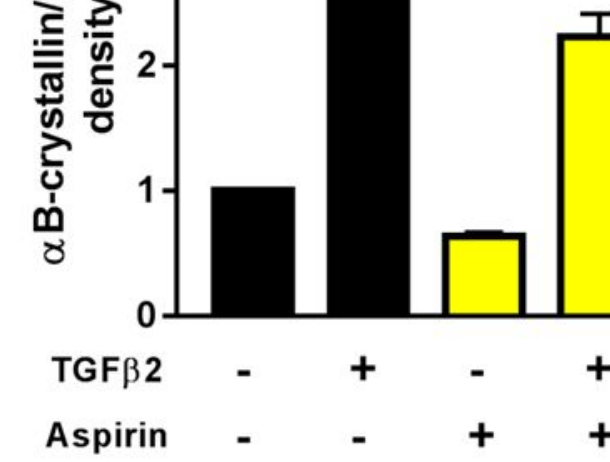
Fig. 4.

A
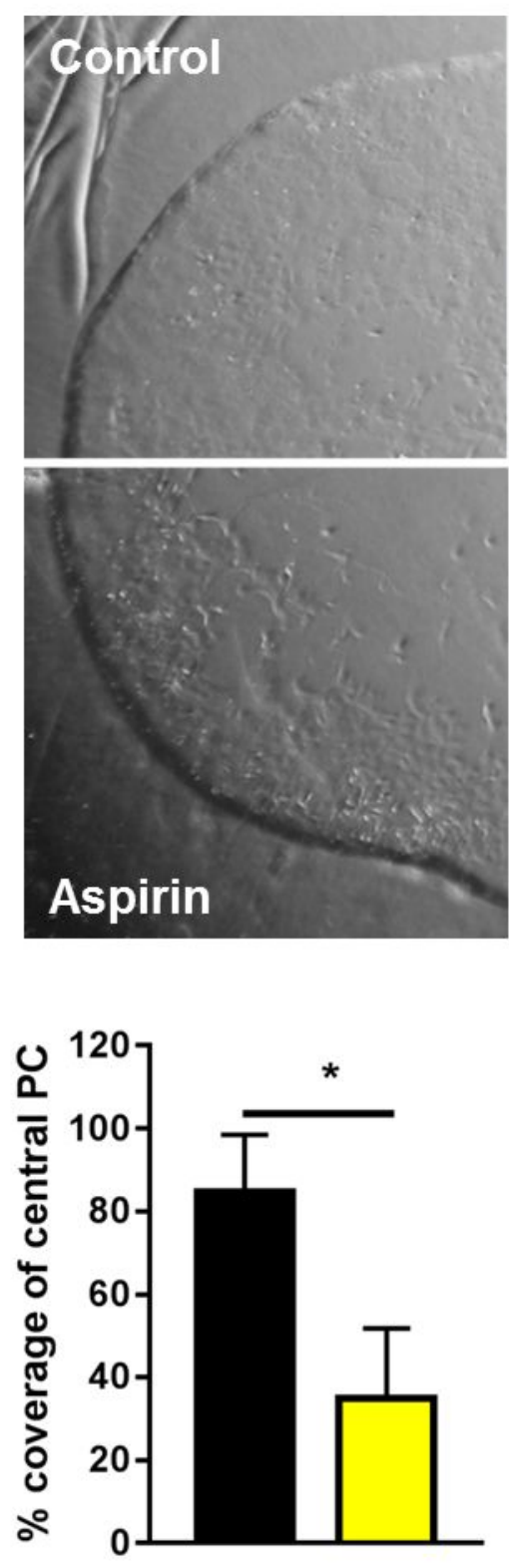

Aspirin
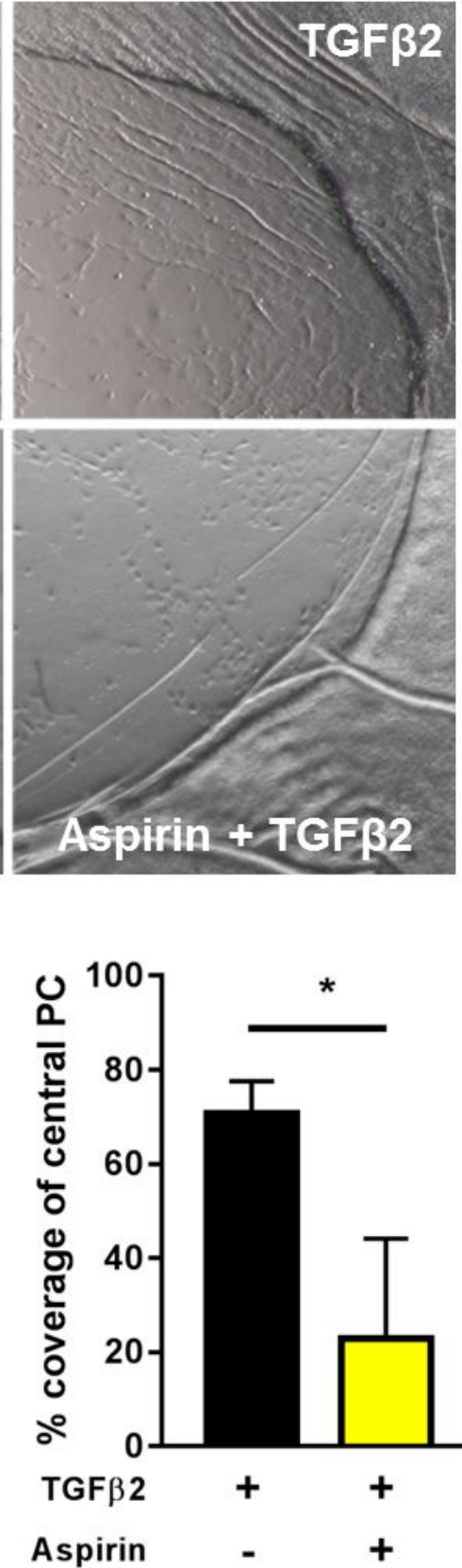

B

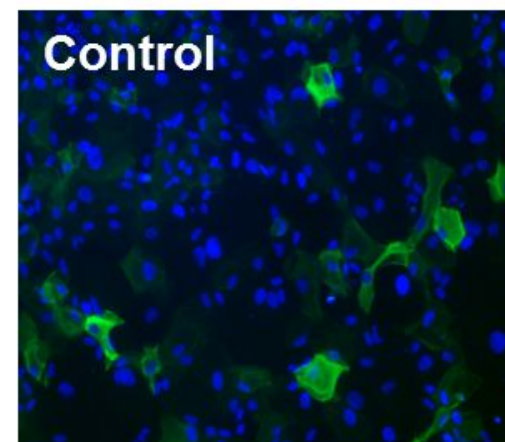

Aspirin
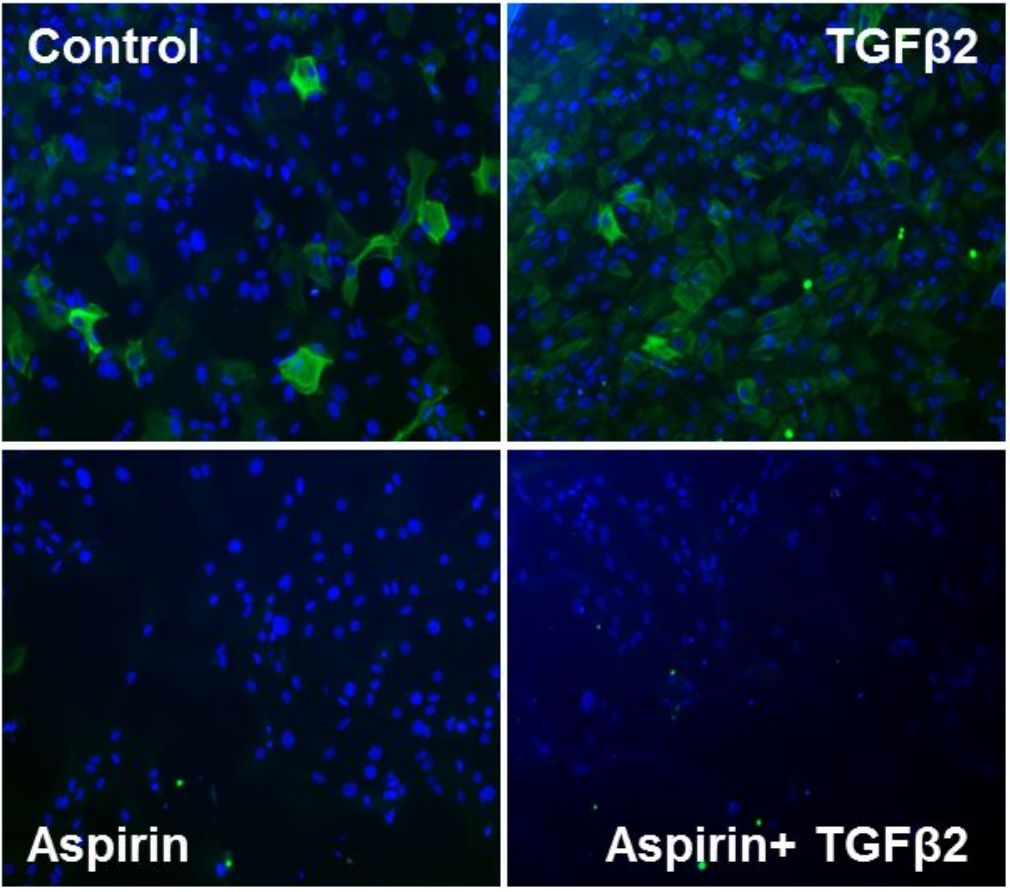

Aspịin + TGF $\beta 2$
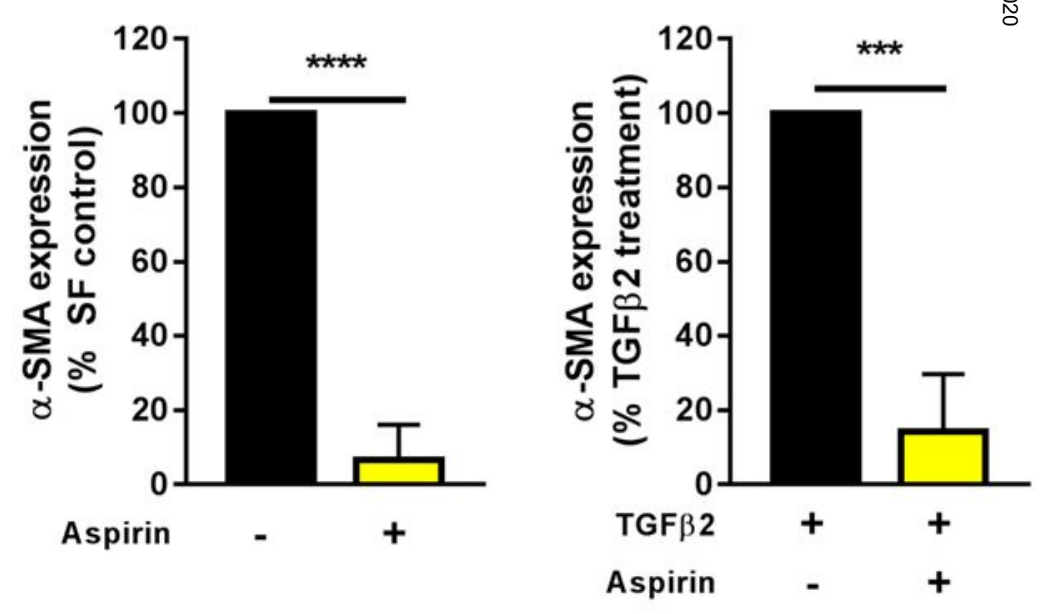

\section{Aspirin}

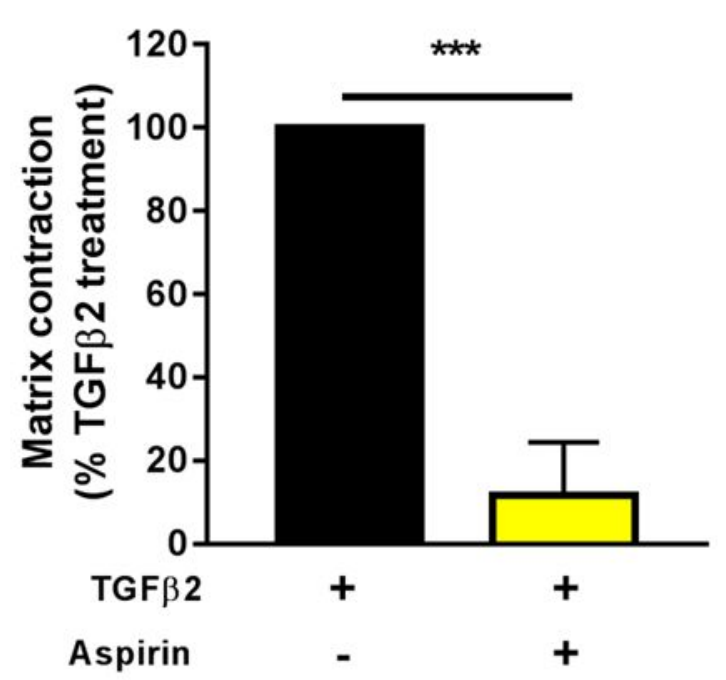

Aspirin + TGF 32

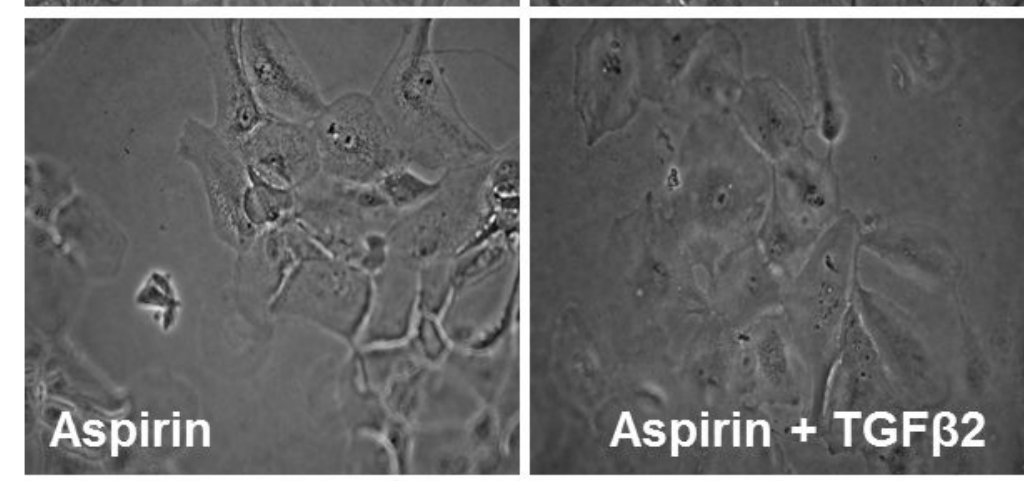



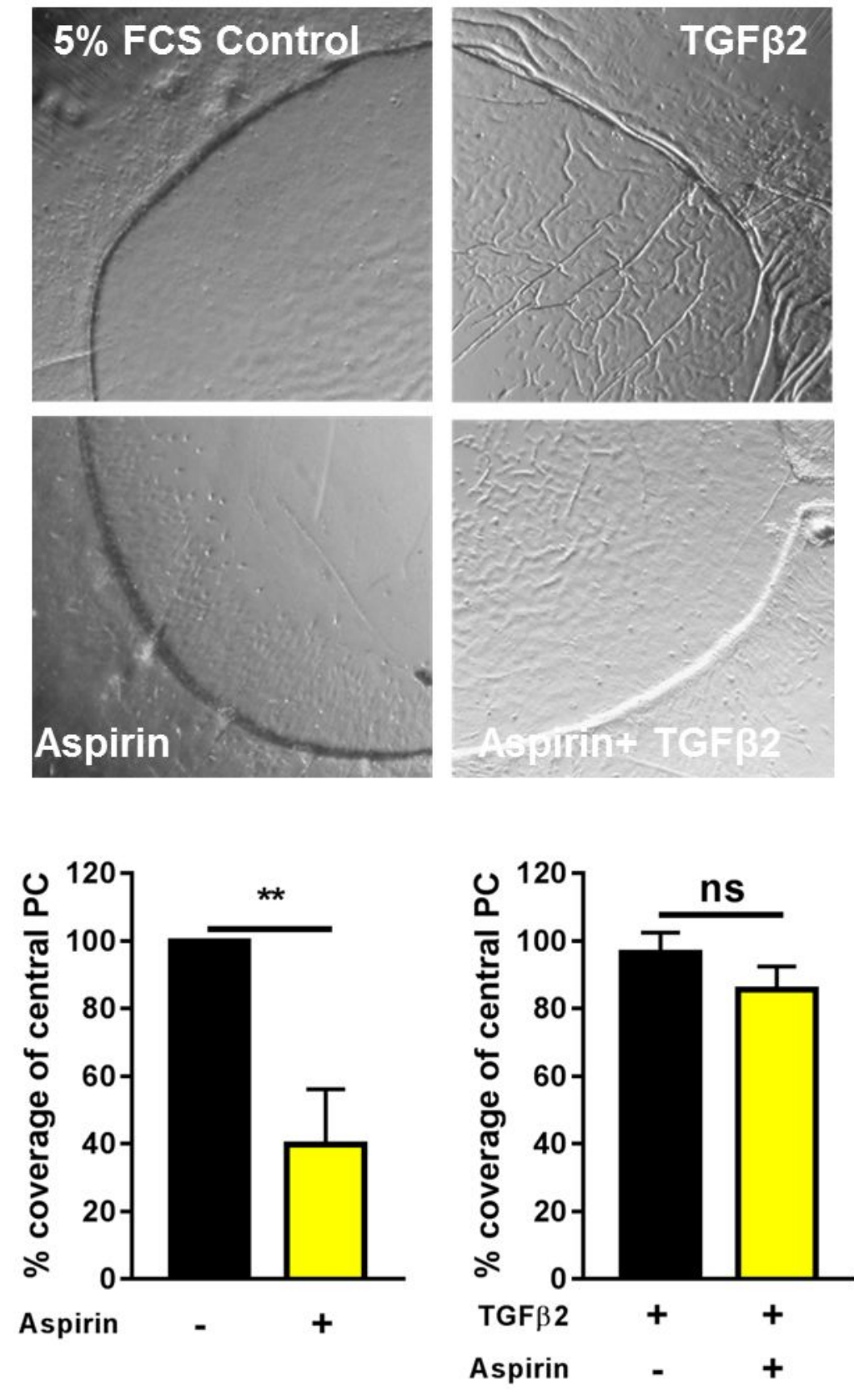

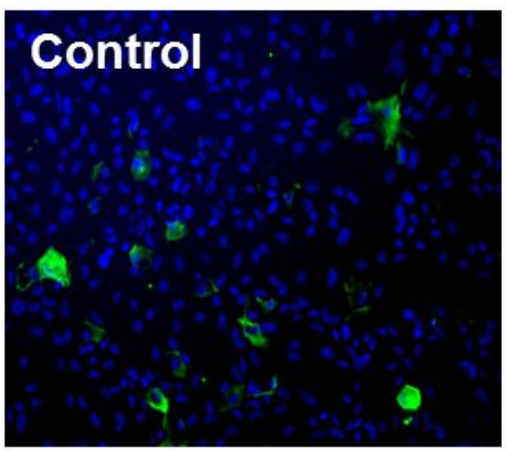

Aspirin
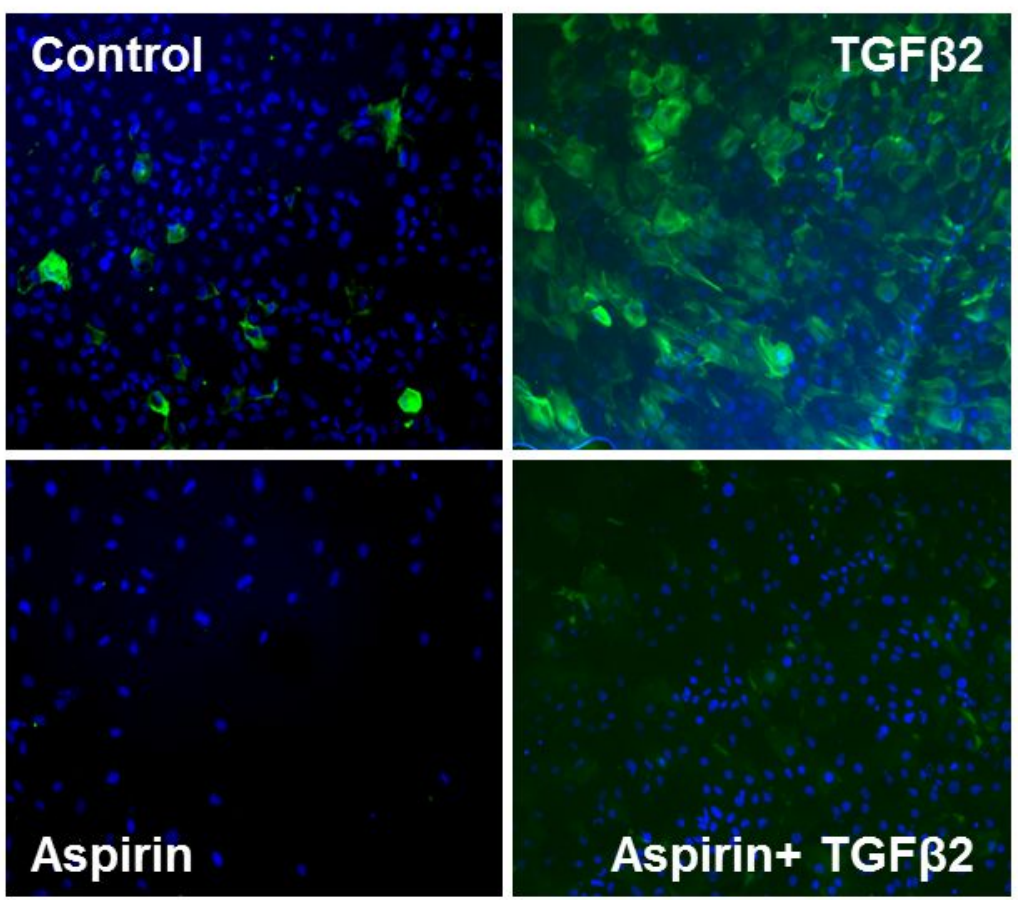

Aspirin+ TGF $\beta 2$
$5 \%$ FCS Control

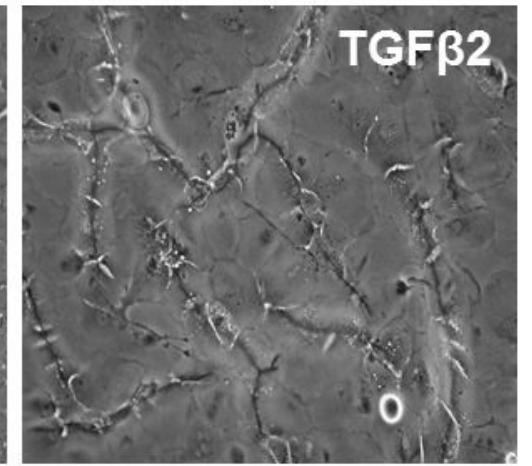

\section{Aspirin}
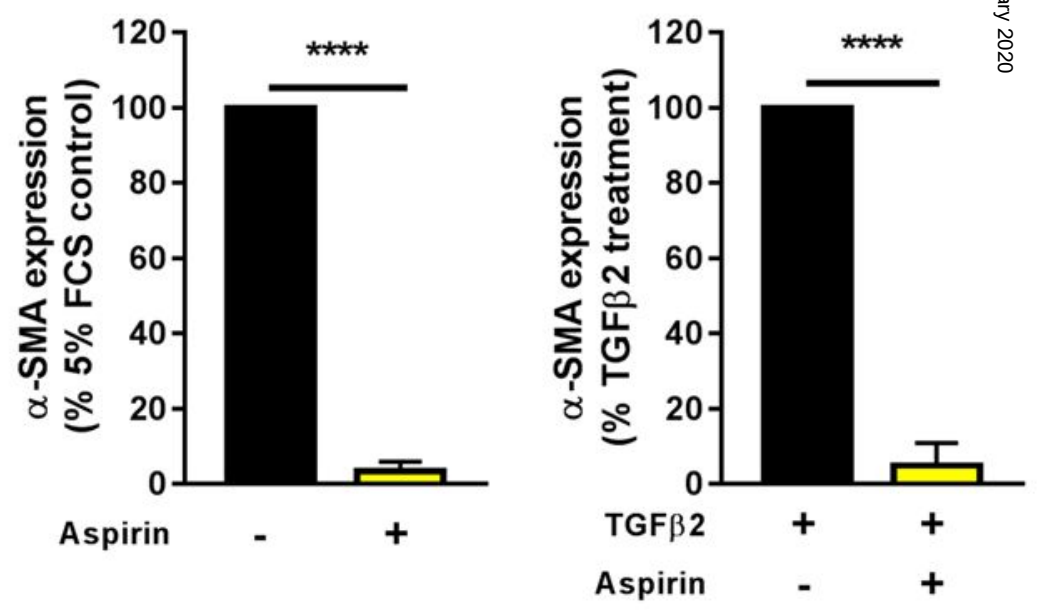
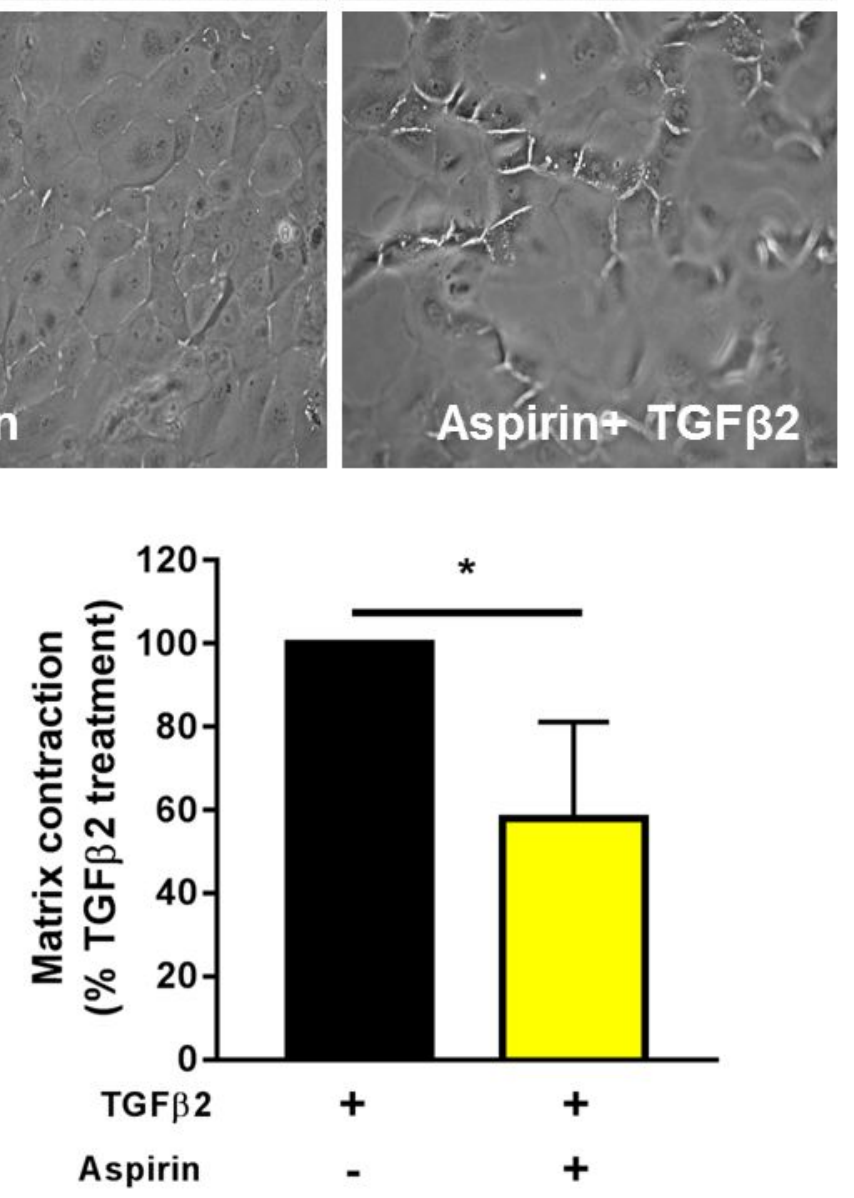
Fig. 5.

A
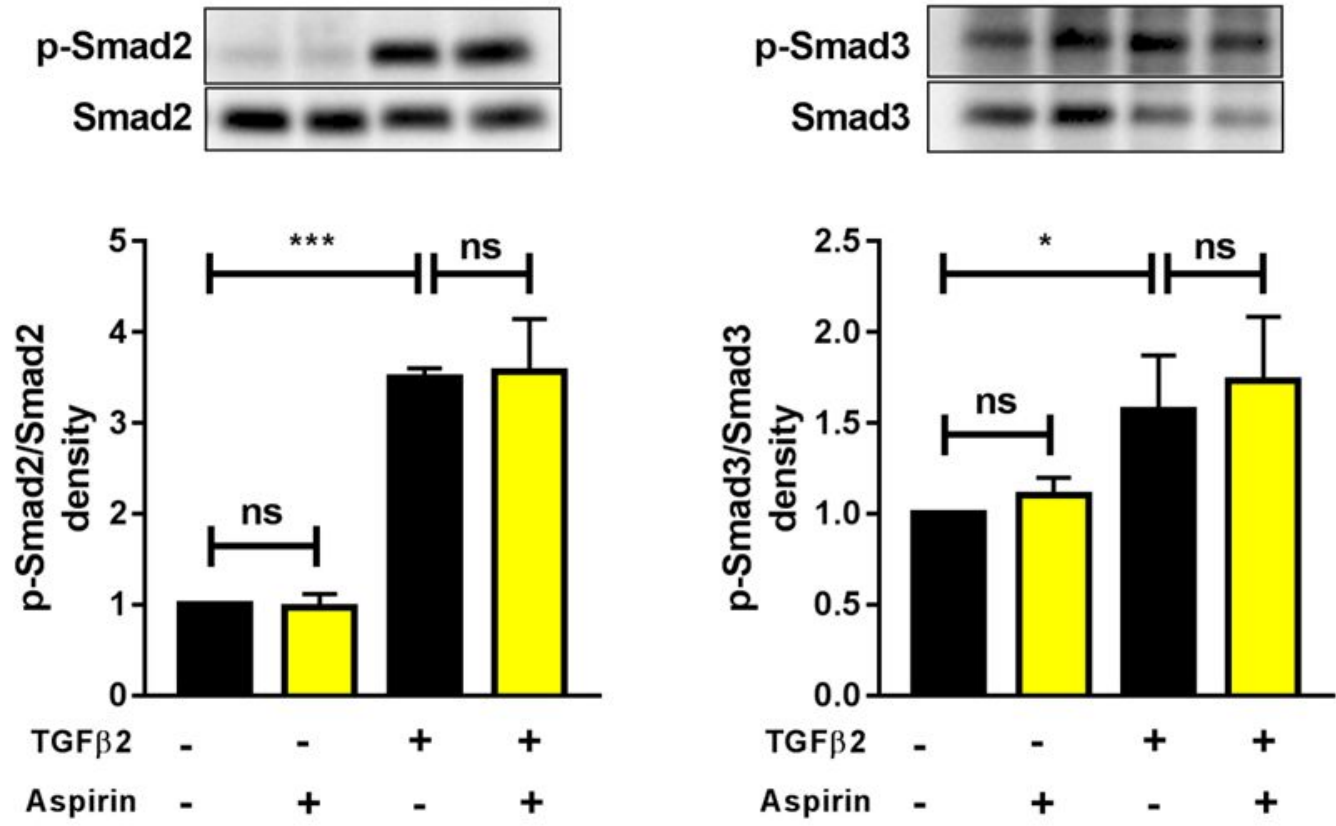

B

Nucleus
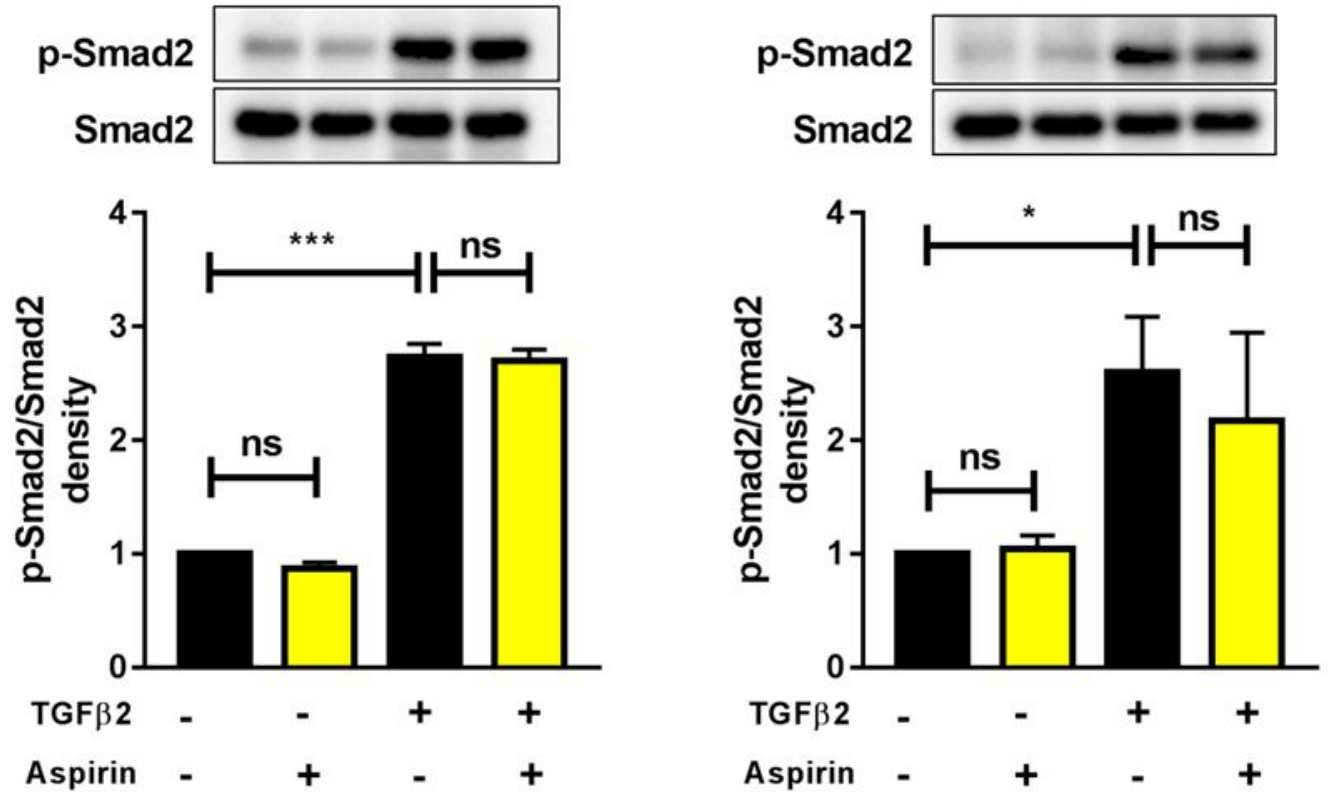

C
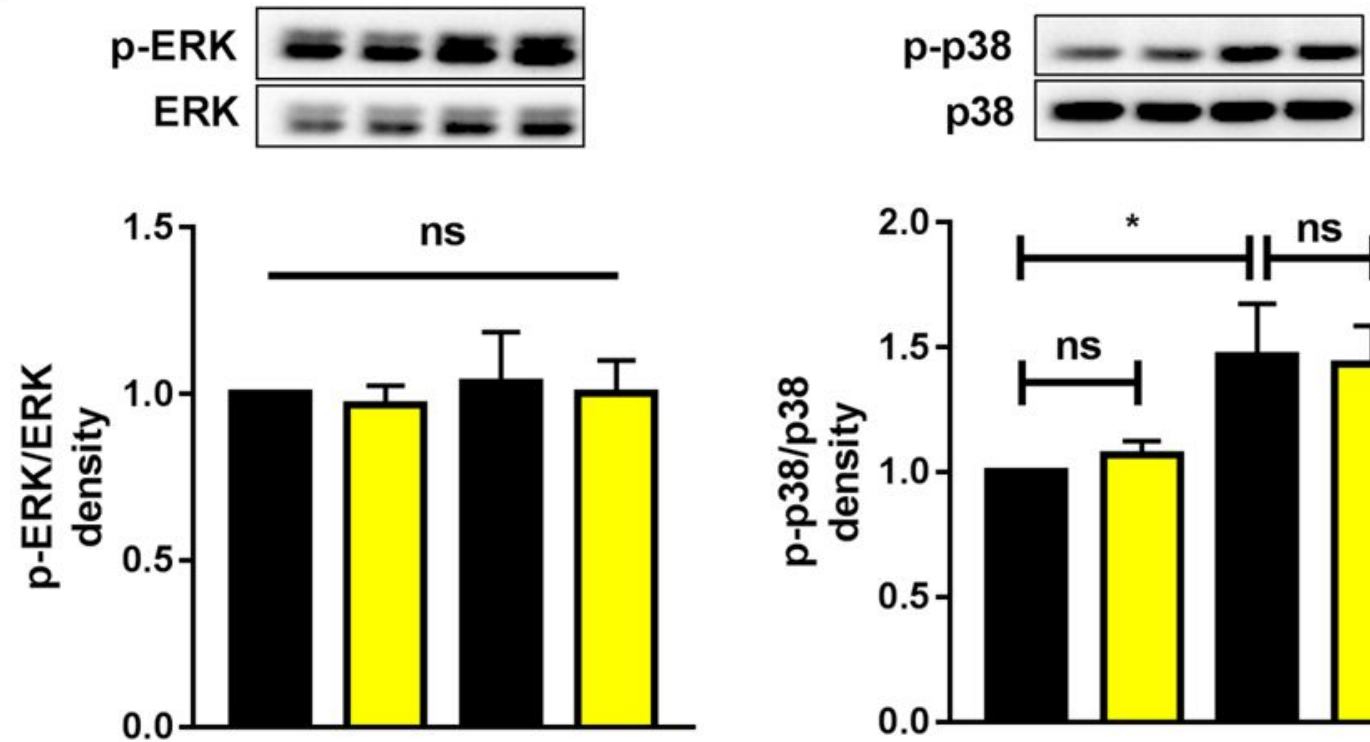

TGFB2 Aspirin - $\quad+\quad$ - $\quad+$
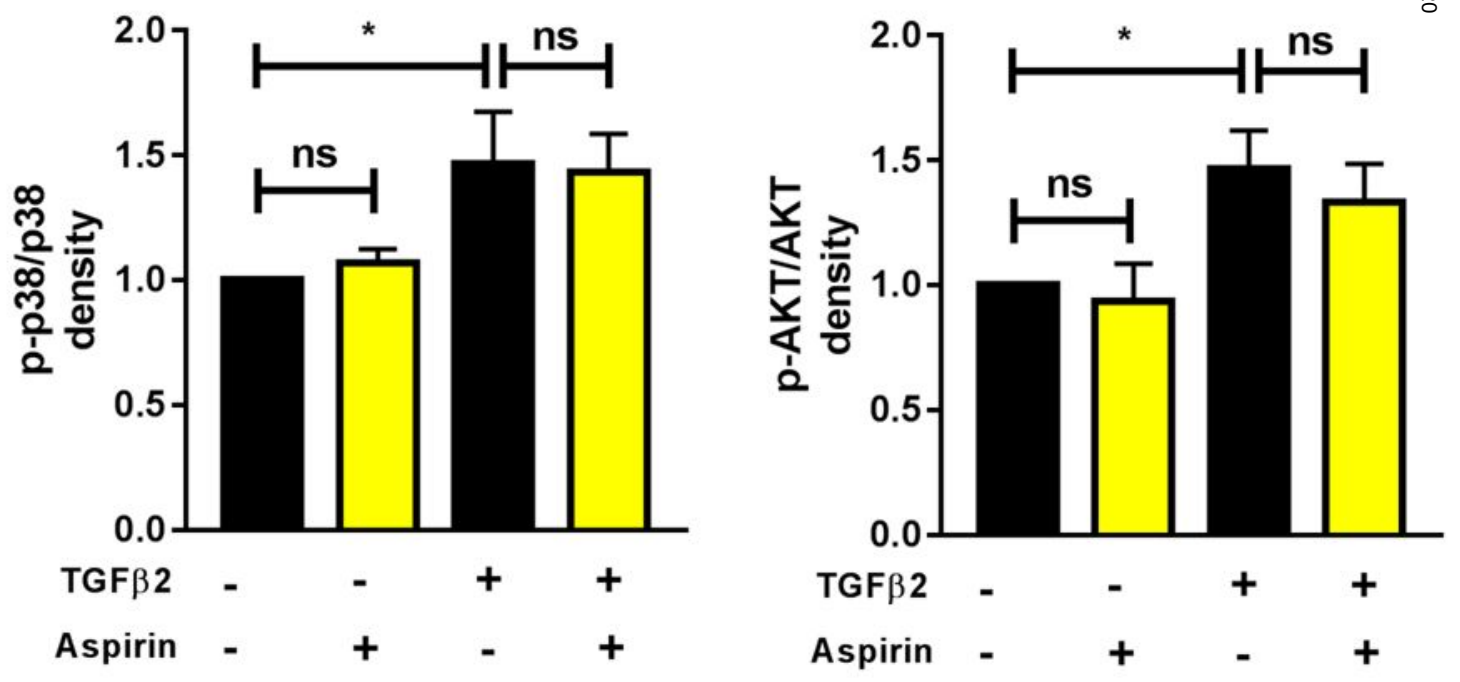


\section{Fig. 6.}

A

Nucleus

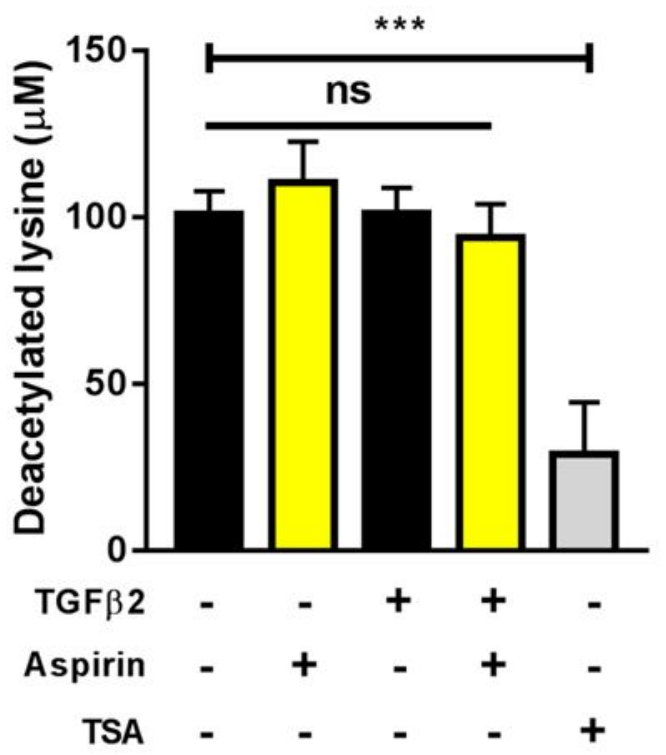

Cytoplasm

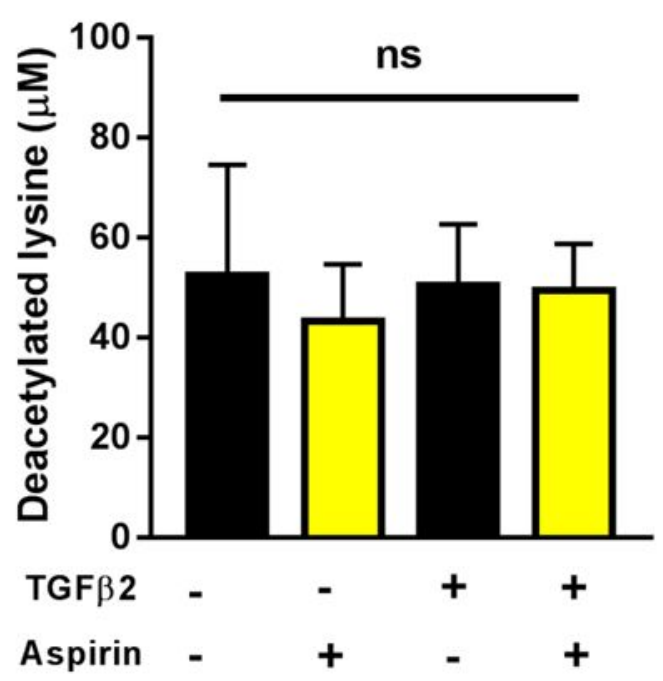

B

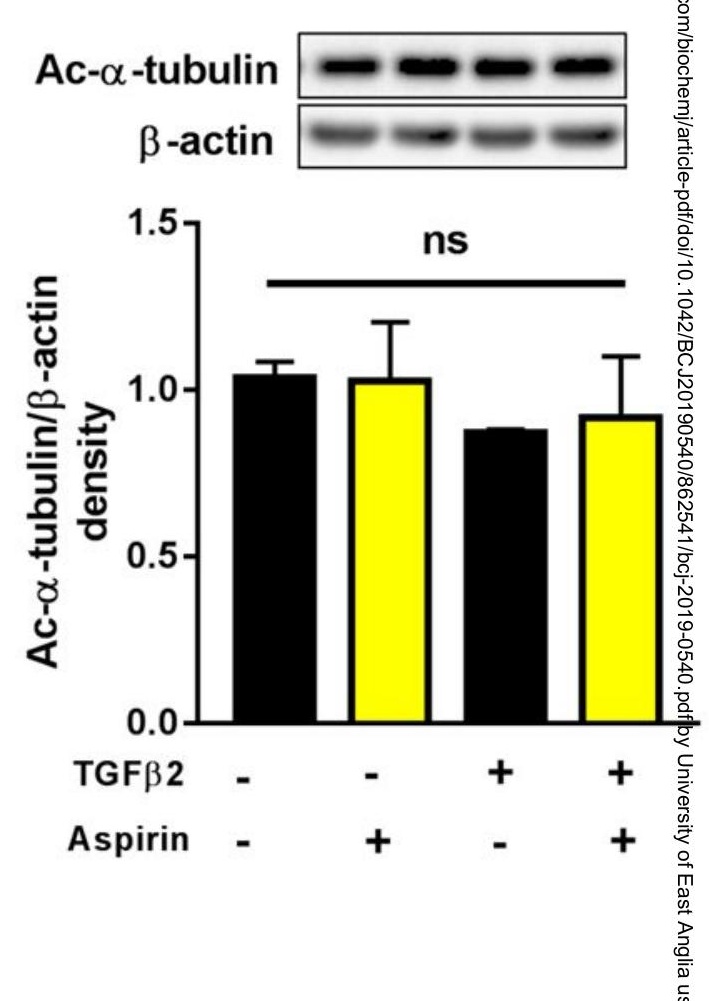


Fig. 7.

A

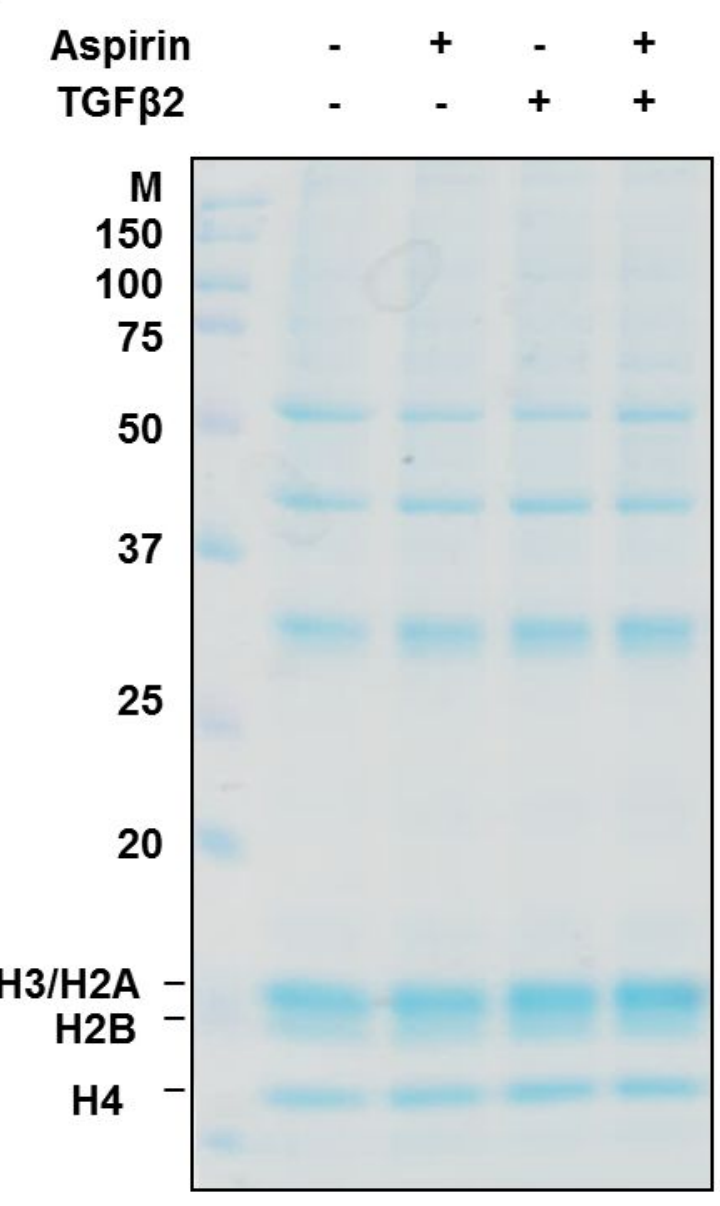

B
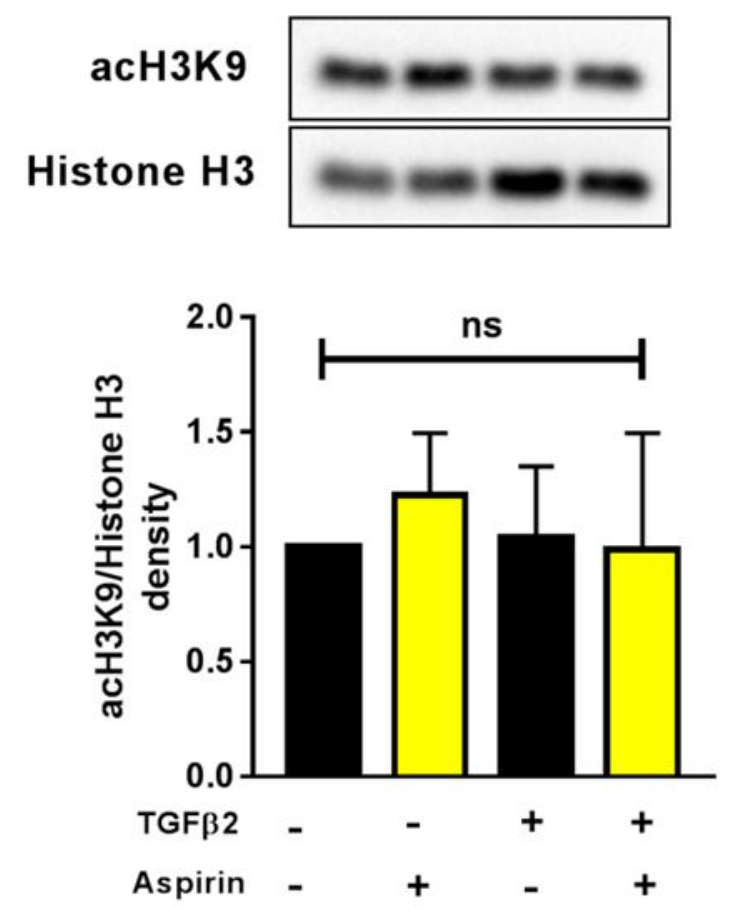

acH3K56

Histone H3
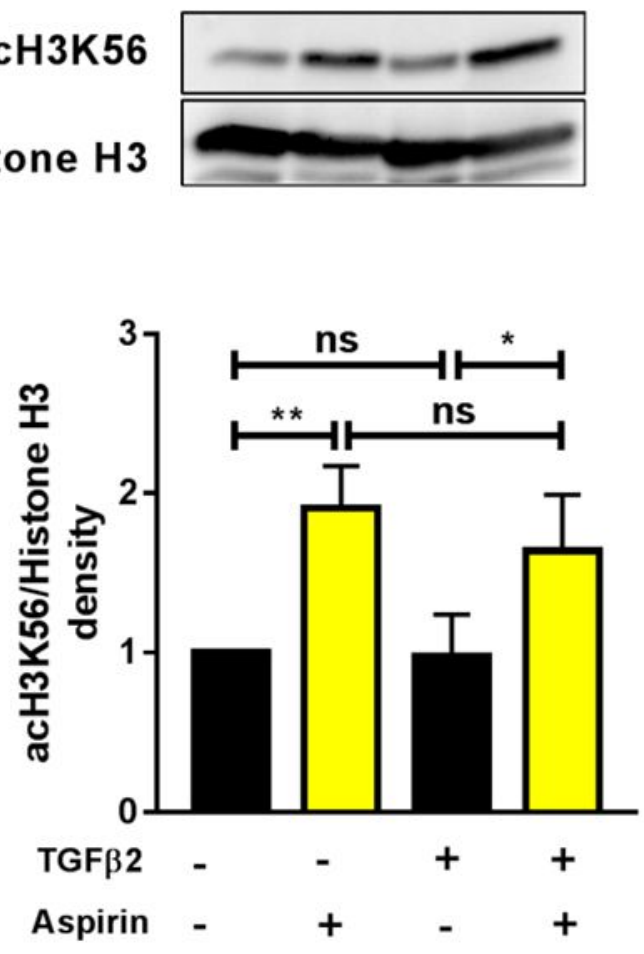
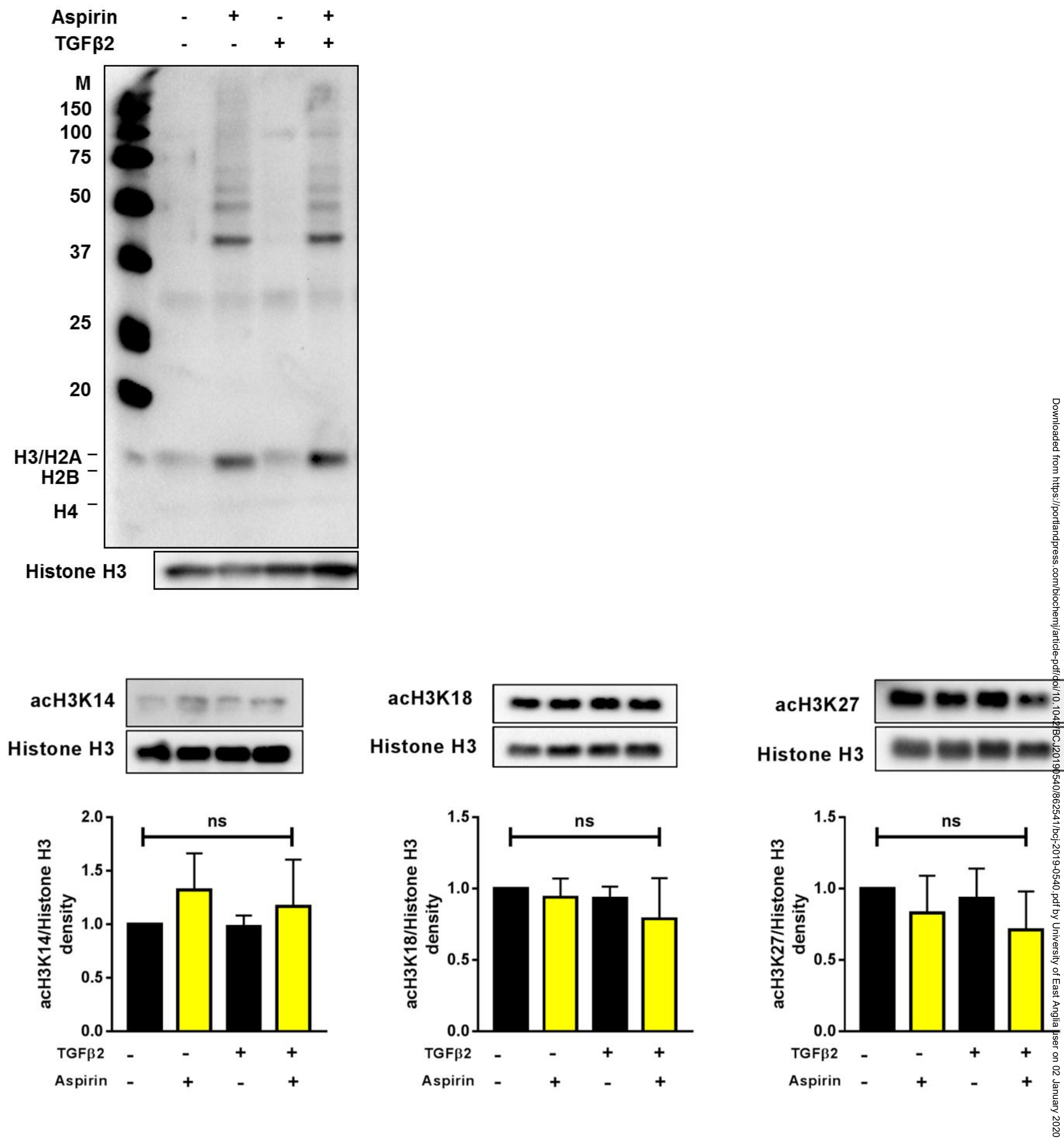

acH3K115

Histone H3
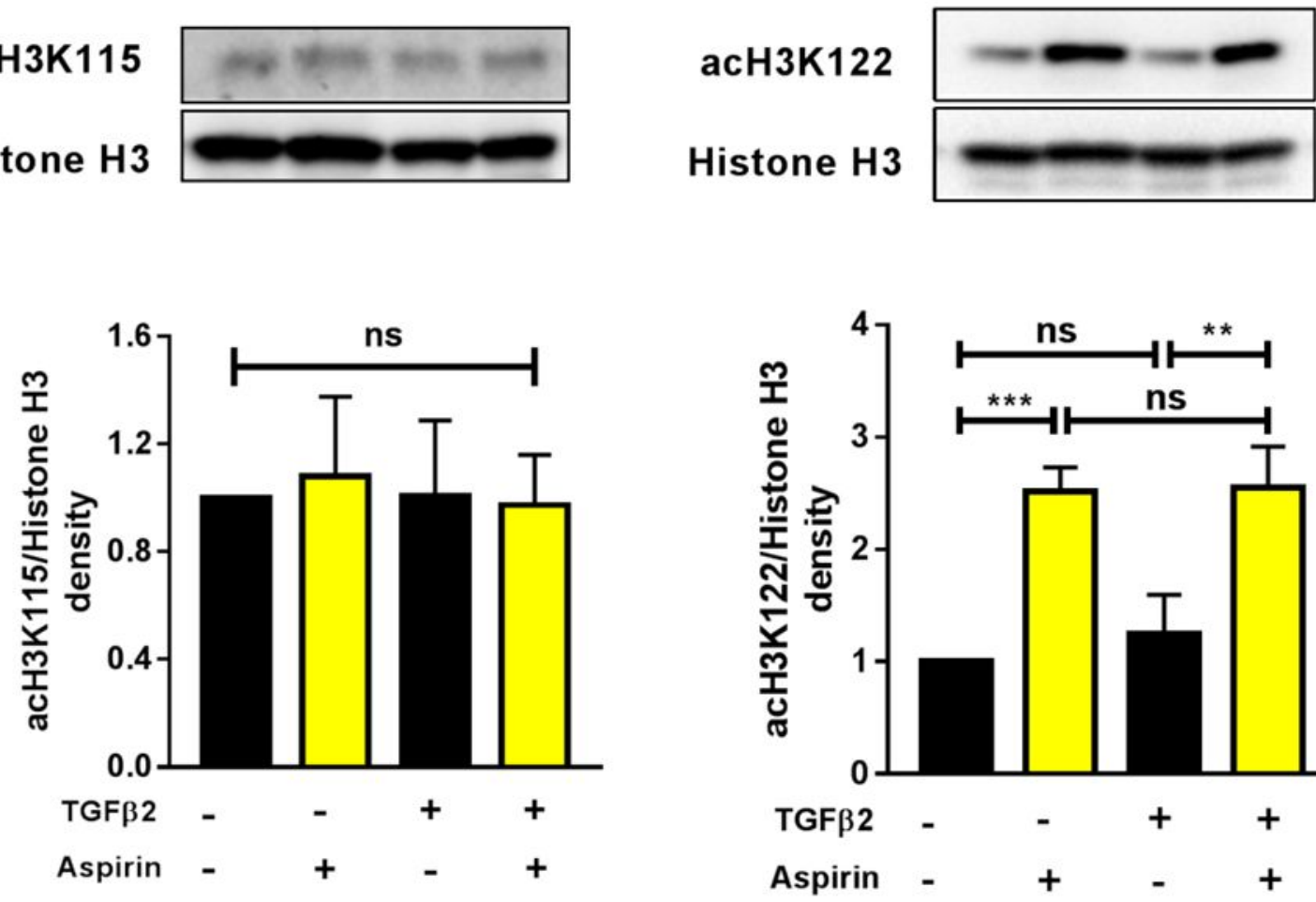
Fig. 8.

A

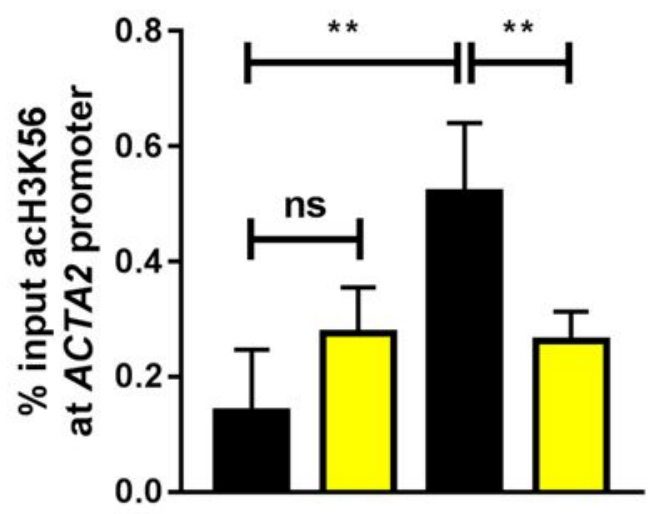

TGF $\beta 2$ - $\quad$ - $\quad+\quad+$

Aspirin $\quad-\quad+\quad-\quad+$
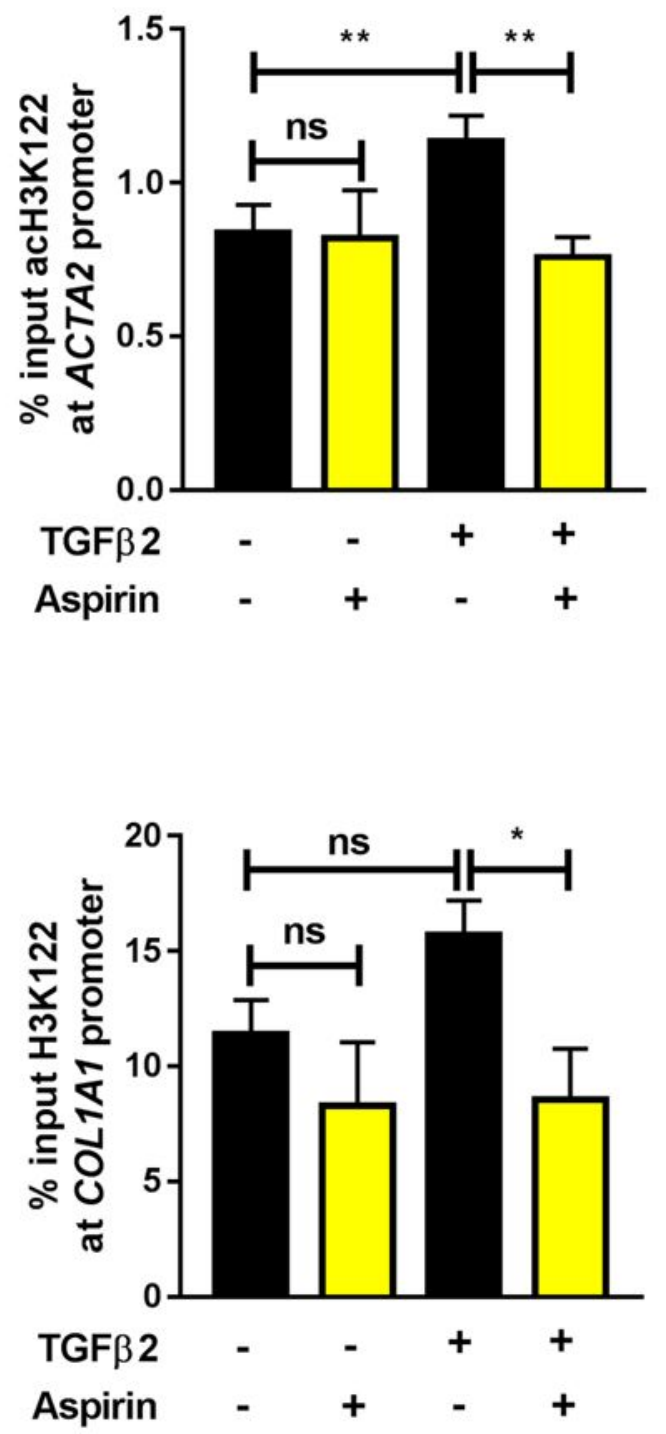

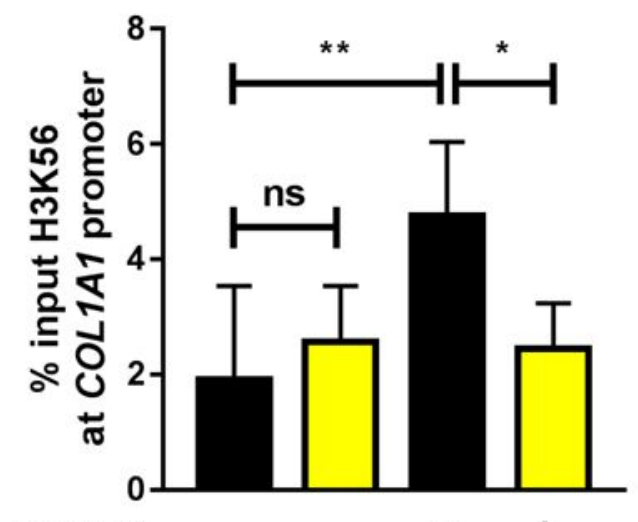

TGF $\beta 2$

Aspirin

IP:

IP:

IP:

acH3K56 acH3K122 rabbit IgG Input

WB: Smad4

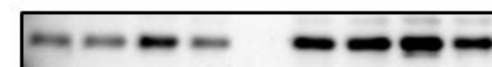

TGF $\beta 2$

$-\quad++\quad-\quad++$

Aspirin

IP: acH3K56

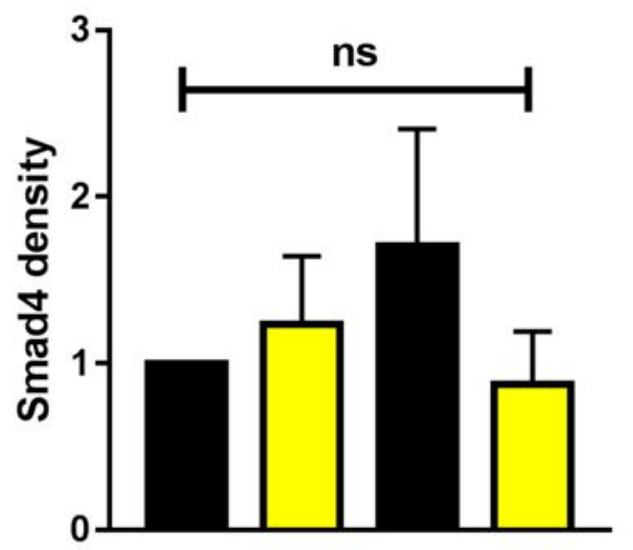

TGF $\beta 2$

Aspirin
IP: acH3K122

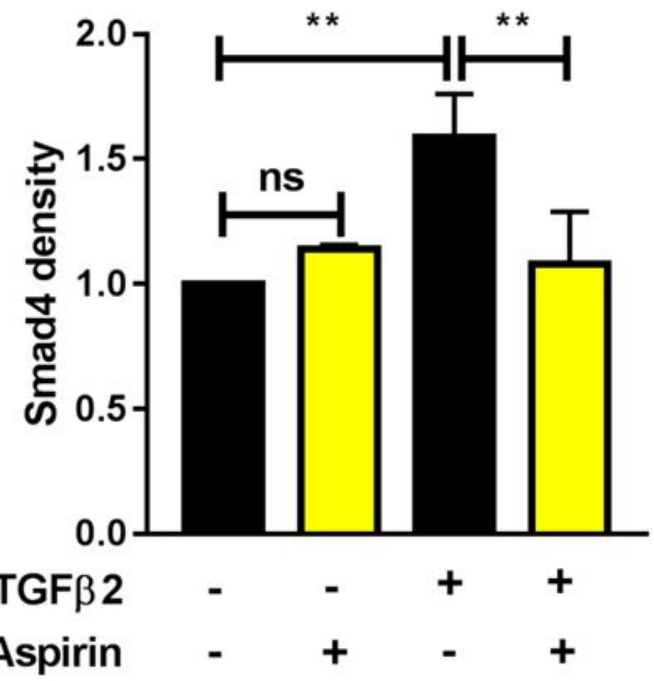

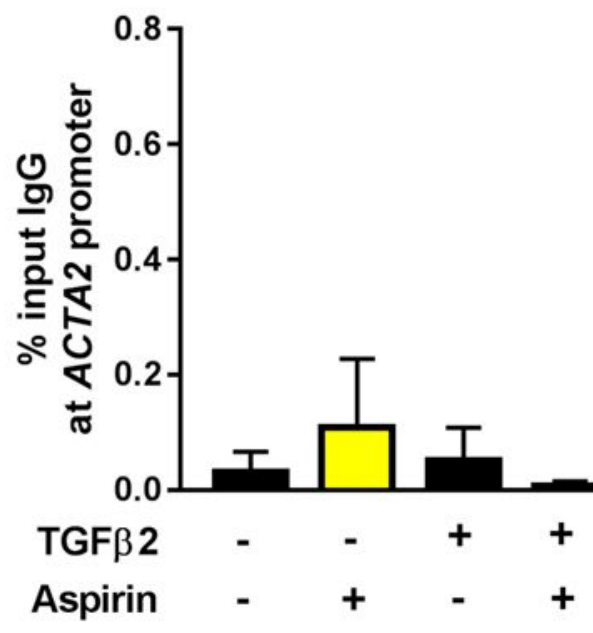

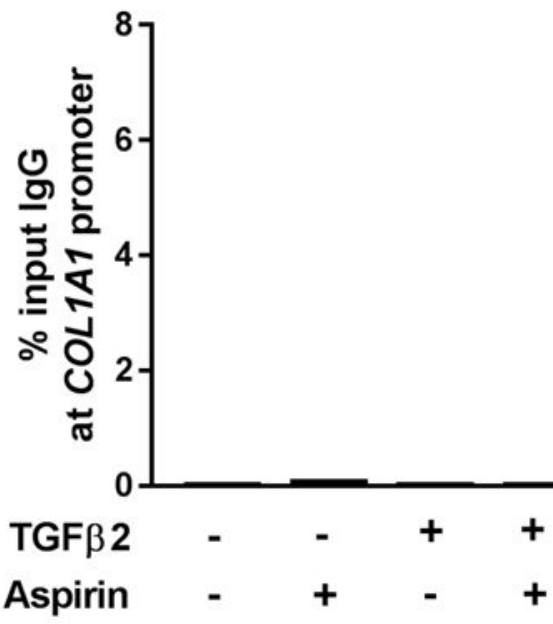




\section{Fig. 9.}

A
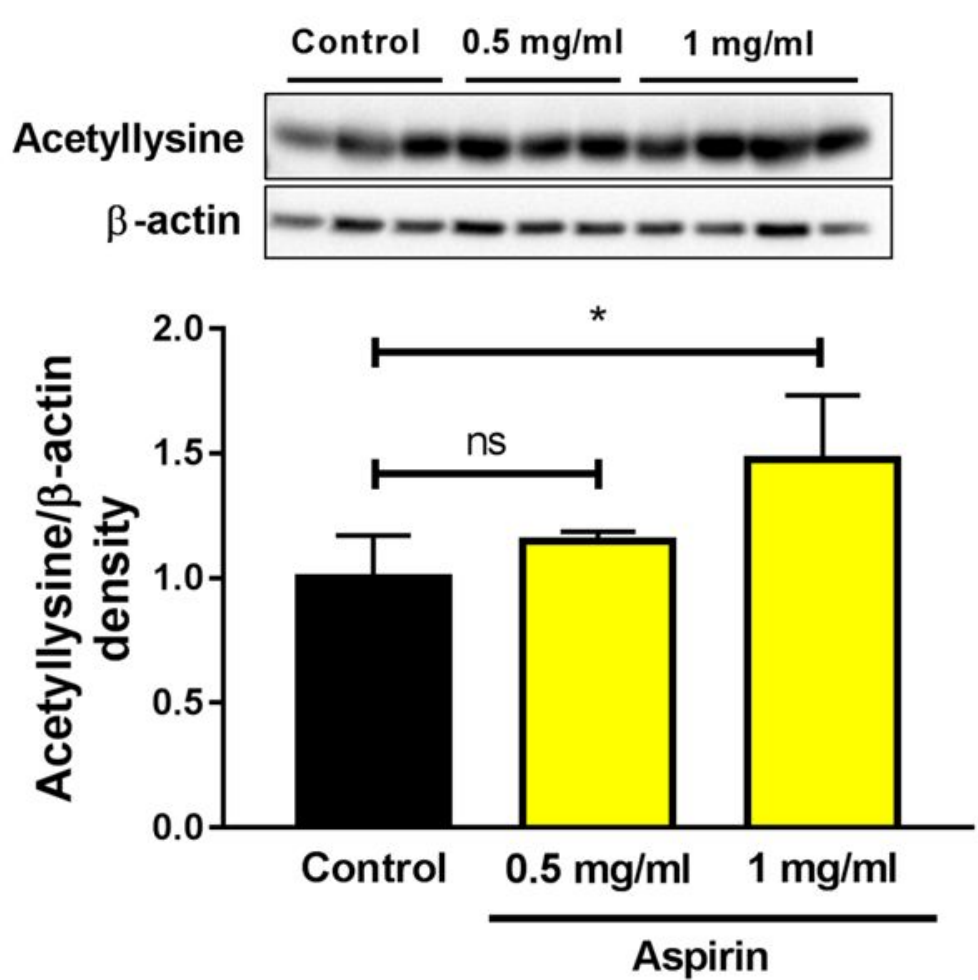

C
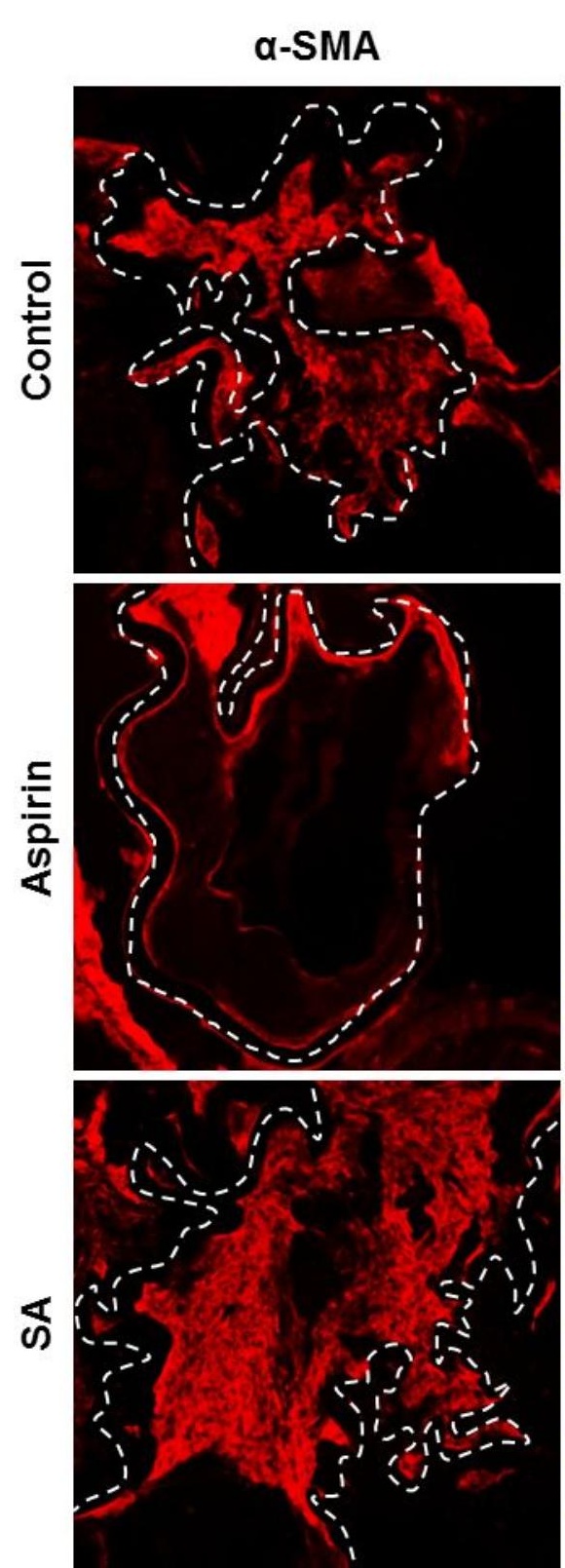

$40 X$
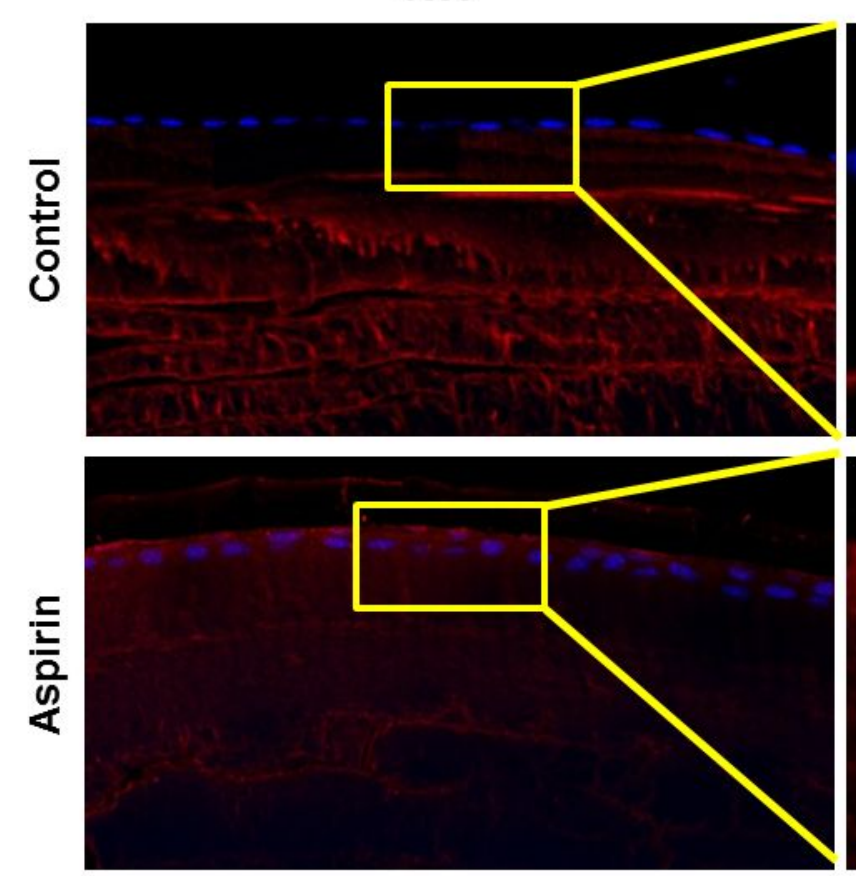

$160 X$

Acetyllysine/D勨PI
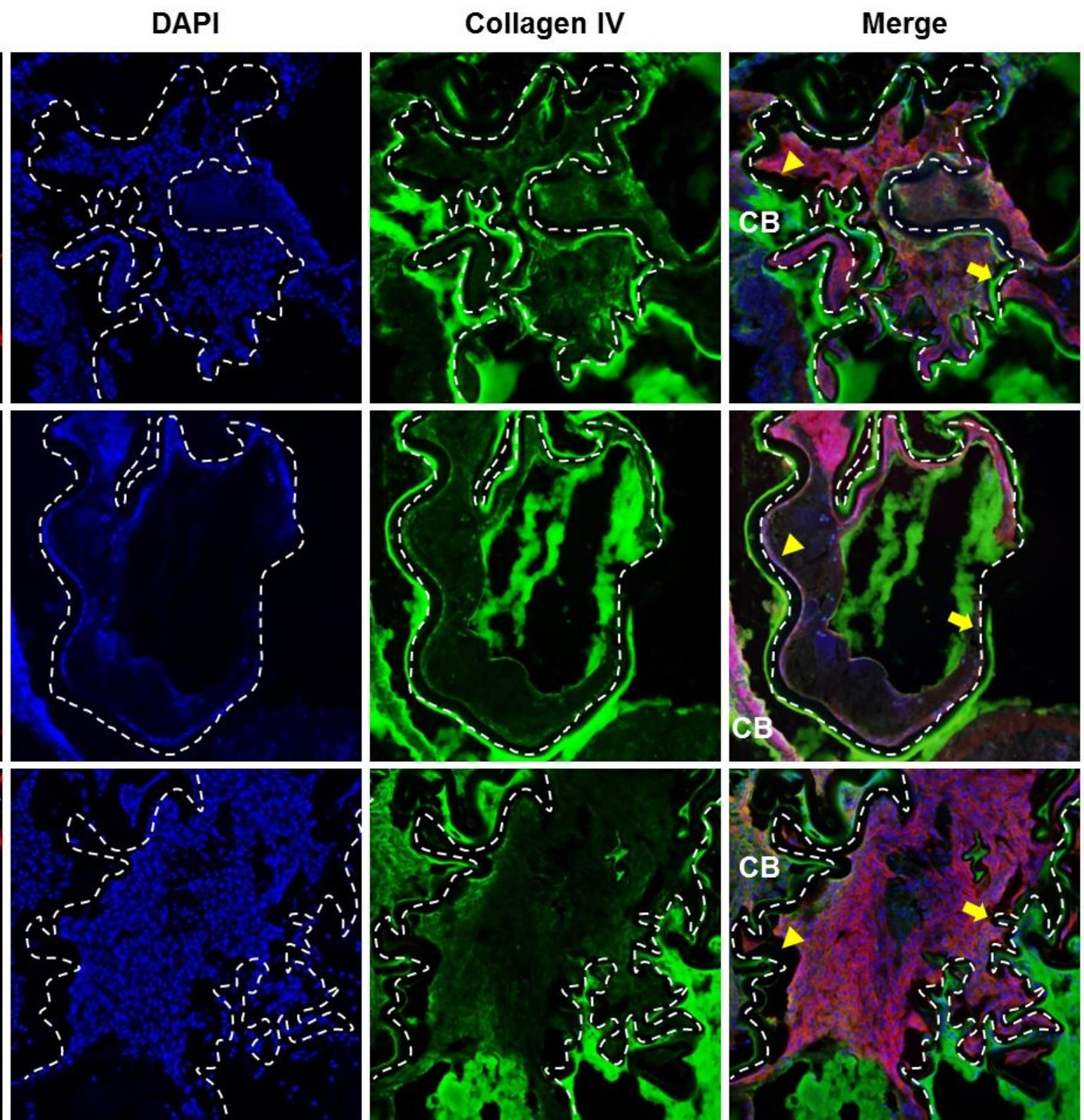
Supplementary Fig. 1. Effective concentration of aspirin in the cell culture medium. Aspirin was incubated in MEM with 5\% FBS or without FBS (SF) for $48 \mathrm{~h}$. Serum protein bound aspirin was removed by ultrafiltration using a $10 \mathrm{kDa}$ filter, and then the concentration of aspirin was measured at $530 \mathrm{~nm}$.

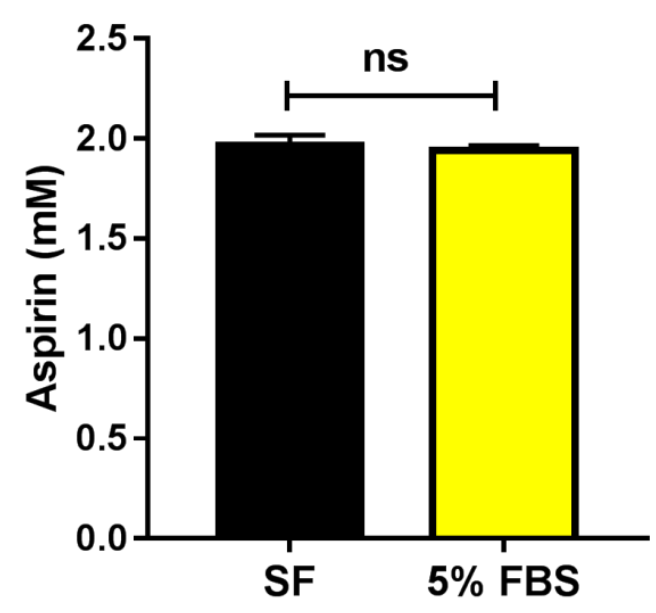


Supplementary Fig. 2. Effect of aspirin on cell proliferation. FHL124 cells were treated with 2 $\mathrm{mM}$ of aspirin for $24 \mathrm{~h}$, followed by $10 \mathrm{ng} / \mathrm{ml}$ TGF $\beta 2$ treatment for an additional $24 \mathrm{~h}$. Cell were labeled with BrdU, fixed, permeabilized, and detected incorporated BrdU using anti-BrdU mouse monoclonal antibody (1:100 dilution, Santa Cruz Biotechnology, Cat\# sc-56255).

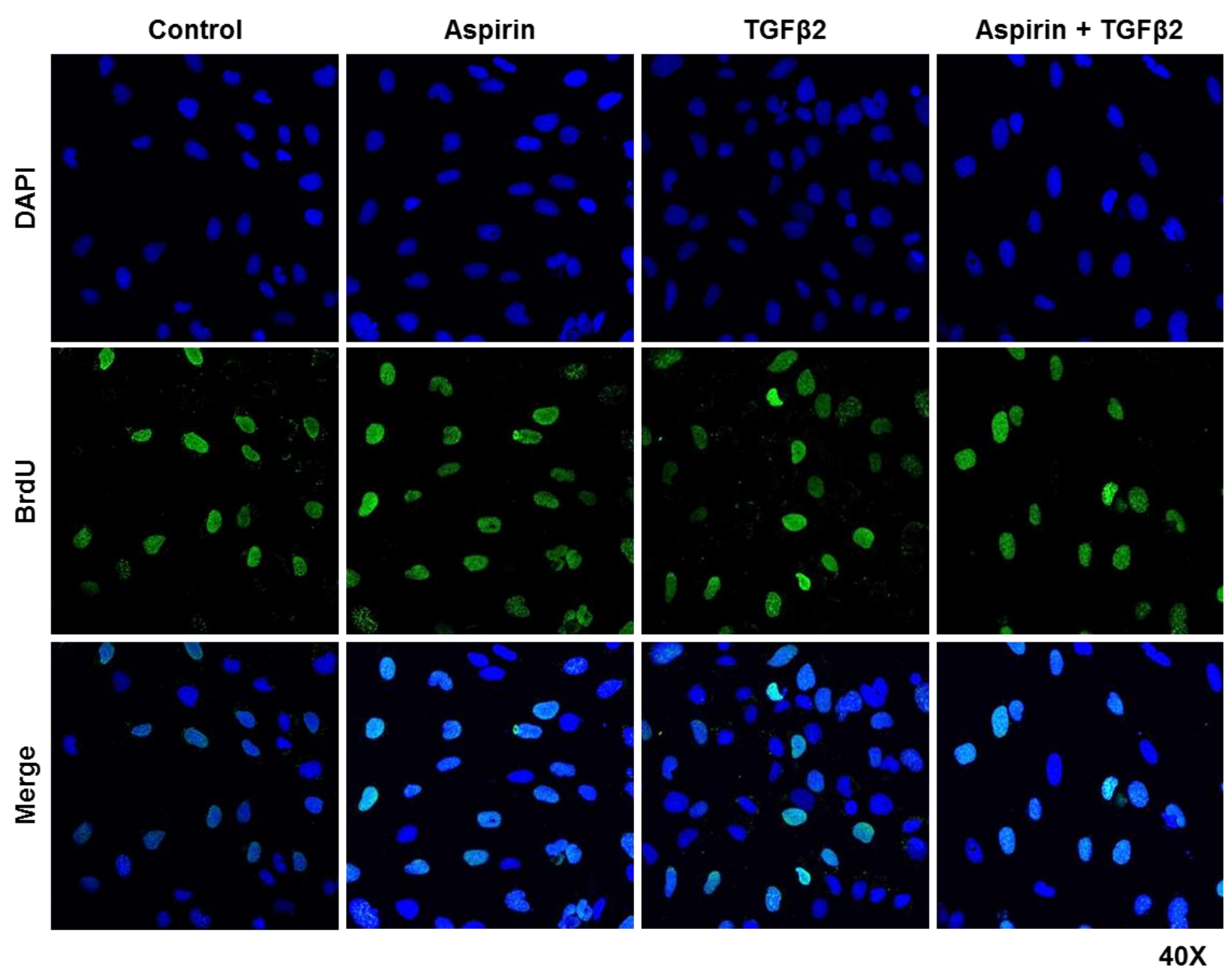


Supplementary Fig. 3. Effect of salicylic acid on TGF $\beta 2$-induced $\alpha$-SMA expression. FHL124 cells were treated with $2 \mathrm{mM}$ of either aspirin or sodium salicylic acid (SA) for $24 \mathrm{~h}$, followed by $10 \mathrm{ng} / \mathrm{ml}$ TGF 32 treatment for an additional $24 \mathrm{~h}$. Total cell lysates were subjected to western blotting to analyze the expression of $\alpha-S M A$.

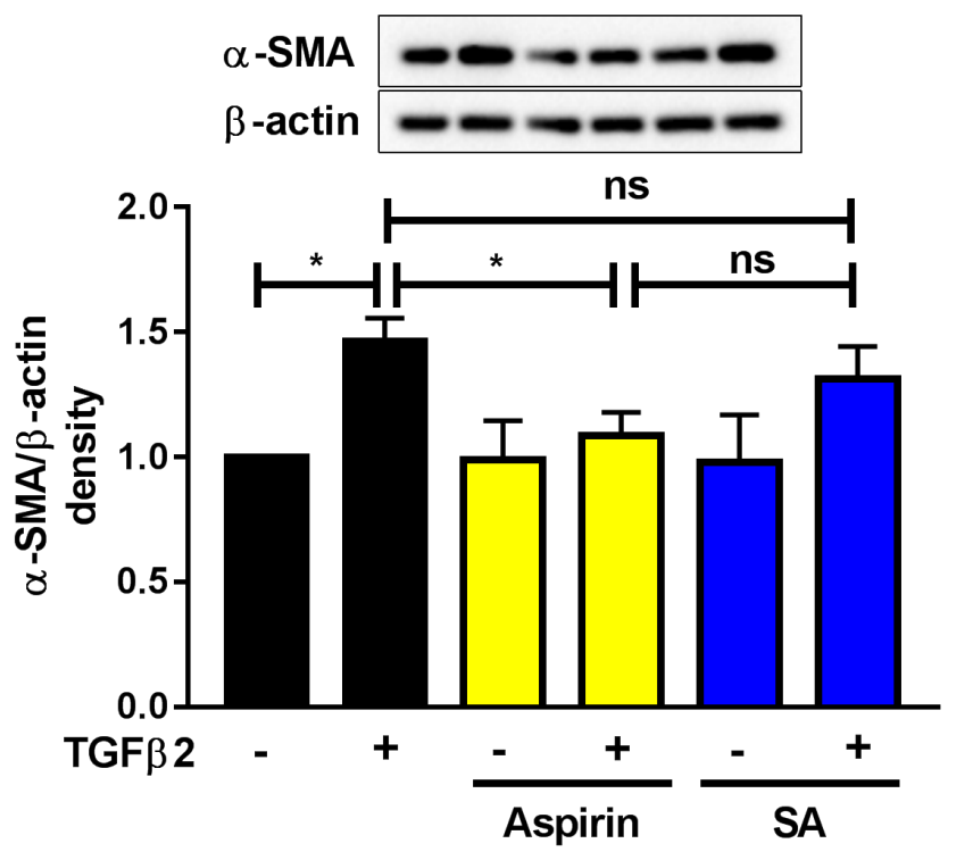


Supplementary Fig. 4. Effect of aspirin and TGF $\beta 2$ on protein acetylation. Western blot analysis of acetyllysine in total cell lysate (A), cytoplasmic and nuclear fractions (B). FHL124 cells treated with aspirin at an indicated $(A)$ or $2 \mathrm{mM}(B)$ concentration for $24 \mathrm{~h}$, followed by 10 $\mathrm{ng} / \mathrm{ml}$ TGF $\beta 2$ treatment for an additional $24 \mathrm{~h}$. $\mathrm{M}=$ molecular weight markers (kDa).

A

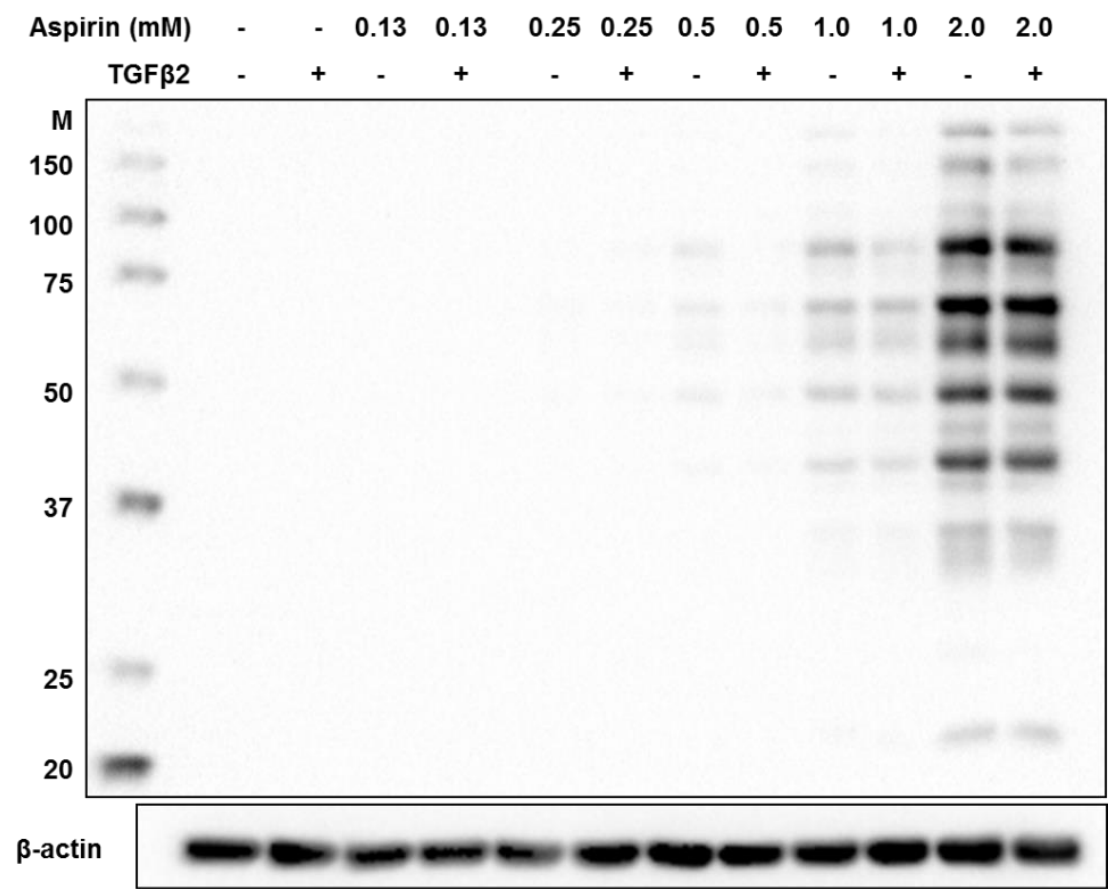

B

Cytoplasm

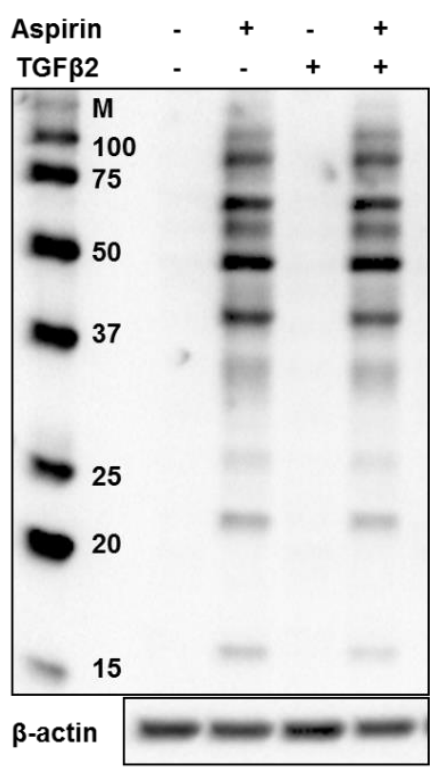

Nucleus

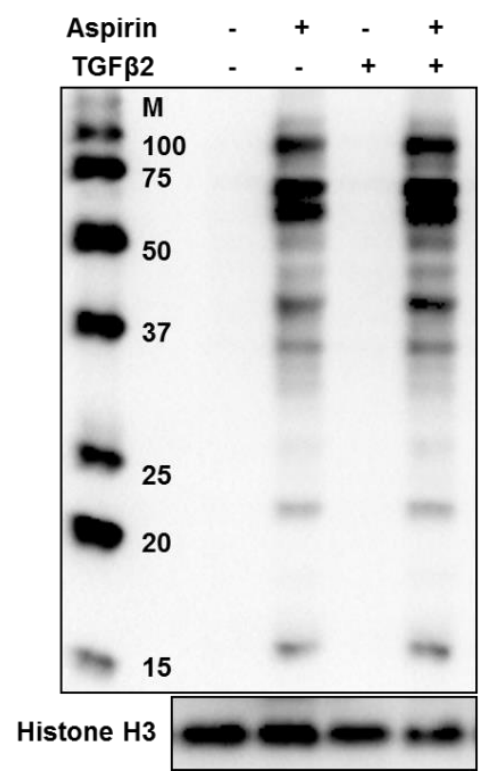


Supplementary Fig. 5. Effect of aspirin on acetylation of mouse lens proteins. Mice were administered with $1 \mathrm{mg}$ of aspirin in $100 \mu \mathrm{l}$ of $25 \mathrm{mM}$ sodium phosphate buffer through an oral gavage daily for 5 days. Control mice received $100 \mu$ of $25 \mathrm{mM}$ sodium phosphate buffer. Lens proteins were subjected to western blotting to analyze the acetyllysine. Ponceau $S$ staining of the membranes served as the loading control. $M=$ molecular weight markers $(\mathrm{kDa})$.

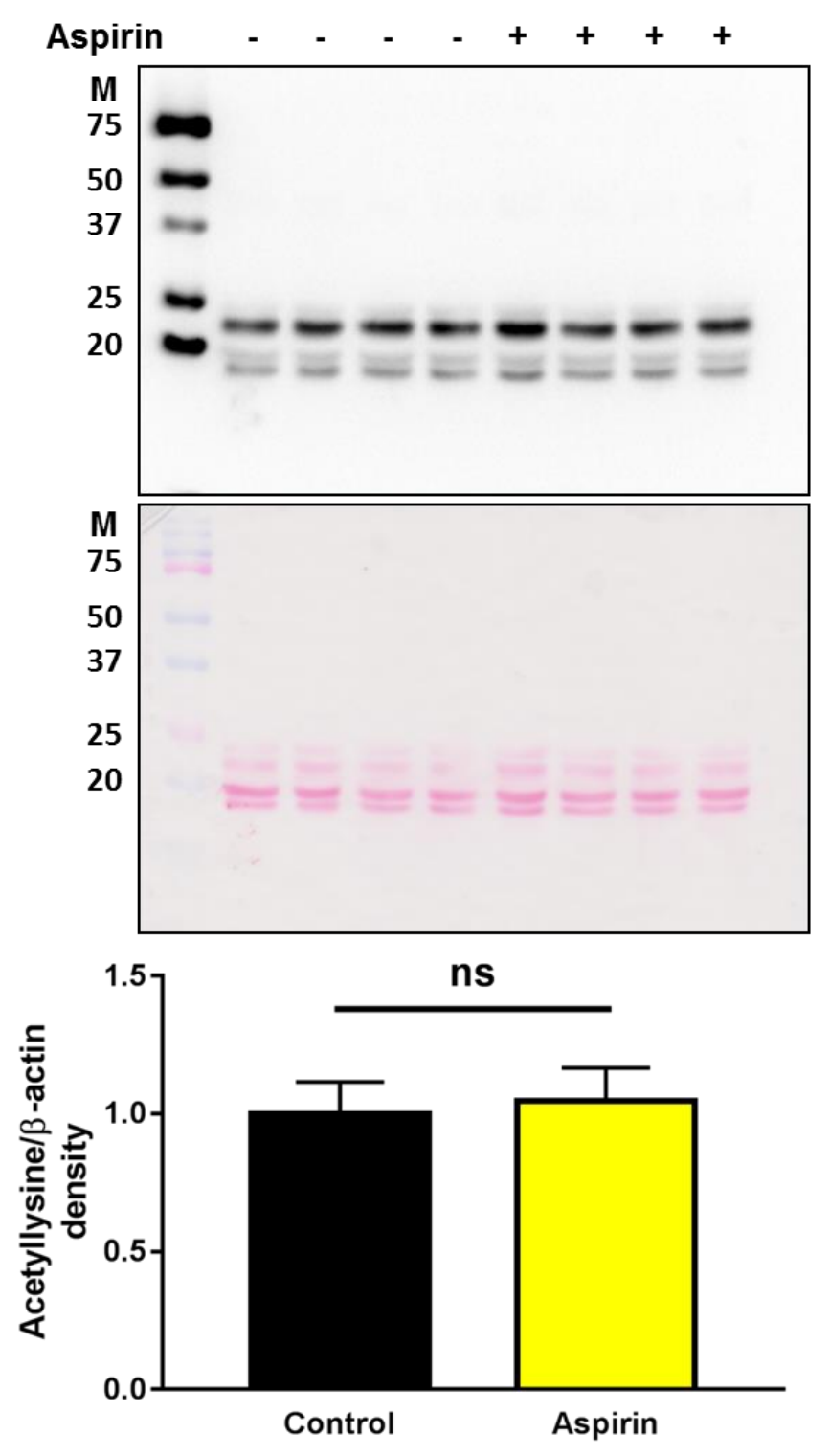


Table 1. Primer sequences for qRT-PCR

\begin{tabular}{|c|c|c|c|}
\hline Gene & & Primer Sequence & Experiment \\
\hline \multirow{2}{*}{$\begin{array}{c}\alpha-S M A \\
(\text { ACTA2) }\end{array}$} & Forward & 5'-TTCAATGTCCCAGCCATGTA-3' & \multirow{2}{*}{ qRT-PCR } \\
\hline & Reverse & 5'-GAAGGAATAGCCACGCTCAG-3' & \\
\hline \multirow{2}{*}{$\begin{array}{c}\alpha \mathrm{B}- \\
\text { Crystallin } \\
(C R Y A B)\end{array}$} & Forward & 5'-CTTTGACCAGTTCTTCGGAG-3' & \multirow{2}{*}{ qRT-PCR } \\
\hline & Reverse & 5'-CСТCAATCACATCTCCCAAC-3' & \\
\hline \multirow{2}{*}{$\begin{array}{l}\text { Fibronectin } \\
\qquad(F N 1)\end{array}$} & Forward & 5'-TTCGAGATCAGTGCATTGTTGAT-3' & \multirow{2}{*}{ qRT-PCR } \\
\hline & Reverse & 5'-TCATGACGCTTGTGGAATGTG-3' & \\
\hline \multirow{2}{*}{ GAPDH } & Forward & 5'-GTCAGTGGTGGACCTGACCT-3' & \multirow{2}{*}{ qRT-PCR } \\
\hline & Reverse & 5'-TGCTGTAGCCAAATTCGTTG-3' & \\
\hline \multirow{2}{*}{ ACTA2 } & Forward & 5' CGGTAAACAAGCCTCCAGAAGC 3' & \multirow{2}{*}{ ChIP } \\
\hline & Reverse & 5' CAGCACCGAAGCAGTGGTTAAG 3' & \\
\hline \multirow{2}{*}{ COL1A1 } & Forward & 5' AGGACAGTATAAAAGGGGCCCG 3' & \multirow{2}{*}{ ChIP } \\
\hline & Reverse & 5' TGTAGACTCTTTGTGGCTGGGG 3' & \\
\hline
\end{tabular}


Table 2. Mass spectrometric identification of acetylation on histone H3 extracts. FHL124 cells were treated with $2 \mathrm{mM}$ aspirin for $24 \mathrm{~h}$, followed by $10 \mathrm{ng} / \mathrm{ml}$ TGF $\beta 2$ treatment for an additional $24 \mathrm{~h}$. Total histones were fractionated by gel electrophoresis, and the level of acetylation on histone $\mathrm{H} 3$ was determined by LC-MS/MS.

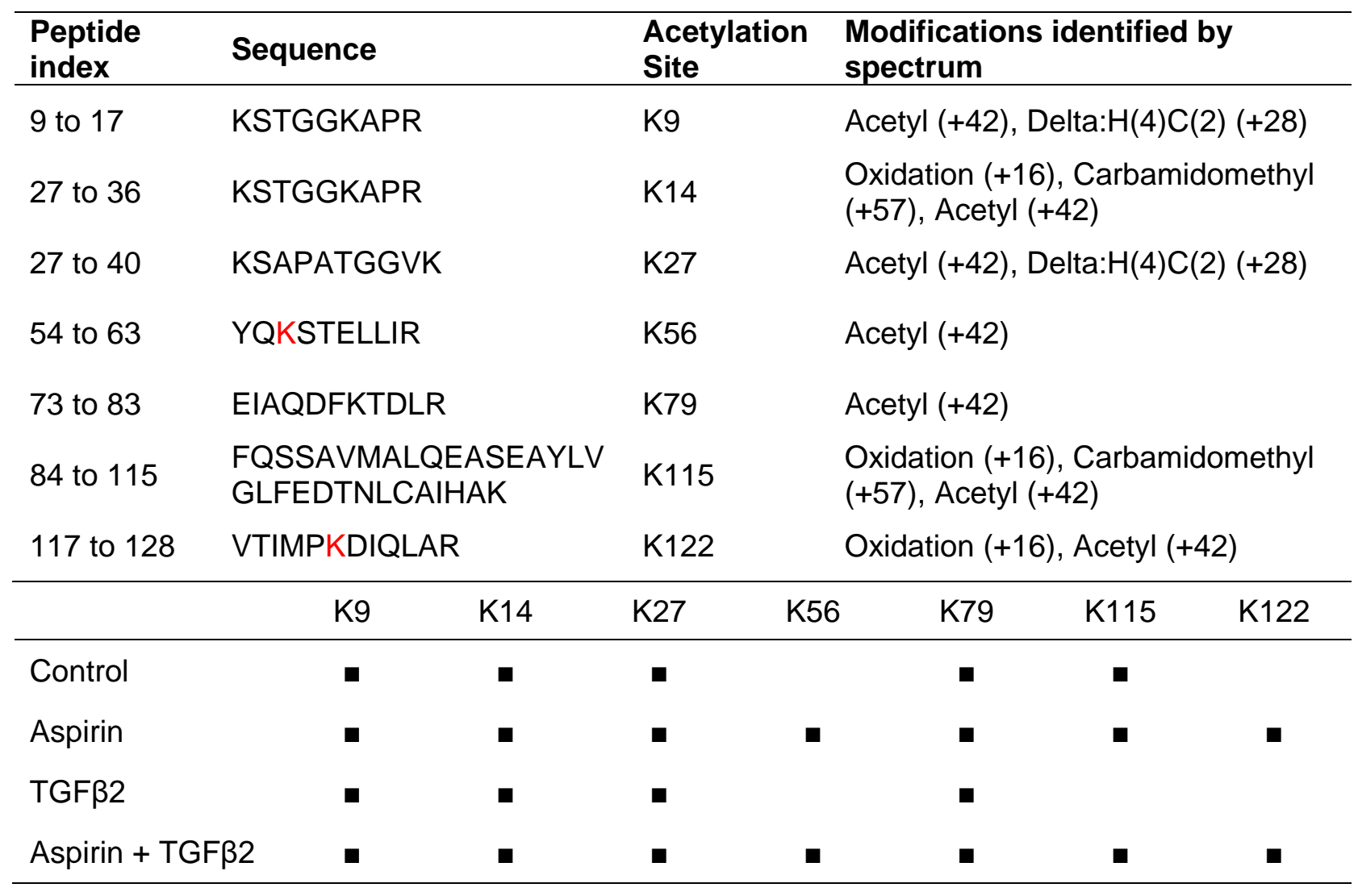

